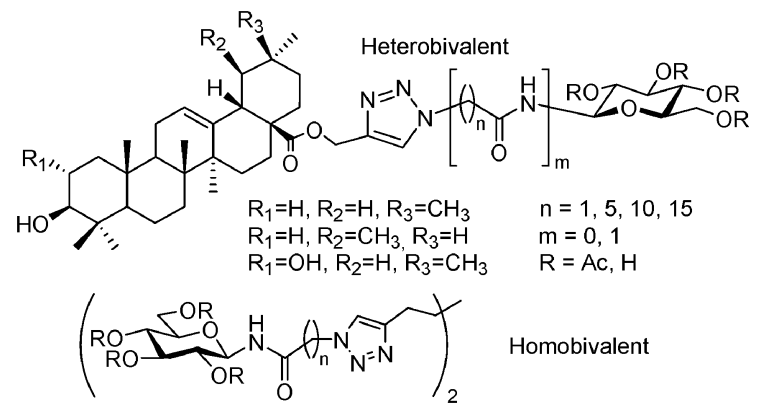

Q1 Tethered derivatives of D-glucose and pentacyclic triterpenes for homo/heterobivalent inhibition of glycogen phosphorylase

Keguang Cheng, Jun Liu, Hongbin Sun,* Éva Bokor, Katalin Czifrák, Bálint Kónya, Marietta Tóth, Tibor Docsa, Pál Gergely and László Somsák* Low micromolar inhibitors $\left(\mathrm{IC}_{50} 40-70 \mu \mathrm{M}\right.$ ) were found among the heterobivalent compounds studied, while homobivalent derivatives proved inactive in assays against rabbit muscle glycogen phosphorylase a or $b$.

Please check this proof carefully. Our staff will not read it in detail after you have returned it. Translation errors between word-processor files and typesetting systems can occur so the whole proof needs to be read. Please pay particular attention to: tabulated material; equations; numerical data; figures and graphics; and references. If you have not already indicated the corresponding author(s) please mark their name(s) with an asterisk. Please e-mail a list of corrections or the PDF with electronic notes attached -- do not change the text within the PDF file or send a revised manuscript.

Please bear in mind that minor layout improvements, e.g. in line breaking, table widths and graphic placement, are routinely applied to the final version.

Please note that, in the typefaces we use, an italic vee looks like this: $v$, and a Greek nu looks like this: $\nu$.

We will publish articles on the web as soon as possible after receiving your corrections; no late corrections will be made.

Please return your final corrections, where possible within $\mathbf{4 8}$ hours of receipt, by e-mail to: njc@ rsc.org

Reprints -Electronic (PDF) reprints will be provided free of charge to the corresponding author. Enquiries about purchasing paper reprints should be addressed via: http://www.rsc.org/Publishing/ReSourCe/PaperReprints/. Costs for reprints are below:

\begin{tabular}{|lrr|}
\hline Reprint costs & & \\
\hline No of pages & Cost for 50 copies & Cost for each additional 50 copies \\
\hline $2-4$ & $£ 190$ & $£ 120$ \\
$5-8$ & $£ 315$ & $£ 230$ \\
$9-20$ & $£ 630$ & $£ 500$ \\
$21-40$ & $£ 1155$ & $£ 915$ \\
$>40$ & $£ 1785$ & \\
\hline \multirow{2}{*}{ Cost for including cover of journal issue: } & & \\
£55 per 50 copies & & \\
\end{tabular}

Queries are marked on your proof like this Q11, Q2, etc. and for your convenience line numbers are indicated like this 5, 10, 15, ... 


\begin{tabular}{|c|c|c|}
\hline $\begin{array}{l}\text { Query } \\
\text { reference }\end{array}$ & Query & Remarks \\
\hline Q1 & $\begin{array}{l}\text { For your information: You can cite this article before you } \\
\text { receive notification of the page numbers by using the } \\
\text { following format: (authors), (journal), (year), DOI: 10.1039/ } \\
\text { (paper number). }\end{array}$ & \\
\hline Q2 & $\begin{array}{l}\text { Could you please check that the contents entry text does } \\
\text { not extend below the horizontal line when typeset? If it } \\
\text { does, please suggest modifications that would shorten it by } \\
\text { a sufficient amount. Many thanks. }\end{array}$ & \\
\hline Q3 & $\begin{array}{l}\text { Should this be "benzimidazole" rather than "benzimidazol" } \\
\text { ? }\end{array}$ & \\
\hline Q4 & Should this be "cynamic acid" rather than "cynnamic acid" ? & \\
\hline Q5 & $\begin{array}{l}\text { Please check that the changes to this part of the sentence } \\
\text { have not affected the meaning. Thank you. }\end{array}$ & \\
\hline Q6 & $\begin{array}{l}\text { There is an isolated plus-minus symbol in the middle of } \\
\text { Scheme } 4 \text {. Can it be deleted? }\end{array}$ & \\
\hline Q7 & $\begin{array}{l}\text { Would you like to provide captions for Charts } 1 \text { or } 2 \text {, to aid } \\
\text { the reader? In particular, what do MA, UA and OA mean in } \\
\text { Chart 2? }\end{array}$ & \\
\hline Q8 & $\begin{array}{l}\text { Chemical names of cpds 19--22: These names contain an } \\
\text { unpaired square bracket, ]. Is part of the name missing? }\end{array}$ & \\
\hline Q9 & $\begin{array}{l}\text { Chemical names of cpds } 31--38 \text { : These names contain an } \\
\text { unusual numbering in the middle, namely "1H-1,2". Is part } \\
\text { of the name missing? }\end{array}$ & \\
\hline Q10 & $\begin{array}{l}\text { Chemical names of cpds } 48--51 \text { : These names contain } \\
\text { ",2]butane". Is this correct? }\end{array}$ & \\
\hline
\end{tabular}




\title{
Q1 Tethered derivatives of D-glucose and pentacyclic triterpenes for homo/heterobivalent inhibition of glycogen phosphorylase $\dagger$
}

\author{
Keguang Cheng, ${ }^{a}$ Jun Liu, ${ }^{b}$ Hongbin Sun, ${ }^{* a}$ Éva Bokor, ${ }^{c}$ Katalin Czifrák, ${ }^{c}$ \\ Bálint Kónya, ${ }^{c}$ Marietta Tóth, ${ }^{c}$ Tibor Docsa ${ }^{d}{ }^{\text {Pál Gergely }}{ }^{e}$ and László Somsák ${ }^{* c}$
}

\author{
Received (in Montpellier, France) 27th October 2009, Accepted 25th January 2010 \\ First published as an Advance Article on the web \\ 10 DOI: $10.1039 / \mathrm{b} 9$ nj00602h
}

Propargyl esters of the C-28 carboxylic acids of pentacyclic triterpenes (oleanolic, ursolic, and maslinic acids) were coupled with $2,3,4,6$-tetra- $O$-acetyl- $\beta$-D-glucopyranosyl azide as well as

$15 \mathrm{~N}$-( $\omega$-azido-[C-2, C-6, and C-11]alkanoyl)- $\beta$-D-glucopyranosylamines under conditions of copper(I)-catalyzed azide-alkyne cycloaddition (CuAAC) to give tethered D-glucose-triterpene heteroconjugates. The $O$-acetyl protecting groups were removed by base-catalyzed hydrolysis. $N$-( $\omega$-Azido-[C-2, C-6, C-11, and C-16]alkanoyl)- $\beta$-D-glucopyranosylamines were also tethered by 1,7-octadiyne under CuAAC conditions to furnish D-glucose homoconjugates. $O$-Deacetylation

20 was carried out by the Zemplén protocol. The new compounds were assayed against rabbit muscle glycogen phosphorylase (RMGP) a or b enzymes. Some of the heteroconjugates inhibited the enzyme in the low micromolar range $\left(\mathrm{IC}_{50}\right.$ values $\left.40-70 \mu \mathrm{M}\right)$, while the homoconjugates proved inefficient as inhibitors.

\section{Introduction}

Type 2 diabetes mellitus has become a widespread disease afflicting a very large proportion of the population all over the 30 world. $^{1-3}$ The diseased state is associated with disorders in glucose metabolism by the liver and periphery resulting in elevated blood glucose levels which, in turn, are responsible for fatal long-term complications. ${ }^{1,4}$ An ideal anti-diabetic agent should be capable of lowering blood glucose in both fed and fasted states. Control of the hepatic glycogen metabolism is one of the key events through which insulin maintains blood glucose homeostasis. Among other means for influencing glucose production in the liver, inhibition of glycogen phosphorylase (GP), the rate-limiting enzyme of 40 glycogen degradation, has been regarded as a promising therapeutic approach to the treatment of type 2 diabetes. $^{5,6}$ Some GP inhibitors have shown efficacy in lowering blood glucose in animal models and clinical trials. ${ }^{7,8}$ In the liver and muscle isoforms of GP enzymes, six binding sites have 45 been identified by X-ray crystallographic studies of enzymeinhibitor complexes: the catalytic, the inhibitor, the allosteric,

${ }^{a}$ Center for Drug Discovery, College of Pharmacy, China

Pharmaceutical University, 24 Tongjiaxiang, Nanjing 210009, China

$50{ }^{b}$ Jiangsu Center for Drug Screening, China Pharmaceutical

University, 24 Tongjiaxiang, Nanjing 210009, China

${ }^{c}$ Department of Organic Chemistry, University of Debrecen, $P O B 20$,

H-4010 Debrecen, Hungary

${ }^{d}$ Cell Biology and Signaling Research Group of the Hungarian

Academy of Sciences at the Department of Medical Chemistry,

Medical and Health Science Centre, University of Debrecen,

55 Egyetem tér 1, H-4032 Debrecen, Hungary

${ }^{e}$ Department of Medical Chemistry, Medical and Health Science

Centre, University of Debrecen, Egyetem tér 1, H-4032 Debrecen,

Hungary

$\dagger$ Electronic supplementary information (ESI) available: Copies of ${ }^{1} \mathrm{H}$

NMR and ${ }^{13} \mathrm{C}$ NMR spectra. See DOI: 10.1039/b9nj00602h the glycogen storage, and the new allosteric sites, ${ }^{6,9}$ as well as the recently discovered benzimidazol site. ${ }^{10}$

Among the large variety of compounds tested as GP inhibitors, the most populated class is that of D-glucose derivatives, ${ }^{11,12}$ which bind primarily to the catalytic site of the enzyme, as proven by several X-ray crystallographic investigations. ${ }^{9}$ These glucose analogue inhibitors of GP are characterized by maintaining an intact hexopyranoid sugar ring with the full $\mathrm{OH}$ substitution pattern of D-gluco configuration, thus resembling the non-reducing end of the natural substrate glycogen. The modifications are located at the anomeric centre as spirocycles, as well as $\beta$-NHCOR, $\beta$-NHCONHCOR, and $\beta$ - $C$-heterocyclic substituents, just to mention the most efficient ones. ${ }^{5,6}$

Pentacyclic triterpenes like 1-3 and related compounds have been reported to represent a new class of glycogen phosphorylase inhibitors. ${ }^{13-15} \mathrm{X}$-Ray crystallographic studies revealed the molecular basis of their inhibitory effect, demonstrating that pentacyclic triterpenes such as asiatic and maslinic acids bind to GP at the allosteric site. ${ }^{16}$ Oleanolic acid (1, OA), ursolic acid (2, UA) and maslinic acid (3, MA) have recently attracted much attention due to their broad biological activities such as protection of the liver against toxic injury, anti-inflammation, anti-HIV, antitumor, antioxidation, anti-hyperglycemia and cardiovascular activities. ${ }^{17}$

Inhibitors having the potential to bind to more than one site of an enzyme may be significantly more efficient than those with a single binding group (for some tentatively selected examples of bi- or trivalent enzyme inhibitors see ref. 18-23). This principle is well known in the interactions of multivalent carbohydrate derivatives with various proteins, and is frequently called the glycoside cluster effect in that field. ${ }^{24}$ Trivalent glucose analogues have very recently been tested for GP inhibition to show a slightly better effect than 
1 that of derivatives with a single sugar unit. ${ }^{25}$ Homobivalent

Q4 indolcarboxamide ${ }^{26}$ as well as cynnamic $\operatorname{acid}^{27,28}$ derivatives proved very efficient inhibitors of GP.

With these preliminaries in mind, we envisaged conjugation 5 of triterpenes and D-glucose in such a way that both could Q5 bind to the site to which they bind on their own, thus providing the first potentially heterobivalent inhibitors of GP. The recently reported triterpene-glucose conjugates were not capable of this because the sugar parts were attached to

10 the triterpene via the C-6 position. ${ }^{29}$ Furthermore, some new bivalent glucose derivatives are also reported.

\section{Results and discussion}

\section{Syntheses}

The new triterpene glycoconjugates were designed to include oleanolic, ursolic, and maslinic acids (1-3) on one hand and $N$-acyl- $\beta$-D-glucopyranosylamines on the other, by connecting them via linker chains of different length. The $\mathrm{Cu}(\mathrm{I})$-catalyzed 20 azide-alkyne cycloaddition ${ }^{30}$ (CuAAC) was chosen as the linking methodology. The syntheses are summarized in Schemes 1-5.

Direct esterification of oleanolic acid 1, ursolic acid 2, and maslinic acid 3 with propargyl bromide (Scheme 1) afforded alkynes $4{ }^{29} \mathbf{5}$, and $\mathbf{6}$, respectively, in excellent yields.

$N$-Acyl- $\beta$-D-glucopyranosylamines with a terminal azide group were synthesized from per- $O$-acetylated- $\beta$-D-glucopyranosyl azide 32 (Scheme 2). $\omega$-Bromoalkanoyl derivatives 8-11 were obtained by a 'Staudinger reaction' of 7 with $\mathrm{PMe}_{3}$, resulting in an intermediate phosphinimine which, without being isolated, was reacted ${ }^{33}$ with the corresponding $\omega$-bromoalkanoic acid. Subsequent substitution with $\mathrm{NaN}_{3}$ in DMF gave compunds 12-15, respectively. Practically each synthetic step furnished the corresponding product in very good yield.

To perform the CuAAC, an alkyne 4-6 and an azide 7 or 12-14 each were dissolved in $\mathrm{CH}_{2} \mathrm{Cl}_{2}-\mathrm{H}_{2} \mathrm{O}$, followed by the addition of a catalytic amount of sodium L-ascorbate and $\mathrm{CuSO}_{4} \cdot 5 \mathrm{H}_{2} \mathrm{O}$. The 'click reactions' proceeded very well at room temperature to afford $\beta$-D-glucopyranosyl-1,2,3-triazoles 16-18 (Scheme 3) and the tethered compounds 22-30 (Scheme 4) in good to excellent yields. The $O$-acetyl groups were cleaved with $4 \mathrm{~N} \mathrm{NaOH} / \mathrm{MeOH}$ to give the corresponding deprotected compounds 19-21 (Scheme 3) and 31-37, respectively (Scheme 4). During deprotection of $\mathbf{2 8}$ the desired compound was not obtained; instead compound $\mathbf{3 8}$ could be isolated as a result of cleavage of the glucosylamide bond.

For bivalent glucose derivatives the $N$-( $\omega$-azidoalkanoyl)- $\beta$ D-glucopyranosylamines $\mathbf{1 2 - 1 5}$ were reacted with 1,7-octadiyne (43) under CuAAC conditions (Scheme 5). The reactions proceeded smoothly to give good to excellent yields of the coupled derivatives 44-47, which were deprotected under Zemplén conditions to give compounds 48-51 in similarly good yields. In order to make comparisons with monovalent glucose derivatives, azides $\mathbf{1 2}$ and $\mathbf{1 3}$ were deprotected by the Zemplén protocol to $\mathbf{3 9}$ and $\mathbf{4 1}$, respectively, which were further reduced to the $\omega$-amino compounds $\mathbf{4 0}$ and $\mathbf{4 2}$.

\section{Glycogen phosphorylase inhibition}

The above-synthesized derivatives were evaluated in enzyme inhibition assays described previously ${ }^{35,36}$ against rabbit muscle glycogen phosphorylase a (RMGPa) or b (RMGPb) which shared considerable sequence similarity with human liver GP (Schemes 1 and 3-5, and Charts 1 and 2. As we found previously, ${ }^{36}$ inhibitions of $\mathrm{a}$ and $\mathrm{b}$ forms of GP showed acceptable similarity.
Scheme 1 Reagents and conditions: (a) $\mathrm{K}_{2} \mathrm{CO}_{3}$, propargyl bromide, DMF, rt. Inhibition of $\mathrm{RMGPa}$ (IC 50 [ $\mu \mathrm{M}$ ], values are means of three experiments).

50
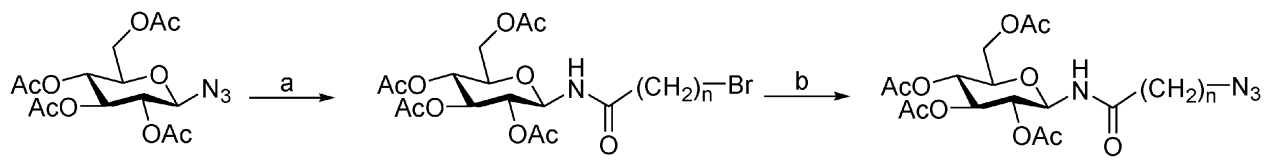

55

7

8 not isolated

$9(93 \%)$

$10(64 \%)$

$11(76 \%)$

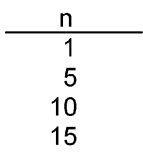

$12(63 \%)$
$13(85 \%)$
$14(88 \%)$
$15(81 \%)$

Scheme 2 Reagents and conditions: (a) $\mathrm{PMe}_{3}, \mathrm{Br}-\left(\mathrm{CH}_{2}\right)_{n}-\mathrm{COOH}, \mathrm{CH}_{2} \mathrm{Cl}_{2}$, rt; (b) $\mathrm{NaN}$, DMF, rt. 

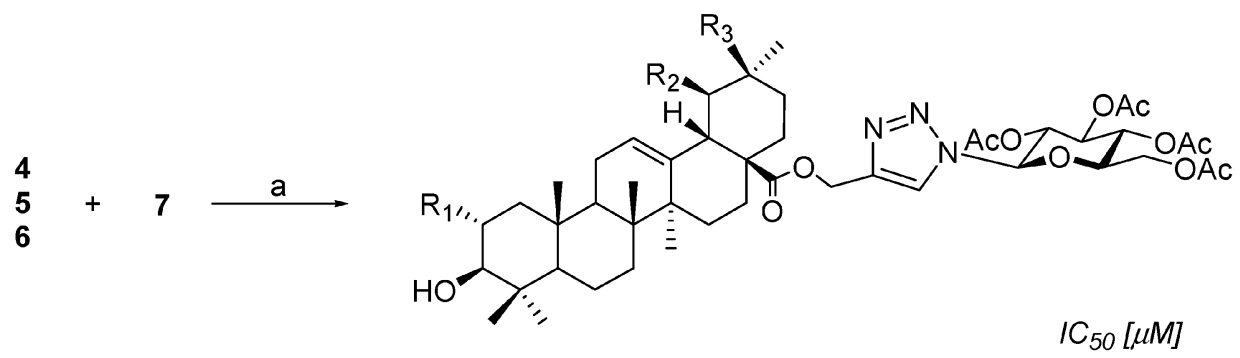

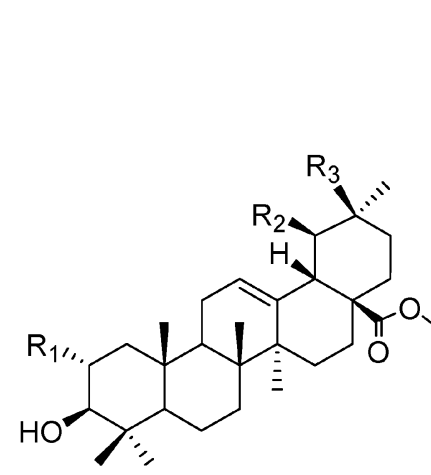<smiles>C[12CH3]</smiles>

Scheme 3 Reagents and conditions: (a) $\mathrm{CuSO}_{4}$, sodium L-ascorbate, $\mathrm{CH}_{2} \mathrm{Cl}_{2}-\mathrm{H}_{2} \mathrm{O}$, rt; (b) $\mathrm{NaOH}, \mathrm{MeOH}$, rt. Inhibition of RMGPa (IC 50 [ $\mu \mathrm{M}$, values are means of three experiments).

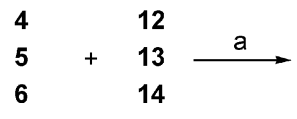<smiles>[R7]C(C)[C@H](O)[C](C)C</smiles>

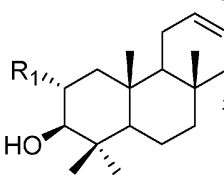

$1 C_{50}[\mu \mathrm{M}]$

$26 \pm 4 \quad(\mathrm{OA})$

$45 \pm 2 \quad(\mathrm{UA})$

$779 \pm 56$ (MA)

$1 C_{50}[\mu \mathrm{M}]$

$22 \mathrm{R}_{1}=\mathrm{H}, \mathrm{R}_{2}=\mathrm{H}, \mathrm{R}_{3}=\mathrm{CH}_{3}, \mathrm{n}=1 \quad$ (85\%) $68 \pm 5$

$\left.23 \mathrm{R}_{1}=\mathrm{H}, \mathrm{R}_{2}=\mathrm{H}, \mathrm{R}_{3}=\mathrm{CH}_{3}, \mathrm{n}=5 \quad(80 \%) \quad 598 \pm 60\right\}(\mathrm{OA})$

$24 \mathrm{R}_{1}=\mathrm{H}, \mathrm{R}_{2}=\mathrm{H}, \mathrm{R}_{3}=\mathrm{CH}_{3}, \mathrm{n}=10 \quad$ (64\%) no inh.

$25 \mathrm{R}_{1}=\mathrm{H}, \mathrm{R}_{2}=\mathrm{CH}_{3}, \mathrm{R}_{3}=\mathrm{H}, \mathrm{n}=1 \quad(11 \%) \quad 382 \pm 28$

$26 \mathrm{R}_{1}=\mathrm{H}, \mathrm{R}_{2}=\mathrm{CH}_{3}, \mathrm{R}_{3}=\mathrm{H}, \mathrm{n}=5 \quad$ (50\%) no inh.

$27 \quad \mathrm{R}_{1}=\mathrm{H}, \mathrm{R}_{2}=\mathrm{CH}_{3}, \mathrm{R}_{3}=\mathrm{H}, \mathrm{n}=10 \quad(74 \%) \quad 65 \pm 5$

$28 \mathrm{R}_{1}=\mathrm{OH}, \mathrm{R}_{2}=\mathrm{H}, \mathrm{R}_{3}=\mathrm{CH}_{3}, \mathrm{n}=1 \quad(57 \%) \quad 78 \pm 3$

$29 \mathrm{R}_{1}=\mathrm{OH}, \mathrm{R}_{2}=\mathrm{H}, \mathrm{R}_{3}=\mathrm{CH}_{3}, \mathrm{n}=5 \quad(71 \%)$ no inh.

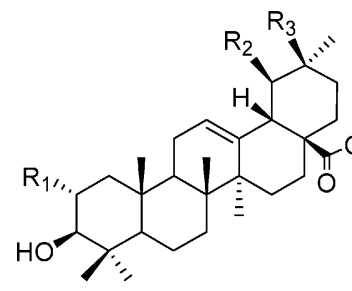

$30 \mathrm{R}_{1}=\mathrm{OH}, \mathrm{R}_{2}=\mathrm{H}, \mathrm{R}_{3}=\mathrm{CH}_{3}, \mathrm{n}=10$ (82\%) no inh.

$32 \mathrm{R}_{1}=\mathrm{H}, \mathrm{R}_{2}=\mathrm{H}, \mathrm{R}_{3}=\mathrm{CH}_{3}, \mathrm{n}=5 \quad(83 \%) 679 \pm 45$

$33 \mathrm{R}_{1}=\mathrm{H}, \mathrm{R}_{2}=\mathrm{H}, \mathrm{R}_{3}=\mathrm{CH}_{3}, \mathrm{n}=10 \quad$ (97\%) no inh.

$34 \mathrm{R}_{1}=\mathrm{H}, \mathrm{R}_{2}=\mathrm{CH}_{3}, \mathrm{R}_{3}=\mathrm{H}, \mathrm{n}=5$ (98\%) no inh.

$35 \mathrm{R}_{1}=\mathrm{H}, \mathrm{R}_{2}=\mathrm{CH}_{3}, \mathrm{R}_{3}=\mathrm{H}, \mathrm{n}=10 \quad$ (93\%) no inh.

$36 \quad \mathrm{R}_{1}=\mathrm{OH}, \mathrm{R}_{2}=\mathrm{H}, \mathrm{R}_{3}=\mathrm{CH}_{3}, \mathrm{n}=5 \quad(93 \%) \quad 778 \pm 33$

50

$37 \mathrm{R}_{1}=\mathrm{OH}, \mathrm{R}_{2}=\mathrm{H}, \mathrm{R}_{3}=\mathrm{CH}_{3}, \mathrm{n}=10 \quad(72 \%) \quad 214 \pm 15$

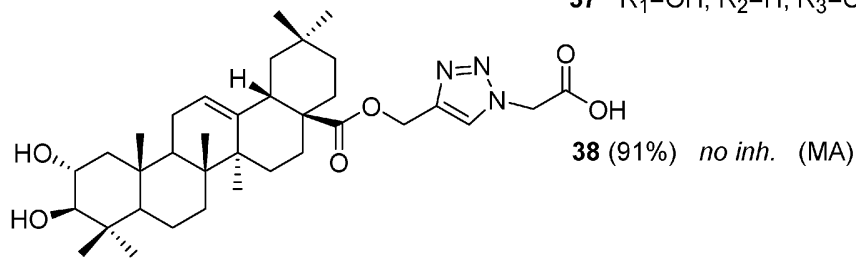

Scheme 4 Reagents and conditions: (a) $\mathrm{CuSO}_{4}$, sodium L-ascorbate, $\mathrm{CH}_{2} \mathrm{Cl}_{2}-\mathrm{H}_{2} \mathrm{O}$, rt; (b) $\mathrm{NaOH}, \mathrm{MeOH}$, rt. Inhibition of RMGPa (IC 50 [ $\mu \mathrm{M}$, values are means of three experiments). 

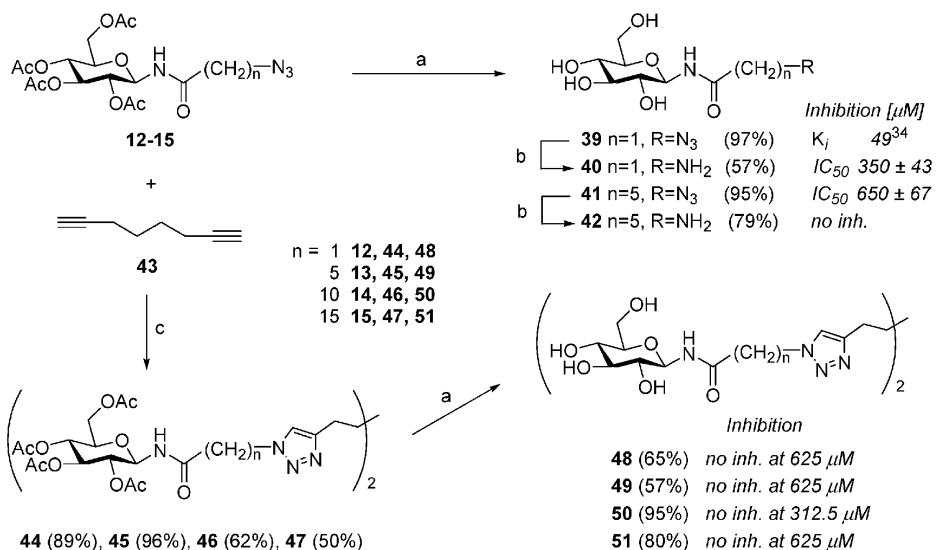

$44(89 \%), 45(96 \%), 46(62 \%), 47(50 \%)$

$51(80 \%)$ no inh. at $625 \mu \mathrm{M}$

5 Scheme 5 Reagents and conditions: (a) cat. $\mathrm{NaOMe}, \mathrm{MeOH}$ rt.; (b) RANEY ${ }^{\mathbb{R}}-\mathrm{Ni}, \mathrm{H}_{2}, \mathrm{MeOH}, 70{ }^{\circ} \mathrm{C}$; (c) $\mathrm{CuSO}_{4}, \mathrm{~L}_{-} \mathrm{ascorbic}$ acid, $\mathrm{CH}_{2} \mathrm{Cl}_{2}-\mathrm{H}_{2} \mathrm{O}, \mathrm{rt}$. Inhibition of RMGPb.

Inhibition by compounds tested against RMGPa

20

25

$\mathrm{HO}$<smiles>[R]OC(=O)[C@]12CCC(C)(C)C[C@H]1C1=CC[C@@H]3[C@](C)(CC[C@@H]4C(C)(C)[C@@H](O)CC[C@@]43C)[C@]1(C)CC2</smiles>

30

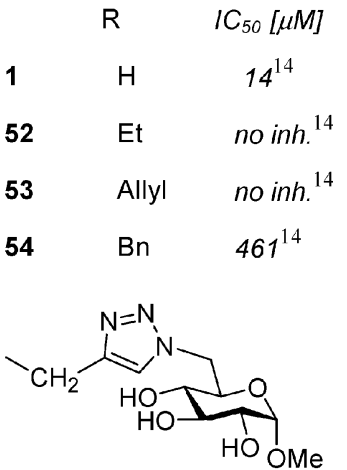

55

$1.14^{29}$

35

Inhibition by compounds tested against RMGPb

40<smiles>OCc1cn(C2OC(O)C3(O)C(O)CC2(O)CC3O)nn1</smiles>

56<smiles>O=C(Cn1cc(-c2ccccc2)nn1)NC(O)C(O)C1(CO)C(O)C(O)C1(O)Br</smiles>

Chart 1
The assay results showed that propargylation of the C-28 carboxyl depressed the GPa enzyme inhibitory activity (compare 1-3 to 4-6 in Scheme 1). This observation is similar to the effect of other esterifications of OA (52-54, Chart 1) resulting in a significant loss of activity. ${ }^{14}$

In the sugar-coupled series (Schemes 3 and 4) the activities of OA derivatives were generally better than those of the derivatives of UA and MA (19 vs. 20 and 21; 22 vs. 25 and 28; 23 vs. 26 and 29; 32 vs. 34 and 36). Deprotection of the sugar part in the 1- $\beta$-D-glucopyranosyl-1,2,3-triazole series (Scheme 3) gave better inhibitors with OA (16 vs. 19) and MA (18 vs. 21), while no significant change was observed with UA (17 vs. 20). Appending the sugar to the triazole via the C-6 position as in $\mathbf{5 5}$ (Chart 1) gave a very good inhibitor, although the $O$-peracetylated analogue had no activity at all. ${ }^{29}$

The effect of the length of the linker between the sugar and the triterpene parts was studied in the $\omega$-triazolylalkanoylamide series (Scheme 4): with OA (22 vs. 23 and 24) and MA (28 vs. 29 and 30) derivatives the one-carbon linkage was significantly better than the longer ones, while among the UA compounds an opposite effect (27 vs. 25 and 26) was observed. Removal of the $O$-acetyl protecting groups in the $\omega$-triazolylalkanoyl-amide series (Scheme 4, 31-37) brought about no obvious difference. Comparison of $\mathbf{1 9}$ with the hydroxymethyl-triazole $\mathbf{5 6}$ shows that the presence of the OA moiety makes the inhibition somewhat better. However, 56 binds to the catalytic site, ${ }^{37}$ while $\mathbf{1 9}$ can be expected to occupy the allosteric site. ${ }^{29}$ Thus, the comparable inhibitory activities may 
1 not be directly relevant, except in the as-yet unproven case of a dual binding mode which could be expected to occur between two enzyme dimers. ${ }^{25}$ Similar considerations may apply to a comparison of $\mathbf{3 1}$ and $\mathbf{5 7}$.

5 In cases of bivalent glucose derivatives 48-51 (Scheme 5) no inhibition could be observed. Study of analogous monovalent compounds revealed that with an azide as endgroup $(39,41)$ the inhibitory activity was moderate and decreased with the length of the linker. Bivalent compound 48 can also be

10 compared with the monovalent triazole $\mathbf{5 7}^{38}$ (Chart 1) to show that the dimeric structures seem to be too large to occupy the catalytic site, and no other interactions exist with the enzyme. In the presence of amine endgroups $(\mathbf{4 0}, \mathbf{4 2})$ the inhibition was much weaker, and with the longer linker chain

15 no effect was detected.

\section{Conclusions}

Copper(I)-catalyzed azide-alkyne cycloaddition - 'click 20 chemistry' - proved suitable for the synthesis of conjugates of pentacyclic triterpenes and D-glucose derivatives as new, potentially heterobivalent inhibitors of glycogen phosphorylase. Compounds $17\left(\mathrm{IC}_{50}=51 \mu \mathrm{M}\right), 19\left(\mathrm{IC}_{50}=26 \mu \mathrm{M}\right), \mathbf{2 0}$ $\left(\mathrm{IC}_{50}=45 \mu \mathrm{M}\right), 22\left(\mathrm{IC}_{50}=68 \mu \mathrm{M}\right), 27\left(\mathrm{IC}_{50}=65 \mu \mathrm{M}\right)$ and $2525\left(\mathrm{IC}_{50}=78 \mu \mathrm{M}\right)$ were the most potent inhibitors of RMGPa. Homobivalent glucose derivatives proved inefficient in $\mathrm{RMGPb}$ inhibition assays. The monovalent analogues of both triterpenes and glucose derivatives proved generally more efficient than the bivalent compounds.

30

\section{Experimental}

\section{General methods}

All commercially available solvents and reagents were used without further purification. Melting points were measured on a RY-1 or on a Kofler hot-stage melting point apparatus. Column chromatography was carried out on E. Merck Silica Gel 60 (230-400 mesh), on silica gel (200-300 mesh, Qindao Ocean Chemical Company, China), or Kieselgel 60 (Merck, particle size $0.063-0.200 \mathrm{~mm})$. IR spectra were recorded on Shimadzu FTIR-8400S spectrometer. ${ }^{1} \mathrm{H}$ - and ${ }^{13} \mathrm{C}$-NMR spectra were measured on Bruker AV-300 (300/75 MHz for $\left.{ }^{1} \mathrm{H} /{ }^{13} \mathrm{C}\right)$, Bruker $360\left(360 / 90 \mathrm{MHz}\right.$ for $\left.{ }^{1} \mathrm{H} /{ }^{13} \mathrm{C}\right)$ or Avance DRX 500 $\left(500 / 125 \mathrm{MHz}\right.$ for $\left.{ }^{1} \mathrm{H} /{ }^{13} \mathrm{C}\right)$ spectrometers. Chemical shifts are 5 reported as values from an internal tetramethylsilane standard. TLC was performed on DC-Alurolle Kieselgel 60 F254 (Merck), and the plates were visualised under UV light and by gentle heating. Mass spectral data were obtained on Agilent 1100 LC/DAD/MSD or Q-Tof Micro MS/MS spectrometers. Optical

50 rotations were measured using a Perkin-Elmer 141 or a PerkinElmer 241 polarimeters at rt. $\mathrm{PMe}_{3}(1 \mathrm{M}$ solution in toluene) and 1,7-octadiyne were purchased from Sigma-Aldrich.

\section{Syntheses}

General procedure I for the propargylation of oleanolic acid, ursolic acid or maslinic acid

To a solution of a carboxylic acid (1 or $\mathbf{2}$ or $3,2.2 \mathrm{mmol}$ ) in DMF $(5 \mathrm{~mL})$, was added propargyl bromide $(2.4 \mathrm{mmol})$ and
$\mathrm{K}_{2} \mathrm{CO}_{3}$ (4.4 mmol). The reaction mixture was stirred at $\mathrm{rt}$ for $18 \mathrm{~h}$, then concentrated. The residue was diluted with EtOAc $(50 \mathrm{~mL})$, washed successively with $1 \mathrm{~N} \mathrm{HCl}$, water, satd. aq. $\mathrm{NaHCO}_{3}$, water and brine, dried $\left(\mathrm{MgSO}_{4}\right)$, filtered and concentrated. The residue was purified by column chromatography.

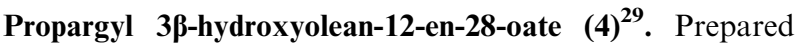
from 1 (1 g, $2.2 \mathrm{mmol})$ and propargyl bromide $(0.27 \mathrm{~mL}$, $2.4 \mathrm{mmol}$ ) according to General procedure I. The residue was purified by column chromatography (EtOAc-hexane, 1:6). Yield: $1.05 \mathrm{~g}, 97 \%$, white solid, mp $121-122{ }^{\circ} \mathrm{C} ; R_{\mathrm{f}}=0.33$ (EtOAc-hexane, $1: 4) ;[\alpha]_{\mathrm{D}}=+67.9\left(c=0.50, \mathrm{CH}_{2} \mathrm{Cl}_{2}\right)$. IR $\left(\mathrm{KBr}, \mathrm{cm}^{-1}\right): 3308,2945,2866,1731,1157,1032,739 ;{ }^{1} \mathrm{H}$ NMR (300 MHz, $\left.\mathrm{CDCl}_{3}\right): \delta 0.74,0.77,0.92,0.98,1.13(5 \mathrm{~s}$, each $\left.3 \mathrm{H}, 5 \times \mathrm{CH}_{3}\right), 0.90\left(\mathrm{~s}, 6 \mathrm{H}, 2 \times \mathrm{CH}_{3}\right), 0.71-2.04(\mathrm{~m}, 22 \mathrm{H})$, $2.41(\mathrm{t}, 1 \mathrm{H}, J=2.6 \mathrm{~Hz}, \mathrm{CH}), 2.87(\mathrm{dd}, 1 \mathrm{H}, J=4.1,9.5 \mathrm{~Hz}$, $\mathrm{H}-18), 3.21(\mathrm{dd}, 1 \mathrm{H}, J=5.1,10.7 \mathrm{~Hz}, \mathrm{H}-3), 4.56(\mathrm{dd}, 1 \mathrm{H}, J=$ 2.6, $\left.15.4 \mathrm{~Hz}, \mathrm{CO}_{2} \mathrm{CH}_{2}\right), 4.68(\mathrm{dd}, 1 \mathrm{H}, J=2.6,15.4 \mathrm{~Hz}$, $\left.\mathrm{CO}_{2} \mathrm{CH}_{2}\right), 5.30(\mathrm{t}, 1 \mathrm{H}, J=3.5 \mathrm{~Hz}, \mathrm{H}-12) ;{ }^{13} \mathrm{C} \mathrm{NMR}$ $\left(75 \mathrm{MHz} \mathrm{CDCl}_{3}\right): \delta 15.3,15.6,17.1,18.3,23.0,23.4,23.6$, $25.8,27.2,27.7,28.1,30.7,32.2,32.8,33.1,33.8,37.0,38.5$, 38.8, 39.4, 41.3, 41.7, 45.9, 46.8, 47.6, 51.6, 55.2, 74.4, 78.1, 79.0, 122.63, 143.4, 176.8. ESI-MS (positive mode) $\mathrm{m} / \mathrm{z}: 517.3$ $[\mathrm{M}+\mathrm{Na}]^{+}$.

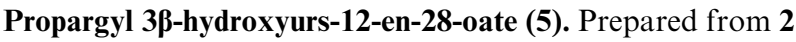
$(2.0 \mathrm{~g}, 4.4 \mathrm{mmol})$ and propargyl bromide $(0.54 \mathrm{~mL}, 4.8 \mathrm{mmol})$ according to General procedure I. The residue was purified by column chromatography (EtOAc-hexane, 1:5). Yield: $2.0 \mathrm{~g}$, 93\%, white solid, mp 129-131 ${ }^{\circ} \mathrm{C} ; R_{\mathrm{f}}=0.48$ (EtOAc-hexane, $1: 5)$. IR ( $\left.\mathrm{KBr}, \mathrm{cm}^{-1}\right): 3309,2927,2871,1729,1454,1383$, 1221, 1167, 1139, 1106, 1032, 996, 757, 667; ${ }^{1} \mathrm{H}$ NMR $\left(300 \mathrm{MHz}, \mathrm{CDCl}_{3}\right): \delta 0.76,0.77,0.91,0.95,0.98,1.08$ $\left(6 \mathrm{~s}\right.$, each $\left.3 \mathrm{H}, 6 \times \mathrm{CH}_{3}\right), 0.87\left(\mathrm{~d}, 3 \mathrm{H}, J=6.4 \mathrm{~Hz}, \mathrm{CH}_{3}\right)$, 0.75-2.10 (m, 22H), $2.26(\mathrm{~d}, 1 \mathrm{H}, J=11.3 \mathrm{~Hz}, \mathrm{H}-18), 2.41$ (t, $1 \mathrm{H}, J=2.4 \mathrm{~Hz}, \mathrm{CH}), 3.20(\mathrm{dd}, 1 \mathrm{H}, J=5.1,10.7 \mathrm{~Hz}, \mathrm{H}-3)$, 4.57 and $4.65\left(\mathrm{dd}\right.$, each $\left.1 \mathrm{H}, J=2.5,15.6 \mathrm{~Hz}, \mathrm{COOCH}_{2}\right), 5.27$ $(1 \mathrm{H}, \mathrm{t}, J=3.6 \mathrm{~Hz}, \mathrm{H}-12) ;{ }^{13} \mathrm{C} \mathrm{NMR}\left(75 \mathrm{MHz}, \mathrm{CDCl}_{3}\right): \delta 5.5$, $15.6,17.0,17.2,18.3,21.1,23.3,23.5,24.6,27.3,28.0,28.1$, $30.6,33.1,36.4,37.0,38.67,38.75,38.8,39.1,39.6,42.1,47.6$, 48.2, 51.6, 52.8, 55.3, 74.3, 78.1, 79.0, 125.9, 137.8, 176.6. ESI-MS (positive mode) $m / z: 495.4[\mathrm{M}+\mathrm{H}]^{+}$.

Propargyl 2 $\alpha, 3 \beta$-dihydroxyolean-12-en-28-oate (6). Prepared from 3 (1.4 g, $3.0 \mathrm{mmol})$ and propargyl bromide $(0.37 \mathrm{~mL}$, $3.3 \mathrm{mmol}$ ) according to General procedure I. The residue was purified by column chromatography (EtOAc-hexane, 1:5). Yield: $1.3 \mathrm{~g}, 87 \%$, white solid, $\mathrm{mp} 233-234{ }^{\circ} \mathrm{C} ; R_{\mathrm{f}}=0.69$ (EtOAc-hexane, 1:5). IR ( $\left.\mathrm{KBr}, \mathrm{cm}^{-1}\right): 3394,3309,2946$, 1729, 1463, 1388, 1364, 1259, 1217, 1157, 1121, 1049, 1033, 995, 758, 669, 633; ${ }^{1} \mathrm{H}$ NMR (300 MHz, $\left.\mathrm{CDCl}_{3}\right): \delta 0.74,0.82$, $0.90,0.92,0.98,1.03,1.13\left(7 \mathrm{~s}\right.$, each $\left.3 \mathrm{H}, 7 \times \mathrm{CH}_{3}\right), 0.75-2.01$ $(\mathrm{m}, 20 \mathrm{H}), 2.41(\mathrm{t}, 1 \mathrm{H}, J=2.4 \mathrm{~Hz}, \mathrm{CH}), 2.87(\mathrm{dd}, 1 \mathrm{H}, J=4.3$, $13.7 \mathrm{~Hz}, \mathrm{H}-18), 3.01$ (d, $1 \mathrm{H}, J=9.5 \mathrm{~Hz}, \mathrm{H}-3), 3.65-3.73$ $(\mathrm{m}, 1 \mathrm{H}, \mathrm{H}-2), 4.57$ and $4.69(\mathrm{dd}$, each $1 \mathrm{H}, J=2.4,15.6 \mathrm{~Hz}$, $\left.\mathrm{COOCH}_{2}\right), 5.31(\mathrm{t}, 1 \mathrm{H}, J=3.5 \mathrm{~Hz}, \mathrm{H}-12) ;{ }^{13} \mathrm{C} \mathrm{NMR}$ $\left(75 \mathrm{MHz} \mathrm{CDCl}_{3}\right): \delta 16.6,16.7,17.2,18.4,23.0,23.5,23.6$, $25.9,27.7,28.6,30.7,32.2,32.7,33.1,33.9,38.3,39.2$, $39.5,41.3,41.8,45.9,46.5,46.8,47.6,51.6,55.4,69.0,74.4$, 
78.1, 84.0, 122.5, 143.5, 176.8. ESI-MS (positive mode) $m / z$ : $533.4[\mathrm{M}+\mathrm{Na}]^{+}$.

General procedure II for the preparation of $N$-( $\omega$-bromoalkanoyl)2,3,4,6-tetra- $O$-acetyl- $\beta$-D-glucopyranosylamines (9-11)

2,3,4,6-Tetra- $O$-acetyl- $\beta$-D-glucopyranosyl azide $(7,0.10 \mathrm{~g}$, $0.27 \mathrm{mmol}$ ) was dissolved in dry $\mathrm{CH}_{2} \mathrm{Cl}_{2}(3 \mathrm{~mL})$. To the solution $\mathrm{Me}_{3} \mathrm{P}$ (1.1 equiv. of a $1 \mathrm{M}$ solution in toluene) was added in one portion. The mixture was stirred at rt. until nitrogen evolution had ceased and TLC (EtOAc-hexane, $1: 1$ ) had indicated complete transformation of the azide. This solution was then reacted with an $\omega$-bromoalkanoic acid (1.1 equiv., as indicated with the particular compounds) till the disappearance of the iminophosphorane (TLC, EtOAchexane, $1: 1)$. Then, it was diluted with $\mathrm{CH}_{2} \mathrm{Cl}_{2}(5 \mathrm{~mL})$ and washed with satd. aq. $\mathrm{NaHCO}_{3}$ solution $(2 \times 5 \mathrm{~mL})$. The organic phase was dried over $\mathrm{MgSO}_{4}$ and the solvent was removed under diminished pressure. The crude product was 20 purified by column chromatography.

$\boldsymbol{N}$-(6-Bromohexanoyl)-2,3,4,6-tetra- $\boldsymbol{O}$-acetyl- $\boldsymbol{\beta}$-D-glucopyranosylamine (9). Prepared from $7(0.50 \mathrm{~g} 1.34 \mathrm{mmol})$ according to General procedure II. The residue was purified by column chromatography (EtOAc-hexane, 1:1). Yield: $0.65 \mathrm{~g}, 93 \%$, colourless oil, $R_{\mathrm{f}}=0.35($ EtOAc-hexane, $1: 1) ;[\alpha]_{\mathrm{D}}=+22$ $\left(c=0.59, \mathrm{CHCl}_{3}\right) ;{ }^{1} \mathrm{H}$ NMR $\left(360 \mathrm{MHz}, \mathrm{CDCl}_{3}\right): \delta(\mathrm{ppm})$ 1.42-1.47 (m, 2H, $\left.\mathrm{CH}_{2}\right), 1.60-1.63\left(\mathrm{~m}, 2 \mathrm{H}, \mathrm{CH}_{2}\right), 1.83-1.90$ $\left(\mathrm{m}, 2 \mathrm{H}, \mathrm{CH}_{2}\right), 2.02,2.04,2.06,2.08\left(4 \mathrm{~s}, 12 \mathrm{H}, 4 \times \mathrm{OCOCH}_{3}\right)$, 30 2.21-2.27 (m, 2H, $\left.\mathrm{CH}_{2}\right), 3.39-3.43\left(\mathrm{~m}, 2 \mathrm{H}, \mathrm{CH}_{2}\right), 3.86$ (ddd, $1 \mathrm{H}, J=1.2,2.6,10.6 \mathrm{~Hz}, \mathrm{H}-5), 4.08(\mathrm{dd}, 1 \mathrm{H}, J=1.2$, $11.9 \mathrm{~Hz}, \mathrm{H}-6 \mathrm{~b}), 4.32$ (dd, $1 \mathrm{H}, J=2.6,11.9 \mathrm{~Hz}, \mathrm{H}-6 \mathrm{a}), 4.93$, $5.06,5.29,5.32$ (4 pseudo t, $4 \mathrm{H}, J=9.2,10.6 \mathrm{~Hz}$ in each, $\mathrm{H}-1$, $\mathrm{H}-2, \mathrm{H}-3, \mathrm{H}-4), 6.63$ (d, $1 \mathrm{H}, J=9.2 \mathrm{~Hz}, \mathrm{NH}) ;{ }^{13} \mathrm{C} \mathrm{NMR}$ $\left(90 \mathrm{MHz}, \mathrm{CDCl}_{3}\right): \delta(\mathrm{ppm}) 20.3(3), 20.5\left(4 \times \mathrm{OCOCH}_{3}\right), 23.9$, 27.3, 32.0, 33.3, $35.9\left(5 \times \mathrm{CH}_{2}\right), 61.5(\mathrm{C}-6), 67.9,70.4,72.5$, 73.2 (C-2, C-3, C-4, C-5), 77.7 (C-1), 169.3, 169.6, 170.4, $170.5\left(4 \times \mathrm{OCOCH}_{3}\right), 172.8(\mathrm{NHCO})$. Anal. calcd. for $\mathrm{C}_{20} \mathrm{H}_{30} \mathrm{BrNO}_{10}$ (524.37): C 45.81, H 5.77, N 2.67. Found: C 40 45.64, H 5.94, N 2.59 .

$\mathrm{N}$-(11-Bromoundecanoyl)-2,3,4,6-tetra- $\boldsymbol{O}$-acetyl- $\beta$-D-glucopyranosylamine (10). Prepared from 7 (5.0 g $13.4 \mathrm{mmol})$ according to General procedure II. The residue was purified 45 by column chromatography (EtOAc-hexane, 1:1). Yield: $5.13 \mathrm{~g}, 64 \%$, white crystalline product, $\mathrm{mp} 61-63{ }^{\circ} \mathrm{C} ;[\alpha]_{\mathrm{D}}=$ $+15\left(c=0.38, \mathrm{CHCl}_{3}\right) ;{ }^{1} \mathrm{H}$ NMR $\left(360 \mathrm{MHz}, \mathrm{CDCl}_{3}\right): \delta(\mathrm{ppm})$ 1.28 (bs, 10H, $\left.5 \times \mathrm{CH}_{2}\right), 1.40-1.45\left(\mathrm{~m}, 2 \mathrm{H}, \mathrm{CH}_{2}\right), 1.57-1.50$ $\left(\mathrm{m}, 2 \mathrm{H}, \mathrm{CH}_{2}\right), 1.80-1.86\left(\mathrm{~m}, 2 \mathrm{H}, \mathrm{CH}_{2}\right), 2.02,2.04,2.06,2.08$

$50\left(4 \mathrm{~s}, 12 \mathrm{H}, 4 \times \mathrm{OCOCH}_{3}\right), 2.17-2.21\left(\mathrm{~m}, 2 \mathrm{H}, \mathrm{CH}_{2}\right), 3.38-3.43$ $\left(\mathrm{m}, 2 \mathrm{H}, \mathrm{CH}_{2}\right), 3.85(\mathrm{ddd}, 1 \mathrm{H}, J=1.2,2.6,10.6 \mathrm{~Hz}, \mathrm{H}-5), 4.07$ $(\mathrm{dd}, 1 \mathrm{H}, J=1.2,11.9 \mathrm{~Hz}, \mathrm{H}-6 \mathrm{~b}), 4.32(\mathrm{dd}, 1 \mathrm{H}, J=2.6,11.9$ $\mathrm{Hz}, \mathrm{H}-6 \mathrm{a}$ ), 4.93, 5.06, 5.27, 5.32 (4 pseudo t, 4H, $J=9.2,10.6$ $\mathrm{Hz}$ in each, H-1, H-2, H-3, H-4), $6.51(\mathrm{~d}, 1 \mathrm{H}, J=9.2 \mathrm{~Hz}$, $55 \mathrm{NH}) ;{ }^{13} \mathrm{C} \mathrm{NMR}\left(90 \mathrm{MHz}, \mathrm{CDCl}_{3}\right): \delta$ (ppm) 20.4(3), 20.5 $\left(4 \times \mathrm{OCOCH}_{3}\right), 24.8,25.0,27.9,28.4,28.8,29.0,29.1,32.5$, 33.7, $36.3\left(10 \times \mathrm{CH}_{2}\right), 61.5(\mathrm{C}-6), 67.9,70.4,72.5,73.3$ (C-2, C-3, C-4, C-5), 77.8 (C-1), 169.3, 169.6, 170.4, 170.6 $\left(4 \times \mathrm{OCOCH}_{3}\right), 173.3(\mathrm{NHCO})$. Anal. calcd. for $\mathrm{C}_{25} \mathrm{H}_{40} \mathrm{BrNO}_{10}$
(594.50): C 50.51, H 6.78, N 2.36. Found: C 50.64, H 6.91, N 2.49 .

$\mathrm{N}$-(16-Bromohexadecanoyl)-2,3,4,6-tetra- $\boldsymbol{O}$-acetyl- $\boldsymbol{\beta}$-D-glucopyranosylamine (11). Prepared from $7(0.50 \mathrm{~g} 1.34 \mathrm{mmol})$ according to General procedure II. The residue was purified by column chromatography (EtOAc-hexane, 1:1). Yield: $0.68 \mathrm{~g}, 76 \%$, white crystalline product, $\mathrm{mp} 91-93{ }^{\circ} \mathrm{C} ;[\alpha]_{\mathrm{D}}=$ $+10\left(c=0.20, \mathrm{CHCl}_{3}\right) ;{ }^{1} \mathrm{H} \mathrm{NMR}\left(360 \mathrm{MHz}, \mathrm{CDCl}_{3}\right): \delta(\mathrm{ppm})$ $1.28\left(\mathrm{~m}, 18 \mathrm{H}, 9 \times \mathrm{CH}_{2}\right), 1.36-1.39\left(\mathrm{~m}, 2 \mathrm{H}, \mathrm{CH}_{2}\right), 1.48-1.52$ $\left(\mathrm{m}, 2 \mathrm{H}, \mathrm{CH}_{2}\right), 1.57-1.61\left(\mathrm{~m}, 2 \mathrm{H}, \mathrm{CH}_{2}\right), 1.84-1.88(\mathrm{~m}, 2 \mathrm{H}$, $\left.\mathrm{CH}_{2}\right), 2.03,2.04,2.06,2.08\left(4 \mathrm{~s}, 12 \mathrm{H}, 4 \times \mathrm{OCOCH}_{3}\right)$, 2.27-2.31 (m, 2H, $\left.\mathrm{CH}_{2}\right), 3.36-3.40\left(\mathrm{~m}, 2 \mathrm{H}, \mathrm{CH}_{2}\right), 3.87$ $(\mathrm{ddd}, 1 \mathrm{H}, J=1.2,2.6,10.6 \mathrm{~Hz}, \mathrm{H}-5), 4.06(\mathrm{dd}, 1 \mathrm{H}, J=$ $1.2,11.9 \mathrm{~Hz}, \mathrm{H}-6 \mathrm{~b}), 4.35$ (dd, $1 \mathrm{H}, J=2.6,11.9 \mathrm{~Hz}, \mathrm{H}-6 \mathrm{a})$, $4.98,5.22,5.27,5.32$ (4 pseudo t, $4 \mathrm{H}, J=9.2,10.6 \mathrm{~Hz}$ in each, $\mathrm{H}-1, \mathrm{H}-2, \mathrm{H}-3, \mathrm{H}-4), 6.50$ (d, $1 \mathrm{H}, J=9.2 \mathrm{~Hz}, \mathrm{NH}) ;{ }^{13} \mathrm{C} \mathrm{NMR}$ $\left(90 \mathrm{MHz}, \mathrm{CDCl}_{3}\right): \delta(\mathrm{ppm}) 20.2(3), 20.3\left(4 \times \mathrm{OCOCH}_{3}\right), 23.0$, 23.4, 24.8, 25.0, 26.0, 26.3, 28.1, 28.8, 29.0, 29.3, 29.4, 32.0, $33.8,34.5,36.2,\left(16 \times \mathrm{CH}_{2}\right), 61.7(\mathrm{C}-6), 68.1,71.2,72.5,74.3$ (C-2, C-3, C-4, C-5), 76.8 (C-1), 169.3, 169.6, 170.4, 170.6 $\left(4 \times \mathrm{OCOCH}_{3}\right), 172.3 \quad(\mathrm{NHCO})$. Anal. calcd. for $\mathrm{C}_{30} \mathrm{H}_{50} \mathrm{BrNO}_{10}$ (664.64): C 54.22, H 7.58, N 2.11. Found: C 54.11, H 7.72, N 2.29.

\section{General procedure III for the preparation of $N$-( $\omega$-azidoalkanoyl)- 2,3,4,6-tetra- $O$-acetyl- $\beta$-D-glucopyranosylamines (12-15)}

An $N$-( $\omega$-bromoalkanoyl)-2,3,4,6-tetra- $O$-acetyl- $\beta$-D-glucopyranosylamine (9-11) was dissolved in dry DMSO (15 mL/mmol). To the solution $\mathrm{NaN}_{3}$ (2 equiv.) was added in one portion. The mixture was stirred at $\mathrm{rt}$ until the disappearance of the starting bromide (TLC EtOAc-hexane 1:1). The solution was diluted with water $(150 \mathrm{~mL})$, washed with $\mathrm{Et}_{2} \mathrm{O}(5 \times 25 \mathrm{~mL})$ and water $(1 \times 25 \mathrm{~mL})$, dried over $\mathrm{MgSO}_{4}$ and the solvent was removed under diminished pressure. The crude product was purified by column chromatography or crystallisation.

$\mathrm{N}$-Azidoacetyl-2,3,4,6-tetra- $\boldsymbol{O}$-acetyl- $\boldsymbol{\beta}$-D-glucopyranosylamine (12). To a solution of azide $7(0.20 \mathrm{~g}, 0.54 \mathrm{mmol})$ in dry $\mathrm{CH}_{2} \mathrm{Cl}_{2}(3 \mathrm{~mL}), \mathrm{PMe}_{3}(0.54 \mathrm{~mL}$ of a $1 \mathrm{M}$ solution in toluene) was added in one portion. The mixture was stirred at $\mathrm{rt}$ until nitrogen evolution had ceased, and TLC (EtOAc-hexane, $1: 1$ ) had indicated complete transformation of 7 (approx. $15 \mathrm{~min}$ ). This soln was then reacted with bromoacetic acid $(0.082 \mathrm{~g}$, $0.59 \mathrm{mmol}$ ). When TLC (EtOAc-hexane, 1:1) showed no more change (conversions were incomplete), the solvent was evaporated, and the pale yellow oil was dissolved in $\mathrm{CH}_{2} \mathrm{Cl}_{2}$ $(30 \mathrm{~mL})$ and extracted with satd. aq. $\mathrm{NaHCO}_{3}$ solution $(2 \times 30 \mathrm{~mL})$. The organic phase was dried over $\mathrm{MgSO}_{4}$, concentrated under diminished pressure, then the residue $(0.20 \mathrm{~g})$ was dissolved in dry DMF $(3 \mathrm{ml})$ and $\mathrm{NaN}_{3}(0.056 \mathrm{~g}$, $0.82 \mathrm{mmol}$ ) was added. The reaction mixture was stirred at $\mathrm{rt}$ for $2 \mathrm{~h}$ (TLC, EtOAc-hexane, 1:1). The mixture was then diluted with water $(20 \mathrm{~mL})$ and extracted with $\mathrm{Et}_{2} \mathrm{O}(5 \times 30 \mathrm{~mL})$. The combined organic phase was dried over $\mathrm{MgSO}_{4}$ and the solvent was removed under diminished pressure. The obtained syrup was purified by column chromatography (EtOAchexane, $4: 6$ ) to give 12 as white crystals: $0.15 \mathrm{~g}, 63 \%$, calcd for $7 ; \mathrm{mp} 150-152{ }^{\circ} \mathrm{C},[\alpha]_{\mathrm{D}}=+39\left(c=0.21, \mathrm{CHCl}_{3}\right)$, 
1 (lit. $\left.{ }^{40}[\alpha]_{\mathrm{D}}+4.1\left(c=1, \mathrm{CHCl}_{3}\right)\right) ;{ }^{1} \mathrm{H}$ NMR $(360 \mathrm{MHz}$, $\left.\mathrm{CDCl}_{3}\right): \delta$ (ppm) 2.03, 2.04, 2.07, $2.09(4 \mathrm{~s}, 12 \mathrm{H}, 4 \times$ $\left.\mathrm{OCOCH}_{3}\right), 3.85(\mathrm{ddd}, 1 \mathrm{H}, J=2.6,4.0,9.2 \mathrm{~Hz}, \mathrm{H}-5)$, 3.93-4.11 (m, 3H, H-6b, $\left.\mathrm{CH}_{2}\right), 4.30$ (dd, $1 \mathrm{H} J=2.6,13.2 \mathrm{~Hz}$, 5 H-6a), 4.99, 5.08, 5.24, 5.33 (4 pseudo t, $4 \mathrm{H}, J=9.2,10.6 \mathrm{~Hz}$ in each, H-1, H-2, H-3, H-4), 7.19 (d, 1H, $J=9.2 \mathrm{~Hz}, \mathrm{NH})$; ${ }^{13} \mathrm{C} \quad \mathrm{NMR} \quad\left(90 \mathrm{MHz}, \mathrm{CDCl}_{3}\right): \quad \delta \quad(\mathrm{ppm}) \quad 20.6, \quad 20.5$ $\left.\left(4 \times \mathrm{OCOCH}_{3}\right), 52.4\left(\mathrm{CH}_{2}\right), 61.5(\mathrm{C}-6)\right)$ 67.9, 70.3, 72.5, 73.6 (C-2, C-3, C-4, C-5), 78.0 (C-1), 167.5, 169.5, 169.8, 170.5

$10\left(4 \times \mathrm{OCOCH}_{3}\right), 170.8(\mathrm{NHCO})$. Anal. calcd. for $\mathrm{C}_{16} \mathrm{H}_{22} \mathrm{~N}_{4} \mathrm{O}_{10}$ (430.37): C, 44.65; H, 5.15; N, 13.02; Found: C, 44.53; H, 5.22; $\mathrm{N}, 13.12$.

$\mathrm{N}$-(6-Azidohexanoyl)-2,3,4,6-tetra- $\mathrm{O}$-acetyl- $\beta$-D-glucopyranosylamine (13). Prepared from $9(2.00 \mathrm{~g}, 3.81 \mathrm{mmol})$ according to General procedure III. Yield: $1.57 \mathrm{~g}, 85 \%$, white crystalline product, mp $135-137{ }^{\circ} \mathrm{C} ;[\alpha]_{\mathrm{D}}=+37\left(c=0.34, \mathrm{CHCl}_{3}\right) ;{ }^{1} \mathrm{H}$ NMR (360 MHz, $\left.\mathrm{CDCl}_{3}\right): \delta(\mathrm{ppm}) 1.36-1.44\left(\mathrm{~m}, 2 \mathrm{H}, \mathrm{CH}_{2}\right)$, 1.57-1.68 (m, 4H, $\left.2 \times \mathrm{CH}_{2}\right), 2.02,2.04,2.05,2.08(4 \mathrm{~s}, 12 \mathrm{H}$, $\left.204 \times \mathrm{OCOCH}_{3}\right), 2.18-2.24\left(\mathrm{~m}, 2 \mathrm{H}, \mathrm{CH}_{2}\right), 3.24-3.29(\mathrm{~m}, 2 \mathrm{H}$, $\mathrm{CH}_{2}$ ), 3.84 (ddd, $\left.1 \mathrm{H}, J=1.2,2.6,10.6 \mathrm{~Hz}, \mathrm{H}-5\right), 4.08(\mathrm{dd}, 1 \mathrm{H}$, $J=1.1,11.9 \mathrm{~Hz}, \mathrm{H}-6 \mathrm{~b}), 4.31$ (dd, $1 \mathrm{H}, J=11.9,4.0 \mathrm{~Hz}, \mathrm{H}-6 \mathrm{a})$, 4.92, 5.06, 5.28, 5.31 (4 pseudo t, $4 \mathrm{H}, J=9.2,10.6 \mathrm{~Hz}$ in each, $\mathrm{H}-1, \mathrm{H}-2, \mathrm{H}-3, \mathrm{H}-4), 6.57$ (d, 1H, $J=9.2 \mathrm{~Hz}, \mathrm{NH}) ;{ }^{13} \mathrm{C} \mathrm{NMR}$ $\left(90 \mathrm{MHz}_{\mathrm{CDCl}}\right): \delta(\mathrm{ppm}) 20.4(3), 20.5\left(4 \times \mathrm{OCOCH}_{3}\right), 24.4$, 26.0, 28.4, 36.1, $51.0\left(5 \times \mathrm{CH}_{2}\right), 61.5(\mathrm{C}-6), 68.0,70.4,73.4$, 72.6 (C-2, C-3, C-4, C-5), 77.9 (C-1), 169.5, 169.7, 170.5, 170.8 $\left(4 \times \mathrm{OCOCH}_{3}\right), 173.0(\mathrm{NHCO})$. Anal. calcd. for $\mathrm{C}_{20} \mathrm{H}_{30} \mathrm{~N}_{4} \mathrm{O}_{10}$ (486.48): C 49.38, H 6.22, N 11.52. Found: C 49.46, H 6.14, 30 N 11.59 .

$\mathrm{N}$-(11-Azidoundecanoyl)-2,3,4,6-tetra- $\boldsymbol{O}$-acetyl- $\beta$-D-glucopyranosylamine (14). Prepared from 10 (1.00 g, $1.69 \mathrm{mmol})$ according to General procedure III. Yield: $0.83 \mathrm{~g}, 88 \%$, white crystalline product, $\mathrm{mp} 68-70{ }^{\circ} \mathrm{C} ;[\alpha]_{\mathrm{D}}=+13(c=0.22$, $\left.35 \mathrm{CHCl}_{3}\right) ;{ }^{1} \mathrm{H}$ NMR $\left(360 \mathrm{MHz}, \mathrm{CDCl}_{3}\right): \delta(\mathrm{ppm}) 1.25-1.31$ $\left(\mathrm{m}, 14 \mathrm{H}, 7 \times \mathrm{CH}_{2}\right), 1.46-1.50\left(\mathrm{~m}, 2 \mathrm{H}, \mathrm{CH}_{2}\right), 2.02,2.04$, $2.05,2.08\left(4 \mathrm{~s}, 12 \mathrm{H}, 4 \times \mathrm{OCOCH}_{3}\right), 2.20-2.25(\mathrm{~m}, 2 \mathrm{H}$, $\left.\mathrm{CH}_{2}\right), 2.52-2.56\left(\mathrm{~m}, 2 \mathrm{H}, \mathrm{CH}_{2}\right), 3.17(\mathrm{ddd}, 1 \mathrm{H}, J=1.2,2.6$, $10.6 \mathrm{~Hz}, \mathrm{H}-5), 3.31(\mathrm{dd}, 1 \mathrm{H}, J=1.1,11.9 \mathrm{~Hz}, \mathrm{H}-6 \mathrm{~b}), 3.53$

$40(\mathrm{dd}, 1 \mathrm{H}, J=4.0,11.9 \mathrm{~Hz}, \mathrm{H}-6 \mathrm{a}), 4.22,4.29,4.56,4.61$ (4 pseudo t, $4 \mathrm{H}, J=9.2,10.6 \mathrm{~Hz}$ in each, H-1, H-2, H-3, $\mathrm{H}-4), 7.49$ (d, $1 \mathrm{H}, J=9.2 \mathrm{~Hz}, \mathrm{NH}) ;{ }^{13} \mathrm{C} \mathrm{NMR}(90 \mathrm{MHz}$, $\left.\mathrm{CDCl}_{3}\right): \delta(\mathrm{ppm}) 20.4(3), 20.5\left(4 \times \mathrm{OCOCH}_{3}\right), 25.0,26.4$, 27.9, 28.0, 28.2, 28.3, 30.1, 32.4, 35.0, $50.2\left(10 \times \mathrm{CH}_{2}\right), 60.9$

45 (C-6), 67.1, 69.6, 72.2, 72.4 (C-2, C-3, C-4, C-5), 77.9 (C-1), $168.5,168.6,168.7,169.3\left(4 \times \mathrm{OCOCH}_{3}\right), 173.0(\mathrm{NHCO})$. Anal. calcd. for $\mathrm{C}_{25} \mathrm{H}_{40} \mathrm{~N}_{4} \mathrm{O}_{10}$ (556.62): C 53.95, H 7.24, N 10.07. Found: C 53.76, H 7.04, N 10.19.

$50 \quad \boldsymbol{N}$-(16-Azidohexadecanoyl)-2,3,4,6-tetra- $\boldsymbol{O}$-acetyl- $\boldsymbol{\beta}$-D-glucopyranosylamine (15). Prepared from $11(0.4 \mathrm{~g}, 0.60 \mathrm{mmol})$ according to General procedure III. Yield: $0.30 \mathrm{~g}, 81 \%$, white crystalline product, $\mathrm{mp} 92-94{ }^{\circ} \mathrm{C} ;[\alpha]_{\mathrm{D}}=+16(c=0.22$, $\left.\mathrm{CHCl}_{3}\right) ;{ }^{1} \mathrm{H}$ NMR $\left(360 \mathrm{MHz}, \mathrm{CDCl}_{3}\right): \delta(\mathrm{ppm})$ 1.24-1.28 $55\left(\mathrm{~m}, 18 \mathrm{H}, 9 \times \mathrm{CH}_{2}\right), 1.36-1.39\left(\mathrm{~m}, 2 \mathrm{H}, \mathrm{CH}_{2}\right), 1.47-1.50$ (m, 2H, $\mathrm{CH}_{2}$ ), 1.56-1.61 (m, 2H, $\left.\mathrm{CH}_{2}\right), 1.84-1.87$ (m, 2H, $\mathrm{CH}_{2}$ ), $2.02,2.04,2.07,2.08\left(4 \mathrm{~s}, 12 \mathrm{H}, 4 \times \mathrm{OCOCH}_{3}\right), 2.27-2.31$ $\left(\mathrm{m}, 2 \mathrm{H}, \mathrm{CH}_{2}\right), 3.38-3.41\left(\mathrm{~m}, 2 \mathrm{H}, \mathrm{CH}_{2}\right), 3.21(\mathrm{ddd}, 1 \mathrm{H}, J=$ 1.2, 2.6, 10.6 Hz, H-5), 3.29 (1H, dd, $J=1.1,11.9 \mathrm{~Hz}, \mathrm{H}-6 \mathrm{~b})$, $3.52(\mathrm{dd}, 1 \mathrm{H}, J=4.0,11.9 \mathrm{~Hz}, \mathrm{H}-6 \mathrm{a}), 4.20,4.25,4.71,4.60$ (4 pseudo t, $4 \mathrm{H}, J=9.2,10.6 \mathrm{~Hz}$, in each, H-1, H-2, H-3, $\mathrm{H}-4), 7.48(\mathrm{~d}, 1 \mathrm{H}, J=9.2 \mathrm{~Hz}, \mathrm{NH}) ;{ }^{13} \mathrm{C} \mathrm{NMR}(90 \mathrm{MHz}$, $\left.\mathrm{CDCl}_{3}\right): \delta(\mathrm{ppm}) 20.4(3), 20.5\left(4 \times \mathrm{OCOCH}_{3}\right), 23.3,23.4,3$ 24.8, 26.0, 27.1, 27.6, 28.2, 28.5, 29.0, 29.7, 30.4, 31.9, 33.8, $36.5,49.2\left(15 \times \mathrm{CH}_{2}\right), 61.5(\mathrm{C}-6), 68.3,70.0,72.1,72.5$ (C-2, C-3, C-4, C-5), 78.7 (C-1), 168.5, 168.6, 168.7, 169.3 $\left(4 \times \mathrm{OCOCH}_{3}\right), 172.1(\mathrm{NHCO})$. Anal. calcd. for $\mathrm{C}_{30} \mathrm{H}_{50} \mathrm{~N}_{4} \mathrm{O}_{10}$ (626.75): C 57.49, H 8.04, N 8.94. Found: C 57.23, H 8.24, N 8.82 .

\section{General procedures IV for the CuAAC 'click' reaction}

(a). To a solution of an alkyne $(0.27 \mathrm{mmol})$ and an azide $(0.27 \mathrm{mmol})$ in $\mathrm{CH}_{2} \mathrm{Cl}_{2}(2 \mathrm{~mL})$ and $\mathrm{H}_{2} \mathrm{O}(2 \mathrm{~mL})$, was added $\mathrm{CuSO}_{4} \cdot 5 \mathrm{H}_{2} \mathrm{O}(0.32 \mathrm{mmol})$ and $\mathrm{Na}-\mathrm{L}-$ ascorbate $(0.64 \mathrm{mmol})$. The resulting solution was stirred for $12 \mathrm{~h}$ at $\mathrm{rt}$. The reaction mixture was diluted with $\mathrm{H}_{2} \mathrm{O}(10 \mathrm{~mL})$, then extracted with $\mathrm{CH}_{2} \mathrm{Cl}_{2}(3 \times 10 \mathrm{~mL})$. The combined organic layer was dried over $\mathrm{MgSO}_{4}$, filtered, and concentrated. The residue was purified by column chromatography.

(b). An $N$-( $\omega$-azidoalkanoyl)-2,3,4,6-tetra- $O$-acetyl- $\beta$-D-glucopyranosylamine $(0.46 \mathrm{mmol})$ was added to a $1: 1(\mathrm{v} / \mathrm{v})$ mixture of $\mathrm{CH}_{2} \mathrm{Cl}_{2}$ and water $(10 \mathrm{~mL} / \mathrm{mmol})$. To the solution 1,7-octadiyne (43, 1.0 equiv.), $\mathrm{CuSO}_{4} \cdot 5 \mathrm{H}_{2} \mathrm{O}(5 \mathrm{~mol} \%)$ and L-ascorbic acid $(15 \mathrm{~mol} \%)$ were added. The mixture was heated at $50{ }^{\circ} \mathrm{C}$ until complete transformation of the starting azide (TLC, EtOAc). The solution was diluted with water (25 mL) and extracted with $\mathrm{CH}_{2} \mathrm{Cl}_{2}(5 \times 12 \mathrm{~mL})$. The organic phase was dried over $\mathrm{MgSO}_{4}$ and the solvent was removed under diminished pressure. The crude product was purified by column chromatography or crystallisation.

\section{General procedure $\mathbf{V}$ for $\boldsymbol{O}$-deacetylation}

To a solution or suspension of an $O$-peracetylated compound $(0.081 \mathrm{mmol})$ in $\mathrm{MeOH}(3 \mathrm{~mL})$ was added $4 \mathrm{~N}$ aq. $\mathrm{NaOH}$ $(0.4 \mathrm{~mL})$, then stirred at $\mathrm{rt}$ for $1 \mathrm{~h}$, and neutralized with $1 \mathrm{~N}$ $\mathrm{HCl}(1.8 \mathrm{~mL})$. The mixture was concentrated in vacuo and the residue was taken up in EtOAc $(50 \mathrm{~mL})$, washed successively with $1 \mathrm{~N} \mathrm{HCl}(3 \times 15 \mathrm{~mL})$, water $(3 \times 15 \mathrm{~mL})$ and brine $(3 \times 15 \mathrm{~mL})$, dried $\left(\mathrm{Na}_{2} \mathrm{SO}_{4}\right)$, filtered and concentrated. The residue was purified by column chromatography.

[1-(2,3,4,6-Tetra- $O$-acetyl- $\beta$-D-glucopyranosyl)-1 $H$-1,2,3-triazol4-ylmethyl] 3ß-hydroxyolean-12-en-28-oate (16). Prepared from $4(0.13 \mathrm{~g}, 0.27 \mathrm{mmol})$ and $7(0.10 \mathrm{~g}, 0.27 \mathrm{mmol})$ according to General procedure IVa. The residue was purified by column chromatography (EtOAc-hexane, 1:1). Yield: $0.13 \mathrm{~g}, 57 \%$, white solid, $\mathrm{mp} 124-125^{\circ} \mathrm{C} . R_{\mathrm{f}}=0.13$ (EtOAc-hexane, $1: 2$ ). IR (KBr, cm $\left.{ }^{-1}\right)$ : 2947, 2869, 1757, 1460, 1369, 1227, 1036, 758; ${ }^{1} \mathrm{H}$ NMR $\left(300 \mathrm{MHz}, \mathrm{CDCl}_{3}\right): \delta 0.66,0.78,0.89,0.90,0.91$, $0.99,1.13\left(7 \mathrm{~s}\right.$, each $\left.3 \mathrm{H}, 7 \times \mathrm{CH}_{3}\right), 0.67-2.09(\mathrm{~m}, 22 \mathrm{H}), 1.86$, 2.03, 2.07, $2.09\left(4 \mathrm{~s}\right.$, each $\left.3 \mathrm{H}, 4 \times \mathrm{OCOCH}_{3}\right), 2.86(\mathrm{dd}, 1 \mathrm{H}$, $J=3.8,13.9 \mathrm{~Hz}, \mathrm{H}-18), 3.18-3.23(\mathrm{~m}, 1 \mathrm{H}, \mathrm{H}-3), 3.96-4.02$ (m, 1H, H-5-Glc), 4.11-4.16 (m, 1H, H-6a-Glc), 4.33 (dd, 1H, $J=4.8,12.6 \mathrm{~Hz}, \mathrm{H}-6 \mathrm{~b}-\mathrm{Glc}), 5.17$ (s, $\left.2 \mathrm{H}, \mathrm{COOCH}_{2}\right), 5.21-5.27$ (m, 1H, H-2-Glc), 5.31 (t, 1H, $J=3.3 \mathrm{~Hz}, \mathrm{H}-12), 5.39-5.43$ (m, 2H, overlapping, $\mathrm{H}-3-\mathrm{Glc}$ and $\mathrm{H}-4-\mathrm{Glc}), 5.84-5.87(\mathrm{~m}, 1 \mathrm{H}$, $\mathrm{H}-1-\mathrm{Glc}), 7.81$ (s, $1 \mathrm{H}, \mathrm{NCH}) ;{ }^{13} \mathrm{C} \mathrm{NMR}\left(75 \mathrm{MHz}, \mathrm{CDCl}_{3}\right)$ : 
$\delta 15.3,15.6,16.9,18.4,20.1,20.5,20.6,23.0,23.4,23.6,25.9$, $27.2,27.7,28.1,29.7,30.7,32.2,32.7,33.1,33.9,37.1,38.5$, $38.8,39.3,41.4,41.8,45.9,46.7,47.6,55.3,57.4,61.5,67.7$, $70.3,72.6,75.3,79.0,85.9,122.0,122.5,143.7,144.0,168.6$, 5 169.3, 169.9, 170.4, 177.4. ESI-MS (positive mode) $m / z: 890.8$ $[\mathrm{M}+\mathrm{Na}]^{+}$.

[1-(2,3,4,6-Tetra- $O$-acetyl- $\beta$-D-glucopyranosyl)-1 $H$-1,2,3-triazol4-ylmethyl] 3ß-hydroxyurs-12-en-28-oate (17). Prepared from 5 $10(0.13 \mathrm{~g}, 0.27 \mathrm{mmol})$ and $7(0.10 \mathrm{~g}, 0.27 \mathrm{mmol})$ according to General procedure IVa. The residue was purified by column chromatography (EtOAc-hexane, $1: 2$ ). Yield: $0.22 \mathrm{~g}, 96 \%$, white solid, mp $120-122{ }^{\circ} \mathrm{C} . R_{\mathrm{f}}=0.20$ (EtOAc-hexane, $1: 2$ ); IR (KBr, cm $\left.{ }^{-1}\right): 2932,2872,1757,1456,1376,1228,1104 ;{ }^{1} \mathrm{H}$ NMR $\left(300 \mathrm{MHz}, \mathrm{CDCl}_{3}\right): \delta$ 0.72, 0.81, 0.94, 0.97, 1.01, 1.11 $\left(6 \mathrm{~s}\right.$, each $\left.3 \mathrm{H}, 6 \times \mathrm{CH}_{3}\right), 0.89\left(\mathrm{~d}, 3 \mathrm{H}, J=6.3 \mathrm{~Hz}, \mathrm{CH}_{3}\right)$, $0.72-2.13(\mathrm{~m}, 22 \mathrm{H}), 1.89,2.06,2.10,2.13(4 \mathrm{~s}$, each $3 \mathrm{H}, 4 \times$ $\left.\mathrm{OCOCH}_{3}\right), 2.25(\mathrm{~d}, 1 \mathrm{H}, J=10.8 \mathrm{~Hz}, \mathrm{H}-18), 3.25(\mathrm{dd}, 1 \mathrm{H}, J=$ 4.3, $10.7 \mathrm{~Hz}, \mathrm{H}-3), 4.00-4.04$ (m, 1H, H-5-Glc), 4.14-4.19 20 (m, 1H, H-6a-Glc), 4.35 (dd, 1H, $J=4.5,12.7$ Hz, H-6b-Glc), 5.17 and $5.18\left(2 \mathrm{~d}\right.$, each $\left.1 \mathrm{H}, J=12.8 \mathrm{~Hz}, \mathrm{COOCH}_{2}\right)$, 5.23-5.30 (m, 2H, overlapping, $\mathrm{H}-12$ and $\mathrm{H}-2-\mathrm{Glc})$, 5.40-5.48 (m, 2H, overlapping, H-3-Glc and H-4-Glc), 5.90 (d, $1 \mathrm{H}, J=9.2 \mathrm{~Hz}, \mathrm{H}-1-\mathrm{Glc}), 7.82(\mathrm{~s}, 1 \mathrm{H}, \mathrm{NCH}) ;{ }^{13} \mathrm{C} \mathrm{NMR}$ $5\left(75 \mathrm{MHz}, \mathrm{CDCl}_{3}\right): \delta 15.5,15.6,19.96,17.0,18.4,20.1,20.5$, 20.6, 21.1, 23.3, 23.6, 24.2, 27.3, 28.1, 28.2, 30.6, 33.0, 36.4, $37.0,38.7,38.8,38.82,39.1,39.6,42.1,47.6,48.1,52.9,55.3$, $57.3,61.5,67.8,70.4,72.7,75.3,79.1,86.9,122.0,125.8,138.1$, 144.1, 168.6, 169.3, 169.9, 177.3. ESI-MS (positive mode) $\mathrm{m} / \mathrm{z}$ : 30 $890.8[\mathrm{M}+\mathrm{Na}]^{+}$.

[1-(2,3,4,6-Tetra- $O$-acetyl- $\beta$-D-glucopyranosyl)-1 $H$-1,2,3-triazol4-ylmethyl] $2 \alpha, 3 \beta$-dihydroxyolean-12-en-28-oate (18). Prepared from $6(0.14 \mathrm{~g}, 0.27 \mathrm{mmol})$ and $7(0.10 \mathrm{~g}, 0.27 \mathrm{mmol})$ according to General procedure IVa. The residue was purified by column 35 chromatography (EtOAc-hexane, $1: 1$ ). Yield: $0.20 \mathrm{~g}, 84 \%$, white solid, mp $158-160{ }^{\circ} \mathrm{C}, R_{\mathrm{f}}=0.17$ (EtOAc-hexane, $1: 1$ ); IR $\left(\mathrm{KBr}, \mathrm{cm}^{-1}\right): 3395,2948,1758,1460,1368,1227,1101$, 1037, 758; ${ }^{1} \mathrm{H}$ NMR $\left(300 \mathrm{MHz}, \mathrm{CDCl}_{3}\right): \delta 0.69,0.85,0.92$, $0.94,1.00,1.06,1.15\left(7 \mathrm{~s}\right.$, each $\left.3 \mathrm{H}, 7 \times \mathrm{CH}_{3}\right), 0.69-2.12$

$40(\mathrm{~m}, 20 \mathrm{H}), 1.88,2.06,2.10,2.12\left(4 \mathrm{~s}\right.$, each $\left.3 \mathrm{H}, 4 \times \mathrm{OCOCH}_{3}\right)$, $2.89(\mathrm{dd}, 1 \mathrm{H}, J=3.1,13.2 \mathrm{~Hz}, \mathrm{H}-18), 3.05(\mathrm{~d}, 1 \mathrm{H}, J=9.5 \mathrm{~Hz}$, $\mathrm{H}-3 \alpha$ ), 3.68-3.76 (m, 1H, H-2 $\beta$ ), 4.00-4.04 (m, 1H, H-5-Glc), 4.14-4.18 (m, 1H, H-6a-Glc), 4.35 (dd, 1H, $J=4.8,12.6 \mathrm{~Hz}$, $\mathrm{H}-6 \mathrm{~b}-\mathrm{Glc}), 5.19$ and $5.20(2 \mathrm{~d}$, each $1 \mathrm{H}, J=12.9 \mathrm{~Hz}$, $\left.5 \mathrm{COOCH}_{2}\right)$, 5.24-5.30 (m, 1H, H-2-Glc), 5.34 (brs, $1 \mathrm{H}$, $\mathrm{H}-12), 5.43-5.46$ (m, 2H, H-3-Glc and H-4-Glc), 5.90 (d, $1 \mathrm{H}, J=9.2 \mathrm{~Hz}, \mathrm{H}-1-\mathrm{Glc}), 7.84$ (s, 1H, NCH); ${ }^{13} \mathrm{C} \mathrm{NMR}$ $\left(75 \mathrm{MHz}, \mathrm{CDCl}_{3}\right)$ : $\delta 16.9,17.0,17.2,18.6,20.3,20.7,20.9$, $23.3,23.7,23.9,26.1,27.9,28.8,30.9,32.4,32.9,33.3,34.1$,

$5038.6,39.3,39.4,39.7,41.6,42.0,46.1,46.7,47.0,47.9,55.6$, 57.6, 61.8, 68.0, 69.2, 70.6, 72.9, 75.5, 77.4, 84.2, 86.1, 122.2, 122.6, 144.0, 144.3, 168.9, 169.5, 170.1, 170.6, 177.7. ESI-MS (positive mode) $m / z: 906.4[\mathrm{M}+\mathrm{Na}]^{+}$.

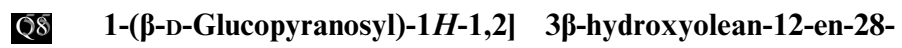
oate (19). Prepared from $16(0.07 \mathrm{~g}, 0.08 \mathrm{mmol})$ according to General procedure V. The residue was purified by column chromatography (EtOAc). Yield: $0.05 \mathrm{~g}, 91 \%$, white solid, $\mathrm{mp} 178-180{ }^{\circ} \mathrm{C}, R_{\mathrm{f}}=0.13($ EtOAc $) ;[\alpha]_{\mathrm{D}}=+45(c=0.05$,
$\mathrm{MeOH}) ; \mathrm{IR}\left(\mathrm{KBr}, \mathrm{cm}^{-1}\right): 3424,2942,1712,1636,1052,1033$, 1016,$772 ;{ }^{1} \mathrm{H}$ NMR $\left(300 \mathrm{MHz}, \mathrm{C}_{5} \mathrm{D}_{5} \mathrm{~N}\right): \delta 0.82,0.85,0.89$, $0.93,1.01,1.17,1.21\left(7 \mathrm{~s}\right.$, each $\left.3 \mathrm{H}, 7 \times \mathrm{CH}_{3}\right), 0.82-1.92$ (m, 22H), 3.08-3.11 (m, 1H, H-18), 3.39-3.44 (m, 1H, H-3), 4.20-4.22 (m, 1H, H-5-Glc), 4.27-4.41 (m, 3H, overlapping, H-6a-Glc, H-6b-Glc, H-4-Glc), 4.50 (m, 1H, H-2-Glc), 4.79 (t, 1H, $J=8.9,8.9 \mathrm{~Hz}, \mathrm{H}-3-\mathrm{Glc}), 5.40$ (s, 1H, H-12), 5.47-5.57 $\left(\mathrm{m}, 2 \mathrm{H}, \mathrm{COOCH}_{2}\right), 6.35$ (d, 1H, $\left.J=9.2 \mathrm{~Hz}, \mathrm{H}-1-\mathrm{Glc}\right), 8.64$ $(\mathrm{s}, 1 \mathrm{H}, \mathrm{NCH}) ;{ }^{13} \mathrm{C} \mathrm{NMR}\left(75 \mathrm{MHz}, \mathrm{C}_{5} \mathrm{D}_{5} \mathrm{~N}\right): \delta 15.7,16.6,17.4$, $18.8,23.4,23.6,23.8,26.0,28.1,28.8,30.8,32.7,33.1,33.2$, $34.0,37.4,39.0,39.4,39.8,41.9,42.1,46.1,47.0,48.1,55.9$, $58.2,62.4,71.1,73.9,78.2,79.1,82.0,89.6,123.0,124.1$, 143.5, 144.0, 177.4. ESI-MS (positive mode) $m / z: 744.3$ $\left[\mathrm{M}+\mathrm{HCOO}^{+}\right.$; HRMS (MALDI) $m / z=\mathrm{C}_{39} \mathrm{H}_{61} \mathrm{~N}_{3} \mathrm{O}_{8}$ $[\mathrm{M}+\mathrm{Na}]^{+}$calcd. 722.4356 , found 722.4371 .

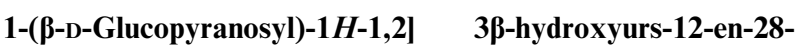
oate (20). Prepared from $17(0.14 \mathrm{~g}, 0.17 \mathrm{mmol})$ according to General procedure V. The residue was purified by column chromatography (EtOAc). Yield: $0.11 \mathrm{~g}, 92 \%$, white solid, mp $160-162{ }^{\circ} \mathrm{C}, R_{\mathrm{f}}=0.16($ EtOAc $) ;[\alpha]_{\mathrm{D}}=+23(c=0.1$, $\mathrm{MeOH})$; IR $\left(\mathrm{KBr}, \mathrm{cm}^{-1}\right): 3381,2923,2869,1723,1454$, 1136, 1098, 1051, 1032, 1016, 772; ${ }^{1} \mathrm{H}$ NMR $(300 \mathrm{MHz}$, $\left.\mathrm{C}_{5} \mathrm{D}_{5} \mathrm{~N}\right): \delta 0.81\left(\mathrm{~d}, 3 \mathrm{H}, J=4.7 \mathrm{~Hz}, \mathrm{CH}_{3}\right), 0.83,0.85,0.89$, $0.97,1.06,1.17\left(6 \mathrm{~s}\right.$, each $\left.3 \mathrm{H}, 6 \times \mathrm{CH}_{3}\right), 2.34(\mathrm{~d}, 1 \mathrm{H}, J=11.2 \mathrm{~Hz}$, $\mathrm{H}-18), 0.75-1.94(\mathrm{~m}, 22 \mathrm{H}), 3.38(\mathrm{~m}, 1 \mathrm{H}, \mathrm{H}-3), 4.09-4.17$ (m, 1H, H-5-Glc), 4.22-4.36 (m, 3H, H-4-Glc and H-6-Glc), $4.46(\mathrm{~d}, 1 \mathrm{H}, J=10.8 \mathrm{~Hz}, \mathrm{H}-2-\mathrm{Glc}), 4.75$ (t, $1 \mathrm{H}, J=8.8,8.8$ $\mathrm{Hz}, \mathrm{H}-3-\mathrm{Glc}$ ), 5.33 (brs, 1H, H-12), 5.44 (s, 2H, $\mathrm{COOCH}_{2}$ ), $6.33(\mathrm{~d}, 1 \mathrm{H}, J=9.2 \mathrm{~Hz}, \mathrm{H}-1-\mathrm{Glc}), 8.58(\mathrm{~s}, 1 \mathrm{H}, \mathrm{NCH}) ;{ }^{13} \mathrm{C}$ NMR $\left(75 \mathrm{MHz}, \mathrm{C}_{5} \mathrm{D}_{5} \mathrm{~N}\right): \delta 15.8,16.6,17.3,18.8,19.1,21.2$, $23.7,23.8,24.6,28.2,28.5,28.8,30.8,33.5,36.8,37.3,39.1$, $39.2,39.3,39.4,40.0,42.4,48.1,48.4,53.4,55.9,58.1,62.4$, $71.1,73.9,78.2,79.1,81.9,89.6,124.1,126.2,129.3,138.6$, 143.5 , 177.1. ESI-MS (positive mode) $m / z$ : $744.5[\mathrm{M}+$ $\mathrm{HCOO}]^{+}$; HRMS (MALDI) $m / z=\mathrm{C}_{39} \mathrm{H}_{61} \mathrm{~N}_{3} \mathrm{O}_{8}[\mathrm{M}+$ $\mathrm{Na}^{+}$calcd. 722.4356 , found 722.4365 .

1-( $\beta$-D-Glucopyranosyl)-1 $H$-1,2] $\quad 2 \alpha, 3 \beta$-dihydroxyolean-12en-28-oate (21). Prepared from $18(0.13 \mathrm{~g}, 0.15 \mathrm{mmol})$ according to General procedure V. The residue was purified by column chromatography $\left(\mathrm{MeOH}-\mathrm{CH}_{2} \mathrm{Cl}_{2}, 1\right.$ : 15). Yield: $0.09 \mathrm{~g}, 85 \%$, white solid, $\mathrm{mp} 205-207{ }^{\circ} \mathrm{C}, R_{\mathrm{f}}=0.18\left(\mathrm{MeOH}-\mathrm{CH}_{2} \mathrm{Cl}_{2}\right.$, $1: 15) ;[\alpha]_{\mathrm{D}}=+27(c=0.07, \mathrm{MeOH})$. IR $\left(\mathrm{KBr}, \mathrm{cm}^{-1}\right)$ : 3461, 2945, 2864, 1720, 1642, 1457, 1051, 1031, 1017, 772, 667; ${ }^{1} \mathrm{H}$ NMR $\left(300 \mathrm{MHz}, \mathrm{C}_{5} \mathrm{D}_{5} \mathrm{~N}\right): \delta 0.82,0.85,0.88,1.03,1.07$, $1.15,1.25\left(7 \mathrm{~s}\right.$, each $\left.3 \mathrm{H}, 7 \times \mathrm{CH}_{3}\right), 0.82-2.26(\mathrm{~m}, 20 \mathrm{H})$, 3.07-3.10 (m, 1H, H-18), 3.29 (d, $1 \mathrm{H}, J=9.3 \mathrm{~Hz}, \mathrm{H}-3 \alpha$ ), 4.09 (m, 1H, H-2 $\beta), 4.23-4.31$ (m, 1H, H-5-Glc), 4.34-4.42 (m, 3H, overlapping, H-4-Glc and H-6a-Glc, and H-6b-Glc), 4.52 (d, $1 \mathrm{H}, J=11.0 \mathrm{~Hz}, \mathrm{H}-2-\mathrm{Glc}), 4.80$ (t, $1 \mathrm{H}, J=8.9,8.9$ $\mathrm{Hz}, \mathrm{H}-3-\mathrm{Glc}$ ), 5.37 (s, 1H, H-12), 5.52 (s, 2H, $\mathrm{COOCH}_{2}$ ), 6.38 (d, $1 \mathrm{H}, J=9.2 \mathrm{~Hz}, \mathrm{H}-1-\mathrm{Glc}), 8.65(\mathrm{~s}, 1 \mathrm{H}, \mathrm{NCH}) ;{ }^{13} \mathrm{C} \mathrm{NMR}$ $\left(75 \mathrm{MHz}, \mathrm{C}_{5} \mathrm{D}_{5} \mathrm{~N}\right): \delta 17.0,17.5,17.7,18.9,23.4,23.6,23.9$, 26.0, 28.1, 29.3, 30.7, 32.7, 33.1, 33.2, 33.9, 38.6, 39.8, 41.9, $42.1,46.1,47.0,47.8,48.1,55.9,58.2,62.4,68.6,71.1,73.9$, 79.1, 81.9, 83.9, 89.6, 122.9, 124.1, 143.5, 144.0, 177.4. ESI-MS (positive mode) $m / z$ : $716.4[\mathrm{M}+\mathrm{H}]^{+}$; HRMS (MALDI) $m / z=\mathrm{C}_{39} \mathrm{H}_{61} \mathrm{~N}_{3} \mathrm{O}_{9}[\mathrm{M}+\mathrm{Na}]^{+}$calcd. 738.4306, found 738.4320 . 
[1-(2,3,4,6-Tetra- $O$-acetyl- $\beta$-D-glucopyranosylaminocarbonyl-

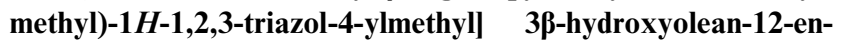
28-oate (22). Prepared from $4(0.11 \mathrm{~g}, 0.23 \mathrm{mmol})$ and 12 $(0.10 \mathrm{~g}, 0.23 \mathrm{mmol})$ according to General procedure IVa. The residue was purified by column chromatography (EtOAchexane, $1: 1)$. Yield: $0.18 \mathrm{~g}, 85 \%$, white solid, $\mathrm{mp} 146-148{ }^{\circ} \mathrm{C}$, $R_{\mathrm{f}}=0.21$ (EtOAc-hexane, $\left.1: 1\right)$; IR $\left(\mathrm{KBr}, \mathrm{cm}^{-1}\right): 2947,2872$, $1755,1552,1463,1374,1230,1175,1159,1045,759,667 ;{ }^{1} \mathrm{H}$ NMR (300 MHz, $\left.\mathrm{CDCl}_{3}\right): \delta 0.57,0.78,0.98,1.11(4 \mathrm{~s}$, each $\left.103 \mathrm{H}, 4 \times \mathrm{CH}_{3}\right), 0.89\left(\mathrm{~s}, 9 \mathrm{H}, 3 \times \mathrm{CH}_{3}\right), 0.57-2.10(\mathrm{~m}, 22 \mathrm{H}), 2.01$, 2.02, 2.03, $2.08\left(4 \mathrm{~s}\right.$, each $\left.3 \mathrm{H}, 4 \mathrm{xOCOCH}_{3}\right), 2.82-2.85(1 \mathrm{H}, \mathrm{m}$, $\mathrm{H}-18), 3.20(\mathrm{dd}, 1 \mathrm{H}, J=5.0,10.4 \mathrm{~Hz}, \mathrm{H}-3), 3.78-3.83(\mathrm{~m}, 1 \mathrm{H}$, H-5-Glc), 4.07 (dd, 1H, $J=2.1,12.6 \mathrm{~Hz}, \mathrm{H}-6 \mathrm{a}-\mathrm{Glc}), 4.28$ (dd, $1 \mathrm{H}, J=4.3,12.5 \mathrm{~Hz}, \mathrm{H}-6 \mathrm{~b}-\mathrm{Glc}), 4.90$ (t, $1 \mathrm{H}, J=9.6,9.6 \mathrm{~Hz}$,

$15 \mathrm{H}-4-\mathrm{Glc}$ ), 4.94-5.32 (m, 8H, overlapping, $\mathrm{NCH}_{2}, \mathrm{COOCH}_{2}$, H-1-Glc, H-2-Glc, H-3-Glc, H-12), 6.78 (d, 1H, $J=8.7 \mathrm{~Hz}$, $\mathrm{OH}), 7.69(\mathrm{~s}, 1 \mathrm{H}, \mathrm{NCH}) ;{ }^{13} \mathrm{C} \mathrm{NMR}\left(75 \mathrm{MHz}, \mathrm{CDCl}_{3}\right): \delta 15.4$, $15.6,16.7,18.3,20.5,20.7,23.0,23.4,23.6,26.0,27.2,27.6$, $28.1,30.6,32.3,32.7,33.0,33.8,37.0,38.4,38.7,39.3,41.3$,

$2041.7,45.8,46.7,47.5,52.5,55.2,57.3,61.5,68.0,70.3,72.4$, 73.8, 78.5, 79.0, 122.5, 125.4, 143.5, 143.9, 165.4, 169.4, 169.8, 170.5, 171.0, 177.6. ESI-MS (positive mode) $m / z$ : 947.6 $[\mathrm{M}+\mathrm{Na}]^{+}$. HRMS (MALDI) $m / z=\mathrm{C}_{45} \mathrm{H}_{72} \mathrm{~N}_{4} \mathrm{O}_{10}$ $[\mathrm{M}+\mathrm{Na}]^{+}$calcd. 852.0638, found 851.5158 .

[1-(2,3,4,6-Tetra- $O$-acetyl- $\beta$-D-glucopyranosylaminocarbonyl-

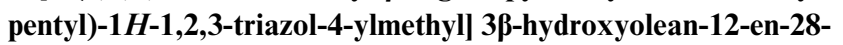
oate (23). Prepared from $4(0.10 \mathrm{~g}, 0.21 \mathrm{mmol})$ and $13(0.10 \mathrm{~g}$, $0.21 \mathrm{mmol}$ ) according to General procedure IVa. The residue

30 was purified by column chromatography (EtOAc-hexane, 1:1). Yield: $0.16 \mathrm{~g}, 80 \%$, white solid, $\mathrm{mp} 99-100{ }^{\circ} \mathrm{C}, R_{\mathrm{f}}=$ 0.12 (EtOAc-hexane, $1: 1$ ); IR $\left(\mathrm{KBr}, \mathrm{cm}^{-1}\right)$ : 2947, 2866, 1755, 1537, 1463, 1367, 1229, 1176, 1039, 757, 667; ${ }^{1} \mathrm{H}$ NMR $\left(300 \mathrm{MHz}, \mathrm{CDCl}_{3}\right): \delta 0.55,0.77,0.89,0.97,1.11(5 \mathrm{~s}$, each $\left.353 \mathrm{H}, 5 \times \mathrm{CH}_{3}\right), 0.88\left(\mathrm{~s}, 6 \mathrm{H}, 2 \times \mathrm{CH}_{3}\right), 0.55-2.07(\mathrm{~m}, 28 \mathrm{H}), 2.02$, $2.03,2.04,2.07\left(4 \mathrm{~s}\right.$, each $\left.3 \mathrm{H}, 4 \times \mathrm{OCOCH}_{3}\right), 2.14-2.18$ $\left(\mathrm{m}, 2 \mathrm{H}, \mathrm{CH}_{2} \mathrm{CO}\right), 2.82-2.85(\mathrm{~m}, 1 \mathrm{H}, \mathrm{H}-18), 3.20(\mathrm{dd}, 1 \mathrm{H}$, $J=4.9,10.6 \mathrm{~Hz}, \mathrm{H}-3), 3.79-3.84$ (m, 1H, H-5-Glc), 4.07 (dd, $1 \mathrm{H}, J=2.1,12.5 \mathrm{~Hz}, \mathrm{H}-6 \mathrm{a}-\mathrm{Glc}), 4.28-4.34(\mathrm{~m}, 3 \mathrm{H}$, 40 overlapping, $\mathrm{NCH}_{2}$ and $\left.\mathrm{H}-6 \mathrm{~b}-\mathrm{Glc}\right), 4.90(\mathrm{t}, 1 \mathrm{H}, J=9.7$, 9.7 Hz, H-4-Glc), 5.06 (t, 1H, $J=9.7,9.7 \mathrm{~Hz}, \mathrm{H}-3-\mathrm{Glc}), 5.20$ (s, 2H, $\left.\mathrm{COOCH}_{2}\right), 5.24-5.34(\mathrm{~m}, 3 \mathrm{H}$, overlapping, H-12, H-1Glc and $\left.\mathrm{H}-12^{\prime}\right), 6.23$ (d, $\left.1 \mathrm{H}, J=9.2 \mathrm{~Hz}, \mathrm{NH}\right), 7.56(\mathrm{~s}, 1 \mathrm{H}$, $\mathrm{NCH}) ;{ }^{13} \mathrm{C}$ NMR $\left(75 \mathrm{MHz}, \mathrm{CDCl}_{3}\right): \delta 15.3,15.6,16.7,18.3$, $4520.6,20.66,20.7,22.9,23.4,23.6,24.2,25.8,25.9,27.2$, 27.6, $28.1,29.9,30.6,32.3,32.7,33.0,33.8,36.0,37.0,38.4,38.7$, $39.3,41.3,41.7,45.8,46.7,47.5,49.9,55.2,57.4,61.6,68.1$, 70.7, 72.6, 73.6, 77.2, 78.2, 79.0, 122.4, 123.9, 143.1, 143.6, $169.5,169.8,170.6,171.1,172.7,177.8$. ESI-MS (positive 50 mode) $m / z: 1003.5[\mathrm{M}+\mathrm{Na}]^{+}$.

[1-(2,3,4,6-Tetra- $O$-acetyl- $\beta$-D-glucopyranosylaminocarbonyldecyl)-1 $H$-1,2,3-triazol-4-ylmethyl] 3ß-hydroxyolean-12-en-28oate (24). Prepared from $4(0.09 \mathrm{~g}, 0.18 \mathrm{mmol})$ and 14 $55(0.10 \mathrm{~g}, 0.18 \mathrm{mmol})$ according to General procedure IVa. The residue was purified by column chromatography (EtOAchexane, $1: 1$ ). Yield: $0.12 \mathrm{~g}, 64 \%$, white solid, mp 90-92 ${ }^{\circ} \mathrm{C}$, $R_{\mathrm{f}}=0.22$ (EtOAc-hexane, $\left.1: 1\right)$; IR $\left(\mathrm{KBr}, \mathrm{cm}^{-1}\right): 3359,2922$, 2860, 1744, 1693, 1364, 1220, 1049, 1032, 772; ${ }^{1} \mathrm{H}$ NMR
(300 $\mathrm{MHz}, \mathrm{CDCl}_{3}$ ): $\delta$ 0.52, 0.77, 0.87, 0.88, 0.90, 0.98, 1.11 $\left(7 \mathrm{~s}\right.$, each $\left.3 \mathrm{H}, 7 \times \mathrm{CH}_{3}\right), 0.52-2.07(\mathrm{~m}, 38 \mathrm{H}), 2.02,2.03,2.04$, $2.07\left(4 \mathrm{~s}\right.$, each $\left.3 \mathrm{H}, 4 \times \mathrm{OCOCH}_{3}\right), 2.13-2.23\left(\mathrm{~m}, 2 \mathrm{H}, \mathrm{CH}_{2} \mathrm{CO}\right)$, $2.82(\mathrm{~m}, 1 \mathrm{H}, \mathrm{H}-18), 3.20(\mathrm{dd}, 1 \mathrm{H}, J=5.0,10.9 \mathrm{~Hz}, \mathrm{H}-3)$, 3.80-3.85 (m, 1H, H-5-Glc), 4.07 (dd, $1 \mathrm{H}, J=1.9,12.5 \mathrm{~Hz}$, H-6a-Glc), 4.28-4.34 (m, 3H, overlapping, H-6b-Glc and $\mathrm{NCH}_{2}$ ), 4.91 (pseudo t, $1 \mathrm{H}, J=9.6,9.7 \mathrm{~Hz}, \mathrm{H}-4-\mathrm{Glc}$ ), 5.06 (pseudo t, $1 \mathrm{H}, J=9.6,9.7 \mathrm{~Hz}, \mathrm{H}-3-\mathrm{Glc}), 5.18$ (s, 2H, $\mathrm{COOCH}_{2}$ ), 5.22-5.34 (m, 3H, overlapping, $\mathrm{H}-12$ and $\mathrm{H}-1-$ Glc, H-2-Glc), 6.30 (d, 1H, $J=9.3 \mathrm{~Hz}, \mathrm{NH}), 7.56$ (s, 1H, s, $\mathrm{NCH}) ;{ }^{13} \mathrm{C}$ NMR $\left(75 \mathrm{MHz}, \mathrm{CDCl}_{3}\right): \delta 15.4,15.6,16.8,18.3$, 20.5, 20.6, 20.7, 23.0, 23.4, 23.6, 25.1, 25.8, 26.5, 27.2, 27.7, $28.1,29.0,29.1,29.2,29.3,29.33,30.2,30.7,32.4,32.7,33.0$, $33.9,36.6,37.1,38.5,38.8,39.4,41.4,41.7,45.9,46.8,47.6$, $50.4,55.2,57.5,61.7,68.3,70.7,72.8,73.6,77.2,78.2,79.0$, 122.4, 123.9, 143.1, 169.5, 170.0, 170.5, 171.0, 173.3, 177.8 . ESI-MS (positive mode) $m / z$ : $1073.9[\mathrm{M}+\mathrm{Na}]^{+}$.

[1-(2,3,4,6-Tetra- $O$-acetyl- $\beta$-D-glucopyranosylaminocarbonyl-

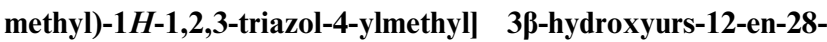
oate (25). Prepared from $5(0.11 \mathrm{~g}, 0.23 \mathrm{mmol})$ and 12 $(0.10 \mathrm{~g}, 0.23 \mathrm{mmol})$ according to General procedure IVa. The residue was purified by column chromatography (EtOAchexane, $1: 1)$. Yield: $0.024 \mathrm{~g}, 11 \%$, white solid, mp $116-118{ }^{\circ} \mathrm{C}$, $R_{\mathrm{f}}=0.21($ EtOAc-hexane, $1: 1) ;[\alpha]_{\mathrm{D}}=+29(c=0.05$, $\left.\mathrm{CHCl}_{3}\right)$. IR ( $\left.\mathrm{KBr}, \mathrm{cm}^{-1}\right): 3340,2947,2871,1756,1454,1377$, 1230, 1046, 1033, 997, 758; ${ }^{1} \mathrm{H}$ NMR (300 $\left.\mathrm{MHz}, \mathrm{CDCl}_{3}\right): \delta$ $0.60,0.78,0.91,0.93,0.98,1.06\left(6 \mathrm{~s}\right.$, each $\left.3 \mathrm{H}, 6 \times \mathrm{CH}_{3}\right), 0.83$ $\left(\mathrm{d}, 3 \mathrm{H}, J=6.4 \mathrm{~Hz}, \mathrm{CH}_{3}\right), 0.60-2.01(\mathrm{~m}, 22 \mathrm{H}), 2.01,2.03,2.08$ (s, $\left.12 \mathrm{H}, 4 \times \mathrm{OCOCH}_{3}\right), 2.20(\mathrm{~d}, 1 \mathrm{H}, J=11.3 \mathrm{~Hz}, \mathrm{H}-18), 3.22$ (dd, $1 \mathrm{H}, J=4.9,10.8 \mathrm{~Hz}, \mathrm{H}-3), 3.78-3.83$ (m, 1H, H-5-Glc), 4.08 (dd, 1H, $J=1.9,12.7 \mathrm{~Hz}, \mathrm{H}-6 \mathrm{a}-\mathrm{Glc}), 4.28$ (dd, 1H, $J=$ 4.3, 12.6 Hz, H-6b-Glc), 4.87 (pseudo t, $1 \mathrm{H}, J=9.5,9.6 \mathrm{~Hz}$, $\mathrm{H}-4-\mathrm{Glc}), 4.99-5.09$ (m, 3H, overlapping, $\mathrm{NCH}_{2} \mathrm{CO}$ and $\mathrm{H}-2-$ Glc), $5.16\left(\mathrm{~d}, 1 \mathrm{H}, J=12.7 \mathrm{~Hz}, \mathrm{COOCH}_{2}\right), 5.19$ (d, 1H, $J=$ $\left.12.7 \mathrm{~Hz}, \mathrm{COOCH}_{2}\right), 5.22-5.23(\mathrm{~m}, 2 \mathrm{H}$, overlapping, H-1-Glc and $\mathrm{H}-12$ ), 5.29 (pseudo t, $1 \mathrm{H}, J=9.5,9.6 \mathrm{~Hz}, \mathrm{H}-3-\mathrm{Glc}$ ), 6.75 $(\mathrm{d}, 1 \mathrm{H}, J=8.7 \mathrm{~Hz}, \mathrm{NH}), 7.68(\mathrm{~s}, 1 \mathrm{H}, \mathrm{NCH}) ;{ }^{13} \mathrm{C} \mathrm{NMR}$ $\left(75 \mathrm{MHz} \mathrm{CDCl}_{3}\right): \delta 15.5,15.6,16.9,17.0,18.3,20.5,20.7$, $21.1,23.3,23.5,24.2,27.3,28.0,28.2,30.6,33.0,36.6,37.0$, 38.7, 38.76, 38.84, 39.1, 39.6, 42.1, 47.6, 48.2, 52.6, 52.9, 55.3, 57.2, 61.6, 68.1, 70.4, 72.5, 73.9, 78.5, 79.1, 125.3, 125.8, 138.0, $144.0,165.3,169.4,169.8,170.5,171.0,177.4$. ESI-MS (positive mode) $m / z: 947.0[\mathrm{M}+\mathrm{Na}]^{+}$.

[1-(2,3,4,6-Tetra- $O$-acetyl- $\beta$-D-glucopyranosylaminocarbonyl-

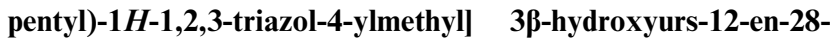
oate (26). Prepared from $5(0.10 \mathrm{~g}, 0.21 \mathrm{mmol})$ and 13 $(0.10 \mathrm{~g}, 0.21 \mathrm{mmol})$ according to General procedure IVa. The residue was purified by column chromatography (EtOAchexane, $1: 1$ ). Yield: $0.10 \mathrm{~g}, 50 \%$, white solid, mp $102-104{ }^{\circ} \mathrm{C}$, $R_{\mathrm{f}}=0.56$ (EtOAc-hexane, $\left.2: 1\right)$; IR $\left(\mathrm{KBr}, \mathrm{cm}^{-1}\right): 3352,2940$, 2870, 1754, 1534, 1455, 1377, 1228, 1043, 756, 666; ${ }^{1} \mathrm{H}$ NMR $\left(300 \mathrm{MHz}, \mathrm{CDCl}_{3}\right): \delta 0.59,0.77,0.90,0.93,0.98,1.06(6 \mathrm{~s}$, each $\left.3 \mathrm{H}, 6 \times \mathrm{CH}_{3}\right), 0.83\left(\mathrm{~d}, J=6.4 \mathrm{~Hz}, 3 \mathrm{H}, \mathrm{CH}_{3}\right), 0.59-2.00$ $(\mathrm{m}, 28 \mathrm{H}), 2.02,2.03,2.04,2.08\left(4 \mathrm{~s}\right.$, each $\left.3 \mathrm{H}, 4 \times \mathrm{OCOCH}_{3}\right)$, 2.14-2.23 (m, 3H, overlapping, $\mathrm{H}-18$ and $\left.\mathrm{CH}_{2} \mathrm{CON}\right), 3.21$ $(\mathrm{dd}, 1 \mathrm{H}, J=4.0,10.1 \mathrm{~Hz}, \mathrm{H}-3), 3.79-3.84(\mathrm{~m}, 1 \mathrm{H}, \mathrm{H}-5-$ Glc), 4.07 (dd, $1 \mathrm{H}, J=2.1,12.7 \mathrm{~Hz}, \mathrm{H}-6 \mathrm{a}-\mathrm{Glc}), 4.29-4.34$ 
1 (m, 3H, overlapping, $\mathrm{H}-6 \mathrm{~b}-\mathrm{Glc}$ and $\mathrm{NCH}_{2}$ ), 4.90 (pseudo t, $1 \mathrm{H}, J=9.5,9.7 \mathrm{~Hz}, \mathrm{H}-4-\mathrm{Glc}$ ), 5.06 (pseudo t, $1 \mathrm{H}, J=9.5$, $9.7 \mathrm{~Hz}, \mathrm{H}-3-\mathrm{Glc}), 5.14$ and $5.15\left(2 \mathrm{~s}\right.$, each $\left.1 \mathrm{H}, \mathrm{COOCH}_{2}\right)$, 5.21-5.34 (m, 3H, overlapping, H-12, H-1-Glc, H-2-Glc), $6.24(\mathrm{~d}, 1 \mathrm{H}, J=8.8 \mathrm{~Hz}, \mathrm{NH}), 7.54(\mathrm{~s}, 1 \mathrm{H}, \mathrm{NCH}) ;{ }^{13} \mathrm{C}$ NMR $\left(75 \mathrm{MHz}, \mathrm{CDCl}_{3}\right): \delta 15.5,15.6,16.9,17.0,18.3,20.6$, $20.67,20.7,21.1,23.3,23.5,24.2,24.22,25.9,27.2,28.0,28.1$, $29.9,30.6,33.0,36.0,36.6,37.0,38.6,38.7,38.8,39.1,39.5$, $42.1,47.5,48.1,49.9,52.8,55.2,57.4,61.6,68.2,70.7,72.6$,

$1073.6,77.2,78.2,79.0,123.8,125.6,138.0,143.2,169.5,169.8$, 170.6, 171.1, 172.7, 177.5. ESI-MS (positive mode) $\mathrm{m} / z$ : 1003.6 $[\mathrm{M}+\mathrm{Na}]^{+}$.

[1-(2,3,4,6-Tetra- $O$-acetyl- $\beta$-D-glucopyranosylaminocarbonyl15 decyl)-1 $\boldsymbol{H}$-1,2,3-triazol-4-ylmethyl] 3及-hydroxyurs-12-en-28oate (27). Prepared from $5(0.09 \mathrm{~g}, 0.18 \mathrm{mmol})$ and 14 $(0.10 \mathrm{~g}, 0.18 \mathrm{mmol})$ according to General procedure IVa. The residue was purified by column chromatography (EtOAchexane, $1: 2$ ). Yield: $0.14 \mathrm{~g}, 74 \%$, white solid, mp $92-93{ }^{\circ} \mathrm{C}$.

$20 R_{\mathrm{f}}=0.30($ EtOAc-hexane, $1: 1)$; IR $\left(\mathrm{KBr}, \mathrm{cm}^{-1}\right): 3369,2928$, 2857, 1756, 1693, 1537, 1455, 1376, 1223, 1141, 1102, 1043, 996, 761, 666; ${ }^{1} \mathrm{H}$ NMR $\left(300 \mathrm{MHz}, \mathrm{CDCl}_{3}\right): \delta 0.57,0.78,0.90$, $0.93,0.99,1.06\left(6 \mathrm{~s}\right.$, each $\left.3 \mathrm{H}, 6 \times \mathrm{CH}_{3}\right), 0.83(\mathrm{~d}, 3 \mathrm{H}, J=6.4 \mathrm{~Hz}$, $\left.\mathrm{CH}_{3}\right), 0.57-2.02(\mathrm{~m}, 38 \mathrm{H}), 2.02,2.03,2.04,2.07$ (4 s, each

$\left.253 \mathrm{H}, 4 \times \mathrm{OCOCH}_{3}\right), 2.13-2.24(\mathrm{~m}, 3 \mathrm{H}$, overlapping, $\mathrm{H}-18$ and $\left.\mathrm{CH}_{2} \mathrm{CON}\right), 3.21(\mathrm{dd}, 1 \mathrm{H}, J=5.0,11.0 \mathrm{~Hz}, \mathrm{H}-3), 3.79-3.85$ (m, 1H, H-5-Glc), 4.07 (dd, 1H, $J=2.0,12.5 \mathrm{~Hz}, \mathrm{H}-6 \mathrm{a}-\mathrm{Glc}$ ), 4.29-4.38 (m, 3H, overlapping, H-6b-Glc and $\left.\mathrm{NCH}_{2}\right), 4.92$ (pseudo t, $1 \mathrm{H}, J=9.6,9.7 \mathrm{~Hz}, \mathrm{H}-4-\mathrm{Glc}$ ), 5.06 (pseudo t, $1 \mathrm{H}$,

$30 J=9.6,9.7 \mathrm{~Hz}, \mathrm{H}-3-\mathrm{Glc}), 5.16$ (s, 2H, $\left.\mathrm{COOCH}_{2}\right), 5.21-5.23$ (m, 1H, H-1-Glc), 5.26-5.34 (m, 2H, overlapping, H-12 and $\mathrm{H}-2-\mathrm{Glc}), 6.30$ (d, 1H, $J=9.4 \mathrm{~Hz}, \mathrm{NH}), 7.55$ (s, 1H, NCH); ${ }^{13} \mathrm{C} \mathrm{NMR}\left(75 \mathrm{MHz}, \mathrm{CDCl}_{3}\right): \delta 15.5,15.7,16.9,17.0,18.3,20.5$, $20.6,20.7,21.1,23.3,23.5,24.2,25.1,26.5,27.3,28.0,28.2$, $3529.0,29.1,29.2,29.3,29.34,30.2,30.7,33.0,36.6,37.0,38.7$, $38.8,38.84,39.1,39.6,42.1,47.6,48.2,50.4,52.9,55.2,57.4$, $60.1,61.7,68.3,70.8,72.8,73.6,77.2,78.2,79.0,123.8,125.6$, $138.1,143.1,169.5,169.8,170.5,171.0,173.3,177.5$. ESI-MS 40 (positive mode) $m / z: 1073.5[\mathrm{M}+\mathrm{Na}]^{+}$.

[1-(2,3,4,6-Tetra- $O$-acetyl- $\beta$-D-glucopyranosylaminocarbonylmethyl)-1 $H$-1,2,3-triazol-4-ylmethyl] $2 \alpha, 3 \beta$-dihydroxyolean-12en-28-oate (28). Prepared from $6(0.12 \mathrm{~g}, 0.23 \mathrm{mmol})$ and 12 $(0.10 \mathrm{~g}, 0.23 \mathrm{mmol})$ according to General procedure IVa. The 45 residue was purified by column chromatography (EtOAchexane, $1: 1$ ). Yield: $0.13 \mathrm{~g}, 57 \%$, white solid, $\mathrm{mp} 178-180{ }^{\circ} \mathrm{C}$, $R_{\mathrm{f}}=0.39$ (EtOAc-hexane, 2: 1); IR $\left(\mathrm{KBr}, \mathrm{cm}^{-1}\right): 3345,2947$, $1755,1556,1460,1371,1230,1175,1160,1048,1034,759 ;{ }^{1} \mathrm{H}$ NMR (300 MHz, $\left.\mathrm{CDCl}_{3}\right): \delta 0.58,0.83,0.89,0.90,0.97,1.03$,

$501.12\left(7 \mathrm{~s}\right.$, each $\left.3 \mathrm{H}, 7 \times \mathrm{CH}_{3}\right), 0.83-2.01(\mathrm{~m}, 20 \mathrm{H}), 2.01,2.02$, 2.03, $2.08\left(4 \mathrm{~s}\right.$, each $\left.3 \mathrm{H}, 4 \times \mathrm{OCOCH}_{3}\right), 2.84(\mathrm{dd}, 1 \mathrm{H}, J=4.1$, $9.7 \mathrm{~Hz}, \mathrm{H}-18), 2.99$ (d, $1 \mathrm{H}, J=9.5 \mathrm{~Hz}, \mathrm{H}-3 \alpha), 3.68-3.71$ (m, 1H, H-2 $\beta$ ), 3.78-3.83 (m, 1H, H-5-Glc), 4.06-4.13 (m, 1H, H-6a-Glc), 4.28 (dd, 1H, $J=4.3,12.5 \mathrm{~Hz}, \mathrm{H}-6 \mathrm{~b}-\mathrm{Glc}), 4.87$ 55 (t, $1 \mathrm{H}, J=9.6,9.6 \mathrm{~Hz}, \mathrm{H}-4-\mathrm{Glc}), 4.95-5.07$ (m, 3H, overlapping, $\mathrm{NCH}_{2} \mathrm{CO}$ and $\left.\mathrm{H}-3-\mathrm{Glc}\right), 5.15-5.21$ (m, 3H, overlapping, $\mathrm{COOCH}_{2}$ and $\left.\mathrm{H}-2-\mathrm{Glc}\right), \quad 5.25-5.32(\mathrm{~m}, 3 \mathrm{H}$, overlapping, H-1-Glc and $\mathrm{H}-12), 6.72(\mathrm{~d}, 1 \mathrm{H}, J=8.7 \mathrm{~Hz}$, $\mathrm{NH}), 7.69$ (s, $1 \mathrm{H}, \mathrm{NCH}) ;{ }^{13} \mathrm{C} \mathrm{NMR}\left(75 \mathrm{MHz}, \mathrm{CDCl}_{3}\right): \delta 16.6$,
$16.7,18.3,20.5,20.7,23.0,23.4,23.6,25.8,27.6,28.6,30.6$, $32.3,32.6,33.0,33.8,38.3,39.2,39.4,41.3,41.8,45.8,46.5$, $46.7,52.6,55.3,57.4,61.6,68.1,68.9,70.4,72.4,73.9,78.5$, 83.9, 122.3, 125.3, 143.6, 144.0, 165.3, 169.4. ESI-MS (positive mode) $m / z: 963.7[\mathrm{M}+\mathrm{Na}]^{+}, 979.7[\mathrm{M}+\mathrm{K}]^{+}$.

[1-(2,3,4,6-Tetra- $O$-acetyl- $\beta$-D-glucopyranosylaminocarbonylpentyl)-1 $H$-1,2,3-triazol-4-ylmethyl] $2 \alpha, 3 \beta$-dihydroxyolean-12en-28-oate (29).. Prepared from $6(0.11 \mathrm{~g}, 0.21 \mathrm{mmol})$ and 13 $(0.10 \mathrm{~g}, 0.21 \mathrm{mmol})$ according to General procedure IVa. The residue was purified by column chromatography (EtOAchexane, $2: 1)$. Yield: $0.15 \mathrm{~g}, 71 \%$, white solid, $\mathrm{mp} 160-162{ }^{\circ} \mathrm{C}$, $R_{\mathrm{f}}=0.06$ (EtOAc-hexane, $\left.1: 1\right)$; IR $\left(\mathrm{KBr}, \mathrm{cm}^{-1}\right): 3369,2947$, 1794, 1745, 1364, 1228, 1175, 1160, 1046, 757, 666; ${ }^{1} \mathrm{H}$ NMR $\left(300 \mathrm{MHz}, \mathrm{CDCl}_{3}\right): \delta 0.55,0.82,0.89,0.90,0.95,1.02,1.11$ $\left(7 \mathrm{~s}\right.$, each $\left.3 \mathrm{H}, 7 \times \mathrm{CH}_{3}\right), 0.81-2.02(\mathrm{~m}, 26 \mathrm{H}), 2.02,2.03,2.04$, $2.08\left(4 \mathrm{~s}\right.$, each $\left.3 \mathrm{H}, 4 \times \mathrm{OCOCH}_{3}\right), 2.14-2.20(\mathrm{~m}, 2 \mathrm{H}$, $\mathrm{CH}_{2} \mathrm{CON}$ ), $2.85(\mathrm{dd}, 1 \mathrm{H}, J=3.7,10.3 \mathrm{~Hz}, \mathrm{H}-18), 2.98$ $(\mathrm{d}, 1 \mathrm{H}, J=9.5 \mathrm{~Hz}, \mathrm{H}-3 \alpha), 3.64-3.71(\mathrm{~m}, 1 \mathrm{H}, \mathrm{H}-2 \beta)$, 3.80-3.85 (m, 1H, H-5-Glc), 4.07 (dd, $1 \mathrm{H}, J=2.0,12.5 \mathrm{~Hz}$, H-6a-Glc), 4.28-4.34 (m, 3H, overlapping, $\mathrm{NCH}_{2}$ and H-6b-Glc), 4.92 (t, 1H, $J=9.6,9.6 \mathrm{~Hz}, \mathrm{H}-4-\mathrm{Glc}), 5.06$ (t, $1 \mathrm{H}, J=9.7,9.7 \mathrm{~Hz}, \mathrm{H}-3-\mathrm{Glc}), 5.17\left(\mathrm{~s}, 2 \mathrm{H}, \mathrm{COOCH}_{2}\right)$, 5.21-5.34 (m, 3H, overlapping, $\mathrm{H}-12$ and $\mathrm{H}-1-\mathrm{Glc}, \mathrm{H}-2-\mathrm{Glc}$ ), $6.23(\mathrm{~d}, 1 \mathrm{H}, J=9.3 \mathrm{~Hz}, \mathrm{NH}), 7.55(\mathrm{~s}, 1 \mathrm{H}, \mathrm{NCH}) ;{ }^{13} \mathrm{C} \mathrm{NMR}$ $\left(75 \mathrm{MHz}_{1} \mathrm{CDCl}_{3}\right)$ : $\delta 16.6,16.7,16.8,18.3,20.5,20.6,20.7$, $23.0,23.5,23.6,24.3,25.8,25.9,27.6,28.6,29.9,30.6,32.4$, $32.6,33.0,33.8,36.0,38.3,39.1,39.4,41.3,41.8,45.8,46.4$, $46.7,47.5,49.9,55.3,57.6,61.7,68.2,68.9,70.8,72.7,73.6$, $76.7,77.2,78.2,83.9,114.6,120.2,121.8,122.2,123.7,143.2$, $143.5,143.7,169.5,169.8,171.1,172.6,177.7$. ESI-MS (positive mode) $m / z: 1019.4[\mathrm{M}+\mathrm{Na}]^{+}$.

[1-(2,3,4,6-Tetra- $O$-acetyl- $\beta$-D-glucopyranosylaminocarbonyldecyl)-1 $H$-1,3-triazol-4-ylmethyl] $2 \alpha, 3 \beta$-dihydroxyolean-12-en28-oate (30). Prepared from $6(0.09 \mathrm{~g}, 0.18 \mathrm{mmol})$ and 14 $(0.10 \mathrm{~g}, 0.18 \mathrm{mmol})$ according to General procedure IVa. The residue was purified by column chromatography (EtOAchexane, 1:1). Yield: $0.16 \mathrm{~g}, 82 \%$, white solid, mp 110-112 ${ }^{\circ} \mathrm{C}$, $R_{\mathrm{f}}=0.23$ (EtOAc-hexane, $\left.1: 1\right)$; IR $\left(\mathrm{KBr}, \mathrm{cm}^{-1}\right): 3374,2931$, 2858, 1795, 1753, 1536, 1461, 1364, 1220, 1175, 1160, 1049, 1034, 770, 667; ${ }^{1} \mathrm{H}$ NMR $\left(300 \mathrm{MHz}, \mathrm{CDCl}_{3}\right): \delta 0.50,0.81$, $0.89,0.90,0.95,1.02,1.11\left(7 \mathrm{~s}\right.$, each $\left.3 \mathrm{H}, 7 \times \mathrm{CH}_{3}\right), 0.81-2.02$ $(\mathrm{m}, 36 \mathrm{H}), 2.02,2.03,2.04,2.08\left(4 \mathrm{~s}\right.$, each $\left.3 \mathrm{H}, 4 \times \mathrm{OCOCH}_{3}\right)$, 2.18-2.29 (m, 2H, $\left.\mathrm{CH}_{2} \mathrm{CON}\right), 2.84(\mathrm{dd}, 1 \mathrm{H}, J=3.5,13.3 \mathrm{~Hz}$, $\mathrm{H}-18), 2.97$ (d, 1H, $J=9.5 \mathrm{~Hz}, \mathrm{H}-3 \alpha), 3.64-3.71(\mathrm{~m}, 1 \mathrm{H}$, $\mathrm{H}-2 \beta$ ), 3.80-3.85 (m, 1H, H-5-Glc), 4.07 (dd, 1H, $J=2.0,12.5$ $\mathrm{Hz}, \mathrm{H}-6 \mathrm{a}-\mathrm{Glc}), 4.28-4.34$ (m, 3H, overlapping, $\mathrm{NCH}_{2}$ and H-6b-Glc), 4.92 (pseudo t, 1H, $J=9.6,9.7 \mathrm{~Hz}, \mathrm{H}-4-\mathrm{Glc}$ ), 5.06 (pseudo t, $1 \mathrm{H}, J=9.6,9.7 \mathrm{~Hz}, \mathrm{H}-3-\mathrm{Glc}$ ), 5.16 and 5.17 $\left(2 \mathrm{~s}\right.$, each $\left.1 \mathrm{H}, \mathrm{COOCH}_{2}\right), 5.22-5.34(\mathrm{~m}, 3 \mathrm{H}$, overlapping, H-12 and H-1-Glc, H-2-Glc), 6.32 (d, 1H, $J=9.3 \mathrm{~Hz}, \mathrm{NH})$, $7.56(\mathrm{~s}, 1 \mathrm{H}, \mathrm{NCH}) ;{ }^{13} \mathrm{C} \mathrm{NMR}\left(75 \mathrm{MHz}, \mathrm{CDCl}_{3}\right): \delta 16.7,16.79$, 16.84, 18.4, 20.5, 20.6, 20.7, 23.0, 23.5, 23.6, 25.1, 23.8, 26.6, $27.6,28.6,29.0,29.1,29.2,29.3,30.3,30.7,32.5,32.6,33.0$, $33.9,36.6,38.3,39.2,39.4,41.3,41.8,45.9,46.4,46.7,47.5$, $50.3,55.3,57.6,61.7,68.3,68.9,68.4,70.8,72.8,73.6,78.2$, $83.9,122.2,123.8,143.1,169.5,169.8,171.0,173.4,177.8$. ESI-MS (positive mode) $m / z: 1089.6[\mathrm{M}+\mathrm{Na}]^{+}$. 
Q9 [3-Triazol-4-ylmethyl,1-( $\beta$-D-glucopyranosylaminocarbonylmethyl)-1 H-1,2] 3ß-hydroxyolean-12-en-28-oate (31). Prepared from $22(0.13 \mathrm{~g}, 0.14 \mathrm{mmol})$ according to General procedure V. The residue was purified by column chromatography 5 (MeOH$\left.-\mathrm{CH}_{2} \mathrm{Cl}_{2}, 1: 15\right)$. Yield: $0.055 \mathrm{~g}, 51 \%$, white solid, $\mathrm{mp}$ 197-199 ${ }^{\circ} \mathrm{C}, \quad R_{\mathrm{f}}=0.09\left(\mathrm{MeOH}-\mathrm{CH}_{2} \mathrm{Cl}_{2}, \quad 1: 10\right)$; $[\alpha]_{\mathrm{D}}=+37(c=0.11, \mathrm{MeOH}) ; \operatorname{IR}\left(\mathrm{KBr}, \mathrm{cm}^{-1}\right): 3407$, 2943, 2860, 1705, 1556, 1389, 1161, 1059, 1032, 1018, 772; ${ }^{1} \mathrm{H}$ NMR $\left(300 \mathrm{MHz}, \mathrm{C}_{5} \mathrm{D}_{5} \mathrm{~N}\right): \delta 0.80,0.90,1.03,1.19,1.24$

$10\left(5 \mathrm{~s}\right.$, each $\left.3 \mathrm{H}, 5 \times \mathrm{CH}_{3}\right), 0.88\left(\mathrm{~s}, 6 \mathrm{H}, 2 \times \mathrm{CH}_{3}\right), 0.80-1.96$ $(\mathrm{m}, 22 \mathrm{H}), 3.13(\mathrm{~d}, 1 \mathrm{H}, J=10.3 \mathrm{~Hz}, \mathrm{H}-18), 3.43(\mathrm{t}, 1 \mathrm{H}, J=$ $7.8 \mathrm{~Hz}, \mathrm{H}-3), 4.02-4.11(\mathrm{~m}, 2 \mathrm{H}$, overlapping, H-5-Glc and $\mathrm{H}-6 \mathrm{a}-\mathrm{Glc}), 4.25-4.27$ (m, 2H, overlapping, H-4-Glc and H-2-Glc), 4.37 (dd, 1H, $J=4.3,11.8 \mathrm{~Hz}, \mathrm{H}-6 \mathrm{~b}-\mathrm{Glc}$ ), 4.49

$15\left(\mathrm{~d}, 1 \mathrm{H}, J=11.5 \mathrm{~Hz}, \mathrm{H}-1^{\prime}\right), 5.43$ (s, 1H, H-12), 5.48 (s, 2H, $\left.\mathrm{NCH}_{2} \mathrm{CO}\right), 5.62\left(\mathrm{~s}, 2 \mathrm{H}, \mathrm{COOCH}_{2}\right), 5.97(\mathrm{t}, 1 \mathrm{H}, J=8.9$, $8.9 \mathrm{~Hz}, \mathrm{H}-3-\mathrm{Glc}), 8.40$ (s, $1 \mathrm{H}, \mathrm{NCH}), 10.60(\mathrm{~d}, 1 \mathrm{H}, J=8.8 \mathrm{~Hz}$, $\mathrm{NH}) ;{ }^{13} \mathrm{C} \mathrm{NMR}\left(75 \mathrm{MHz}, \mathrm{C}_{5} \mathrm{D}_{5} \mathrm{~N}\right): \delta 15.6,16.5,17.1,18.7$, 23.3, 23.6, 23.7, 26.0, 28.0, 28.1, 28.7, 29.9, 30.7, 32.7, 33.05,

$2033.1,33.9,37.3,38.9,39.3,39.7,41.9,42.0,46.1,46.9,48.0$, $52.7,55.8,58.0,62.4,71.5,74.5,78.1,79.5,80.3,81.5,123.1$, $123.8,126.7,135.8,143.5,144.0,150.2,166.9,177.3$. ESI-MS (negative mode) $m / z: 755.5[\mathrm{M}-\mathrm{H}]^{+}$; HRMS (MALDI) $m / z$ $=\mathrm{C}_{41} \mathrm{H}_{64} \mathrm{~N}_{4} \mathrm{O}_{9}[\mathrm{M}+\mathrm{Na}]^{+}$calcd. 779.4571, found 779.4594.

[3-Triazol-4-ylmethyl,1-( $\beta$-D-glucopyranosylaminocarbonylpentyl)-1H-1,2] 3及-hydroxyolean-12-en-28-oate (32). Prepared from $23(0.11 \mathrm{~g}, 0.11 \mathrm{mmol})$ according to the general procedure $\mathrm{V}$. The residue was purified by column chromato-

30 graphy $\left(\mathrm{MeOH}-\mathrm{CH}_{2} \mathrm{Cl}_{2}, 1: 15\right)$. Yield: $0.076 \mathrm{~g}, 83 \%$, white solid, mp 164-166 ${ }^{\circ} \mathrm{C}, R_{\mathrm{f}}=0.25\left(\mathrm{MeOH}-\mathrm{CH}_{2} \mathrm{Cl}_{2}, 1: 10\right)$; $[\alpha]_{\mathrm{D}}=+42(c=0.06, \mathrm{MeOH}) ; \mathrm{IR}\left(\mathrm{KBr}, \mathrm{cm}^{-1}\right): 3367,2939$, 2864, 1725, 1663, 1382, 1053, 1032, 1013, 773; ${ }^{1} \mathrm{H}$ NMR $\left(300 \mathrm{MHz}, \mathrm{C}_{5} \mathrm{D}_{5} \mathrm{~N}\right): \delta 0.81,0.94,1.05,1.20,1.24(5 \mathrm{~s}$, each

$\left.353 \mathrm{H}, 5 \times \mathrm{CH}_{3}\right), 0.89\left(\mathrm{~s}, 6 \mathrm{H}, 2 \mathrm{CH}_{3}\right), 0.81-1.93(\mathrm{~m}, 28 \mathrm{H}), 2.41$ (t, $\left.2 \mathrm{H}, J=7.3 \mathrm{~Hz}, \mathrm{CH}_{2} \mathrm{CO}\right), 3.15(\mathrm{~d}, 1 \mathrm{H}, J=13.3 \mathrm{~Hz}, \mathrm{H}-18)$, 3.45 (brs, 1H, H-3), 4.05-4.13 (m, 2H, H-5-Glc and H-6a-Glc), 4.23-4.30 (m, 4H, H-2-Glc, H-4-Glc and $\left.\mathrm{NCH}_{2}\right), 4.37$ (dd, $1 \mathrm{H}$, $J=4.6,11.8 \mathrm{~Hz}, \mathrm{H}-6 \mathrm{~b}-\mathrm{Glc}), 4.48(\mathrm{~d}, 1 \mathrm{H}, J=11.8 \mathrm{~Hz}$,

40 H-1-Glc), 5.43 (s, 1H, H-12), 5.53 and 5.54 ( 2 d, each $1 \mathrm{H}, J=$ $\left.12.6 \mathrm{~Hz}, \mathrm{COOCH}_{2}\right), 6.01(\mathrm{t}, 1 \mathrm{H}, J=9.0,9.0 \mathrm{~Hz}, \mathrm{H}-3-\mathrm{Glc})$, $8.13(\mathrm{~s}, 1 \mathrm{H}, \mathrm{NCH}), 9.62(\mathrm{~d}, 1 \mathrm{H}, J=9.1 \mathrm{~Hz}, \mathrm{NH}) ;{ }^{13} \mathrm{C} \mathrm{NMR}$ $\left(75 \mathrm{MHz}, \mathrm{C}_{5} \mathrm{D}_{5} \mathrm{~N}\right): \delta 15.6,16.5,17.2,18.8,23.3,23.6,23.8$, $25.1,26.0,26.4,28.0,28.1,28.8,30.3,30.7,32.8,33.1,33.2$,

$4533.9,36.3,37.3,39.0,39.4,39.7,41.9,42.0,46.1,47.0,48.0$, 50.0, 55.8, 58.1, 62.7, 71.8, 74.6, 78.1, 79.7, 80.1, 81.3, 123.0, 124.6, 143.4, 144.0, 173.6, 177.4. ESI-MS (negative mode) $\mathrm{m} / \mathrm{z}$ : $811.4[\mathrm{M}-\mathrm{H}]^{+}$; HRMS (MALDI) $m / z=\mathrm{C}_{45} \mathrm{H}_{72} \mathrm{~N}_{4} \mathrm{O}_{9}$ $[\mathrm{M}+\mathrm{Na}]^{+}$calcd. 835.5197, found 835.5203.

50

[3-Triazol-4-ylmethyl,1-( $\beta$-D-glucopyranosylaminocarbonyldecyl)-1H-1,2] 3及-hydroxyolean-12-en-28-oate (33). Prepared from $24(0.083 \mathrm{~g}, 0.08 \mathrm{mmol})$ according to General procedure $\mathrm{V}$. The residue was purified by column chromatography

$55\left(\mathrm{MeOH}-\mathrm{CH}_{2} \mathrm{Cl}_{2}, 1: 20\right)$. Yield: $0.068 \mathrm{~g}, 97 \%$, white solid, mp 195-196 ${ }^{\circ} \mathrm{C}, R_{\mathrm{f}}=0.27\left(\mathrm{MeOH}-\mathrm{CH}_{2} \mathrm{Cl}_{2}, 1: 15\right) ;[\alpha]_{\mathrm{D}}=$ $+31(c=0.1, \mathrm{MeOH})$; IR $\left(\mathrm{KBr}, \mathrm{cm}^{-1}\right): 3392,2928,1727$, 1463, 1386, 1158, 1123, 1050, 1032, 1012, 756, 697; ${ }^{1} \mathrm{H}$ NMR $\left(300 \mathrm{MHz}, \mathrm{C}_{5} \mathrm{D}_{5} \mathrm{~N}\right): \delta 0.59,0.86,1.04,1.10(4 \mathrm{~s}$, each $3 \mathrm{H}$, $\left.4 \times \mathrm{CH}_{3}\right), 0.74\left(\mathrm{~s}, 9 \mathrm{H}, 3 \times \mathrm{CH}_{3}\right), 0.59-1.95(\mathrm{~m}, 38 \mathrm{H}), 2.36$ $\left(\mathrm{t}, 2 \mathrm{H}, J=7.3 \mathrm{~Hz}, \mathrm{CH}_{2} \mathrm{CON}\right), 2.94(\mathrm{dd}, 1 \mathrm{H}, J=3.6,10.0 \mathrm{~Hz}$, $\mathrm{H}-18), 3.28(\mathrm{t}, 1 \mathrm{H}, J=8.0 \mathrm{~Hz}, \mathrm{H}-3), 3.92-3.93(\mathrm{~m}, 2 \mathrm{H}$, overlapping, H-5-Glc and H-6a-Glc), 4.04-4.10 (m, 3H, m, overlapping, $\mathrm{NCH}_{2}$ and $\left.\mathrm{H}-6 \mathrm{~b}-\mathrm{Glc}\right), 4.26-4.38(\mathrm{~m}, 3 \mathrm{H}, \mathrm{m}$, overlapping, H-2-Glc, H-3-Glc, and $\mathrm{H}-4-\mathrm{Glc}), 5.26$ (s, $1 \mathrm{H}$, $\mathrm{H}-12), 5.42$ (d, 1H, $\left.J=14.1 \mathrm{~Hz}, \mathrm{COOCH}_{2}\right), 5.46$ (d, 1H, $J=$ $14.1 \mathrm{~Hz}, \mathrm{COOCH}_{2}$ ), 5.63 (d, 1H, $\left.J=8.6 \mathrm{~Hz}, \mathrm{H}-1-\mathrm{Glc}\right), 8.18$ $(\mathrm{s}, 1 \mathrm{H}, \mathrm{NCH}), 9.67(\mathrm{~d}, 1 \mathrm{H}, J=8.8 \mathrm{~Hz}, \mathrm{NH}) ;{ }^{13} \mathrm{C} \mathrm{NMR}$ $\left(75 \mathrm{MHz}, \mathrm{C}_{5} \mathrm{D}_{5} \mathrm{~N}\right): \delta 15.7,16.6,17.3,18.8,23.4,23.7,23.8$, $25.9,26.0,26.7,28.1,28.8,29.2,29.6,29.64,29.7,30.6,30.8$, $32.8,33.1,33.2,34.0,36.9,37.4,39.0,39.4,39.8,41.9,42.1$, $46.1,47.0,48.0,50.3,55.8,58.1,62.7,71.8,74.5,78.1,79.6$, 80.0, 81.4, 122.8, 124.7, 143.4, 144.0, 174.1, 177.4. ESI-MS (positive mode) $m / z: 917.5[\mathrm{M}+\mathrm{Cl}]^{+}$; HRMS (MALDI) $m / z=\mathrm{C}_{50} \mathrm{H}_{82} \mathrm{~N}_{4} \mathrm{O}_{9}[\mathrm{M}+\mathrm{Na}]^{+}$calcd. 905.5980, found 905.6013

[3-Triazol-4-ylmethyl,1-( $\beta$-D-glucopyranosylaminocarbonylpentyl)-1H-1,2] 3ß-hydroxyurs-12-en-28-oate (34). Prepared from $26(0.065 \mathrm{~g}, 0.07 \mathrm{mmol})$ according to General procedure V. The residue was purified by column chromatography (MeOH- $\mathrm{CH}_{2} \mathrm{Cl}_{2}, 1: 20$ ). Yield: $0.053 \mathrm{~g}, 98 \%$, white solid, $\operatorname{mp} 214-216{ }^{\circ} \mathrm{C}, R_{\mathrm{f}}=0.67\left(\mathrm{MeOH}-\mathrm{CH}_{2} \mathrm{Cl}_{2}, 1: 15\right) ;[\alpha]_{\mathrm{D}}=$ $+26(c=0.1, \mathrm{MeOH})$. IR $\left(\mathrm{KBr}, \mathrm{cm}^{-1}\right): 3386,2924,2869$, 1724, 1657, 1456, 1392, 1049, 1032, 1017; ${ }^{1} \mathrm{H}$ NMR $(300 \mathrm{MHz}$, $\left.\mathrm{C}_{5} \mathrm{D}_{5} \mathrm{~N}\right): \delta 0.83,0.91,0.94,1.04,1.13,1.23(6 \mathrm{~s}$, each $3 \mathrm{H}$, $\left.6 \times \mathrm{CH}_{3}\right), 0.88\left(\mathrm{~d}, 3 \mathrm{H}, J=3.9 \mathrm{~Hz}, \mathrm{CH}_{3}\right), 0.83-2.00(\mathrm{~m}, 28 \mathrm{H})$, 2.39-2.47 (m, 3H, overlapping, $\mathrm{H}-18$ and $\left.\mathrm{CH}_{2} \mathrm{CON}\right), 3.44$ (dd, $1 \mathrm{H}, J=6.1,9.8 \mathrm{~Hz}, \mathrm{H}-3), 4.04$ (m, 1H, H-5-Glc), 4.16 (t, $1 \mathrm{H}, J=9.8,9.8 \mathrm{~Hz}, \mathrm{H}-4-\mathrm{Glc}), 4.24-4.45$ (m, 6H, overlapping, $\mathrm{NCH}_{2}, \mathrm{H}-2-\mathrm{Glc}, \mathrm{H}-3-\mathrm{Glc}$ and H-6a-Glc, H-6b-Glc), 5.40 (s, $1 \mathrm{H}, \mathrm{H}-12), 5.50\left(\mathrm{~s}, 2 \mathrm{H}, \mathrm{COOCH}_{2}\right), 5.96(1 \mathrm{H}$, over\left. lapping, ${\mathrm{H}-1^{\prime}}^{\prime}\right), 8.13(\mathrm{~s}, 1 \mathrm{H}, \mathrm{NCH}), 9.69(\mathrm{~d}, 1 \mathrm{H}, J=8.2 \mathrm{~Hz}$, $\mathrm{NH}) ;{ }^{13} \mathrm{C}$ NMR $\left(75 \mathrm{MHz}, \mathrm{C}_{5} \mathrm{D}_{5} \mathrm{~N}\right): \delta 15.8,16.6,17.3,18.8$, $21.2,23.7,23.8,24.6,25.1,26.4,28.1,28.4,28.8,30.0,30.3$, $30.8,33.5,36.4,37.0,37.3,39.1,39.2,39.3,39.4,40.0,42.4$, $48.0,48.4,50.1,53.4,55.8,58.0,62.7,71.8,74.5,78.2,79.6$, 80.0, 81.3, 124.6, 126.2, 138.6, 143.3, 173.7, 177.1. ESI-MS (positive mode) $m / z: 847.5[\mathrm{M}+\mathrm{Cl}]^{+}$. HRMS (MALDI) $m / z=\mathrm{C}_{45} \mathrm{H}_{72} \mathrm{~N}_{4} \mathrm{O}_{9}[\mathrm{M}+\mathrm{Na}]^{+}$calcd. 835.5197, found 835.5206 .

[3-Triazol-4-ylmethyl,1-( $\beta$-D-glucopyranosylaminocarbonyldecyl)-1H-1,2] 3ß-hydroxyurs-12-en-28-oate (35). Prepared from $27(0.10 \mathrm{~g}, 0.1 \mathrm{mmol})$ according to General procedure V. The residue was purified by column chromatography ( $\mathrm{MeOH}-\mathrm{CH}_{2} \mathrm{Cl}_{2}, 1: 12$ ). Yield: $0.078 \mathrm{~g}, 93 \%$, white solid, $\mathrm{mp} \quad 199-200{ }^{\circ} \mathrm{C}, \quad R_{\mathrm{f}}=0.12\left(\mathrm{MeOH}-\mathrm{CH}_{2} \mathrm{Cl}_{2}, \quad 1: 15\right)$; $[\alpha]_{\mathrm{D}}=+32(c=0.06, \mathrm{MeOH}) ; \mathrm{IR}\left(\mathrm{KBr}, \mathrm{cm}^{-1}\right): 3409$, 2924, 2861, 1726, 1662, 1453,1382, 1052, 1032, 1013. ${ }^{1} \mathrm{H}$ NMR $\left(300 \mathrm{MHz}, \mathrm{C}_{5} \mathrm{D}_{5} \mathrm{~N}\right): \delta 0.81,0.91,0.94,1.03,1.13,1.23$ $\left(6 \mathrm{~s}\right.$, each $\left.3 \mathrm{H}, 6 \times \mathrm{CH}_{3}\right), 0.88\left(\mathrm{~d}, 3 \mathrm{H}, J=3.6 \mathrm{~Hz}, \mathrm{CH}_{3}\right)$, 0.81-1.99 (m, 38H), 2.43-2.49 (m, 3H, overlapping, H-18 and $\mathrm{CH}_{2} \mathrm{CON}$ ), 3.44 (dd, $\left.1 \mathrm{H}, J=6.8,9.7 \mathrm{~Hz}, \mathrm{H}-3\right), 4.04(\mathrm{~m}, 1 \mathrm{H}$, H-5-Glc), 4.14 (t, 1H, $J=8.8,8.8 \mathrm{~Hz}, \mathrm{H}-4-G l c), 4.21-4.33$ $\left(\mathrm{m}, 2 \mathrm{H}, \mathrm{NCH}_{2}\right), 4.35-4.47(\mathrm{~m}, 3 \mathrm{H}$, overlapping, H-3-Glc, H-2-Glc and H-1-Glc), 5.39 (brs, $1 \mathrm{H}, \mathrm{H}-12$ ), 5.51 and 5.52 $\left(2 \mathrm{~d}\right.$, each $\left.1 \mathrm{H}, J=12.5 \mathrm{~Hz}, \mathrm{COOCH}_{2}\right), 8.19(\mathrm{~s}, 1 \mathrm{H}, \mathrm{NCH})$, 
$19.62(\mathrm{~d}, 1 \mathrm{H}, J=9.0 \mathrm{~Hz}, \mathrm{NH}) ;{ }^{13} \mathrm{C} \mathrm{NMR}\left(75 \mathrm{MHz}, \mathrm{C}_{5} \mathrm{D}_{5} \mathrm{~N}\right): \delta$ $15.8,16.6,17.3,17.4,18.8,21.2,23.7,23.8,24.6,26.0,26.8$, $28.2,28.5,28.9,29.3,29.6,29.67,29.7,30.0,30.6,30.8,33.5$, $36.9,37.0,37.4,39.2,39.3,39.4,40.0,42.4,48.0,48.4,50.3$, 5 53.4, 55.9, 58.1, 62.8, 71.9, 74.6, 78.2, 79.7, 80.0, 81.4, 124.7, 126.2, 143.4, 174.1, 177.2. ESI-MS (positive mode) $m / z: 927.5$ $[\mathrm{M}+\mathrm{HCOO}]^{+}$; HRMS (MALDI) $m / z=\mathrm{C}_{50} \mathrm{H}_{82} \mathrm{~N}_{4} \mathrm{O}_{9}$ $[\mathrm{M}+\mathrm{Na}]^{+}$calcd. 905.5980 , found 905.6004.

10 [3-Triazol-4-ylmethyl,1-( $\beta$-D-glucopyranosylaminocarbonyl-

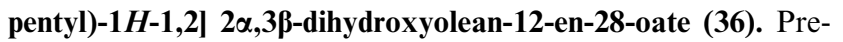
pared from $29(0.10 \mathrm{~g}, 0.1 \mathrm{mmol})$ according to General procedure V. The residue was purified by column chromatography $\left(\mathrm{MeOH}-\mathrm{CH}_{2} \mathrm{Cl}_{2}, 1: 10\right)$. Yield: $0.075 \mathrm{~g}, 93 \%$, white 15 solid, mp 180-182 ${ }^{\circ} \mathrm{C}, R_{\mathrm{f}}=0.09\left(\mathrm{MeOH}-\mathrm{CH}_{2} \mathrm{Cl}_{2}, 1: 15\right)$; $[\alpha]_{\mathrm{D}}=+23(c=0.05, \mathrm{MeOH}) ; \mathrm{IR}\left(\mathrm{KBr}, \mathrm{cm}^{-1}\right): 3369,2944$, 2873, 1725, 1664, 1546, 1461, 1260, 1159, 1122, 1049, 1033; ${ }^{1} \mathrm{H}$ NMR $\left(300 \mathrm{MHz}, \mathrm{C}_{5} \mathrm{D}_{5} \mathrm{~N}\right): \delta 0.79,0.90,1.02,1.09,1.16$ $\left(5 \mathrm{~s}\right.$, each $\left.3 \mathrm{H}, 5 \times \mathrm{CH}_{3}\right), 0.87\left(\mathrm{~s}, 6 \mathrm{H}, 2 \times \mathrm{CH}_{3}\right), 0.79-2.30$ $20(\mathrm{~m}, 26 \mathrm{H}), 2.40\left(\mathrm{t}, 2 \mathrm{H}, J=7.3 \mathrm{~Hz}, \mathrm{CH}_{2} \mathrm{CON}\right), 3.11(\mathrm{dd}, 1 \mathrm{H}$, $J=4.2,13.5 \mathrm{~Hz}, \mathrm{H}-18), 3.37$ (d, $1 \mathrm{H}, J=9.3 \mathrm{~Hz}, \mathrm{H}-3 \alpha), 4.10$ (m, 1H, H-2 $)$ ), 4.15-4.49 (m, 6H, overlapping, H-1-Glc, H-2Glc, H-4-Glc, H-5-Glc and H-6-Glc), 5.38 (s, 1H, H-12), 5.52 (s, 2H, $\mathrm{COOCH}_{2}$ ), 5.99 (t, 1H, $\left.J=9.0,9.0 \mathrm{~Hz}, \mathrm{H}-3-\mathrm{Glc}\right), 8.11$ $5(\mathrm{~s}, 1 \mathrm{H}, \mathrm{NCH}), 9.62(\mathrm{~d}, 1 \mathrm{H}, J=9.0 \mathrm{~Hz}, \mathrm{NH}) ;{ }^{13} \mathrm{C} \mathrm{NMR}$ $\left(75 \mathrm{MHz}, \mathrm{C}_{5} \mathrm{D}_{5} \mathrm{~N}\right): \delta 16.9,17.3,17.7,18.9,23.4,23.7,23.9$, $25.1,26.0,26.5,28.0,29.3,30.0,30.4,36.4,38.6,39.8,41.9$, $42.1,46.1,47.0,47.8,48.1,50.0,55.9,58.2,62.8,68.6,71.8$, 74.6, 79.7, 80.0, 81.3, 83.8, 122.9, 124.6, 143.3, 144.0, 173.6, 30 177.4. ESI-MS (positive mode) $m / z: 873.5\left[\mathrm{M}+\mathrm{HCOO}^{+}\right.$; HRMS (MALDI) $m / z=\mathrm{C}_{45} \mathrm{H}_{72} \mathrm{~N}_{4} \mathrm{O}_{10}[\mathrm{M}+\mathrm{Na}]^{+}$calcd. 851.5146 , found 851.5158 .

[3-Triazol-4-ylmethyl,1-( $\beta$-D-glucopyranosylaminocarbonyldecyl)-1H-1,2] 2 $\alpha, 3 \beta$-dihydroxyolean-12-en-28-oate (37). Prepared from $30(0.11 \mathrm{~g}, 0.1 \mathrm{mmol})$ according to General procedure $\mathrm{V}$. The residue was purified by column chromatography $\left(\mathrm{MeOH}-\mathrm{CH}_{2} \mathrm{Cl}_{2}, 1: 15\right)$. Yield: $0.065 \mathrm{~g}, 72 \%$, white solid, mp 163-165 ${ }^{\circ} \mathrm{C}, R_{\mathrm{f}}=0.18\left(\mathrm{MeOH}-\mathrm{CH}_{2} \mathrm{Cl}_{2}, 1: 15\right)$; $[\alpha]_{\mathrm{D}}=+33(c=0.07, \mathrm{MeOH}), \mathrm{IR}\left(\mathrm{KBr}, \mathrm{cm}^{-1}\right): 3377,2923$,

40 2861, 1725, 1053, 1032, 1015, 772; ${ }^{1} \mathrm{H}$ NMR $(300 \mathrm{MHz}$, $\left.\mathrm{C}_{5} \mathrm{D}_{5} \mathrm{~N}\right): \delta 0.79,1.04,1.10,1.18\left(4 \mathrm{~s}\right.$, each $\left.3 \mathrm{H}, 4 \times \mathrm{CH}_{3}\right)$, $0.89\left(\mathrm{~s}, 9 \mathrm{H}, 3 \times \mathrm{CH}_{3}\right), 0.79-2.30(\mathrm{~m}, 36 \mathrm{H}), 2.48(\mathrm{t}, 2 \mathrm{H}, J=$ $7.5 \mathrm{~Hz}, \mathrm{CH}_{2} \mathrm{CON}$ ), 3.12 (dd, $\left.1 \mathrm{H}, J=3.8,9.9 \mathrm{~Hz}, \mathrm{H}-18\right), 3.38$ $(\mathrm{d}, 1 \mathrm{H}, J=9.2 \mathrm{~Hz}, \mathrm{H}-3 \alpha), 4.05(\mathrm{~m}, 1 \mathrm{H}, \mathrm{H}-2 \beta), 4.07-4.51$ 5 (m, 8H, overlapping, H-1-Glc, H-2-Glc, H-4-Glc, H-5-Glc, H-6-Glc and $\left.\mathrm{NCH}_{2}\right), 5.40(\mathrm{~s}, 1 \mathrm{H}, \mathrm{H}-12), 5.54$ and 5.57 $\left(2 \mathrm{~d}\right.$, each $\left.1 \mathrm{H}, J=12.6 \mathrm{~Hz}, \mathrm{COOCH}_{2}\right), 6.03(\mathrm{t}, 1 \mathrm{H}, J=$ 9.0, 9.0 Hz, H-3-Glc), $8.12(\mathrm{~s}, 1 \mathrm{H}, \mathrm{NCH}), 9.61(\mathrm{~d}, 1 \mathrm{H}, J=$ $8.9 \mathrm{~Hz}, \mathrm{NH}) ;{ }^{13} \mathrm{C} \mathrm{NMR}\left(75 \mathrm{MHz}, \mathrm{C}_{5} \mathrm{D}_{5} \mathrm{~N}\right): \delta 17.0,17.3,17.7$, $18.9,23.4,23.9,25.95,26.0,26.8,28.0,29.3,29.4,29.6,29.66$, $29.7,30.0,30.6,30.8,32.8,33.1,34.0,36.9,38.6,39.9,41.9$, $42.1,46.1,47.0,47.8,48.1,50.3,55.9,58.2,62.8,68.6,71.9$, 74.7, 79.8, 80.1, 81.4, 83.9, 122.9, 124.7, 143.4, 144.1, 174.0, 177.4. ESI-MS (positive mode) $m / z: 943.6\left[\mathrm{M}+\mathrm{HCOO}^{+}\right.$; 55 HRMS (MALDI) $m / z=\mathrm{C}_{50} \mathrm{H}_{82} \mathrm{~N}_{4} \mathrm{O}_{10}[\mathrm{M}+\mathrm{Na}]^{+}$calcd. 921.5929, found 921.5937 .

2-[2,3-Triazol-1-yl,3ß-dihydroxyolean-12-en-28-carbonyloxy-

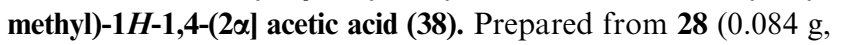

$0.09 \mathrm{mmol}$ ) according to General procedure V. The residue was purified by column chromatography $\left(\mathrm{MeOH}-\mathrm{CH}_{2} \mathrm{Cl}_{2}\right.$, $1: 10)$. Yield: $0.05 \mathrm{~g}, 91 \%$, white solid, $\mathrm{mp} 225-227{ }^{\circ} \mathrm{C}, R_{\mathrm{f}}=$ $0.06\left(\mathrm{MeOH}-\mathrm{CH}_{2} \mathrm{Cl}_{2}, 1: 15\right) ;[\alpha]_{\mathrm{D}}=+82(c=0.06, \mathrm{MeOH})$; IR $\left(\mathrm{KBr}, \mathrm{cm}^{-1}\right): 3403,2940,2862,1724,1450,1386,1229$, $1159,1050,1033 ;{ }^{1} \mathrm{H}$ NMR $\left(300 \mathrm{MHz}, \mathrm{C}_{5} \mathrm{D}_{5} \mathrm{~N}\right): \delta 0.84,1.02$, $1.07,1.13,1.17\left(5 \mathrm{~s}\right.$, each $\left.3 \mathrm{H}, 5 \times \mathrm{CH}_{3}\right), 0.87\left(\mathrm{~s}, 6 \mathrm{H}, 2 \times \mathrm{CH}_{3}\right)$, 0.84-2.22 (m, 20H), $3.12(\mathrm{dd}, 1 \mathrm{H}, J=3.7,13.5 \mathrm{~Hz}, \mathrm{H}-18)$, $3.37(\mathrm{~d}, 1 \mathrm{H}, J=9.4 \mathrm{~Hz}, \mathrm{H}-3 \alpha), 4.06-4.14(\mathrm{~m}, 1 \mathrm{H}, \mathrm{H}-2 \beta), 5.40$ (s, 1H, H-12), 5.54 (s, 2H, $\left.\mathrm{NCH}_{2} \mathrm{CO}\right), 5.64$ (s, 2H, $\mathrm{COOCH}_{2}$ ), $5.67\left(\mathrm{~s}, 2 \mathrm{H}, \mathrm{COOCH}_{2}\right), 8.45(\mathrm{~s}, 1 \mathrm{H}, \mathrm{NCH}) ;{ }^{13} \mathrm{C} \mathrm{NMR}$ $\left(75 \mathrm{MHz}, \mathrm{C}_{5} \mathrm{D}_{5} \mathrm{~N}\right): \delta 16.9,17.3,17.7,18.9,23.4,23.7,23.9$, 26.0, 28.1, 29.3, 30.0, 30.8, 32.7, 33.1, 34.0, 38.6, 39.8, 39.9, $41.9,42.1,46.1,47.0,47.8,48.1,52.3,55.9,58.2,68.6,83.9$, 122.6, 126.3, 143.5, 144.0, 177.4. ESI-MS (positive mode) $m / z$ : $634.9[\mathrm{M}+\mathrm{Na}]^{+}$; HRMS (MALDI) $m / z=\mathrm{C}_{35} \mathrm{H}_{53} \mathrm{~N}_{3} \mathrm{O}_{6}$ $[\mathrm{M}+\mathrm{Na}]^{+}$calcd. 634.3832, found 634.3845.

\section{General procedure VI for the Zemplén-deacetylation}

To a solution of an $O$-acetyl-protected compound in dry $\mathrm{MeOH} 1-2$ drops of a $\sim 1 \mathrm{M}$ methanolic $\mathrm{NaOMe}$ solution were added, and the reaction mixture was kept at $\mathrm{rt}$ until completion of the transformation (TLC, $\mathrm{CHCl}_{3}-\mathrm{MeOH}, 1: 1$ ). Amberlyst $15\left(\mathrm{H}^{+}\right.$form $)$was then added to remove sodium ions, the resin was filtered off, and the solvent removed in vacuo. If the residue was chromatographically non-uniform it was purified by column chromatography or crystallisation.

\section{General procedure VII for reduction}

An $\quad N$-( $\omega$-azidoalkanoyl)- $\beta$-D-glucopyranosyl-amine was dissolved in dry $\mathrm{MeOH}(12 \mathrm{~mL} / \mathrm{mmol})$. To the solution RANEY $^{\mathbb{R}}$-Ni ( $\left.\sim 2 \mathrm{mmol}\right)$ was added, and $\mathrm{H}_{2}$ gas was bubbled through the mixture at $70{ }^{\circ} \mathrm{C}$ until the complete transformation of the starting azide TLC $\left(\mathrm{CHCl}_{3}-\mathrm{MeOH}, 1: 1\right)$. The solution was filtered over a Celite pad and the solvent was removed in vacuo.

$\mathrm{N}$-Azidoacetyl- $\boldsymbol{\beta}$-D-glucopyranosylamine (39). Prepared from $12(0.10 \mathrm{~g}, 0.23 \mathrm{mmol})$ according to General procedure VI. The residue was purified by column chromatography $\left(\mathrm{CHCl}_{3}-\mathrm{MeOH}, 7: 3\right)$. Yield: $0.058 \mathrm{~g}, 95 \%$, colourless oil, $R_{\mathrm{f}}=0.34\left(\mathrm{CHCl}_{3}-\mathrm{MeOH}, 7: 3\right) ;[\alpha]_{\mathrm{D}}=-12(c=0.22$, $\mathrm{MeOH})$, (lit. $\left.^{40}[\alpha]_{\mathrm{D}}=-61\left(c=1, \mathrm{H}_{2} \mathrm{O}\right)\right) ;{ }^{1} \mathrm{H}$ NMR (360 MHz, CD $3 \mathrm{OD}): \delta(\mathrm{ppm})$ 3.29-3.37 (m, 3H, H-3, H-4, $\mathrm{H}-5), 3.44$ (t, $1 \mathrm{H}, J=9.2,9.2 \mathrm{~Hz}, \mathrm{H}-2), 3.68(\mathrm{dd}, 1 \mathrm{H}, J=4.0$, $11.9 \mathrm{~Hz}, \mathrm{H}-6 \mathrm{~b}), 3.83-3.99$ (m, 3H, $\left.\mathrm{CH}_{2}, \mathrm{H}-6 \mathrm{a}\right), 4.95$ (d, $1 \mathrm{H}$, $J=9.2 \mathrm{~Hz}, \mathrm{H}-1) .{ }^{13} \mathrm{C} \mathrm{NMR}\left(90 \mathrm{MHz}, \mathrm{D}_{2} \mathrm{O}\right): \delta(\mathrm{ppm}) 52.8$ $\left(\mathrm{CH}_{2}\right), 62.6$ (C-6), 71.2, 73.8, 78.8, 79.7 (C-2, C-3, C-4, C-5), $81.0(\mathrm{C}-1), 171.3(\mathrm{CONH})$. Analysis: Calcd for $\mathrm{C}_{8} \mathrm{H}_{14} \mathrm{~N}_{4} \mathrm{O}_{6}$ (262.22): C, 36.64; H, 5.38; N, 21.37. Found: C, 36.73; H, 5.42; $\mathrm{N}, 21.25$.

N-Glycyl- $\beta$-D-glucopyranosylamine (40). Prepared from 39 $(0.097 \mathrm{~g}, 0.37 \mathrm{mmol})$ according to General procedure VII. Yield: $0.07 \mathrm{~g}, 79 \%$, amorphous oil, $R_{\mathrm{f}}=0.16(\mathrm{MeOH}) ;[\alpha]_{\mathrm{D}}=$ $+34\left(c=0.08\right.$, DMSO); ${ }^{1} \mathrm{H}$ NMR $\left(360 \mathrm{MHz}, \mathrm{CD}_{3} \mathrm{OD}\right)$ : $\delta(\mathrm{ppm}) 3.48-3.61$ (m, 6H, H-2, H-3, H-4, H-5, $\left.\mathrm{CH}_{2}\right), 3.76$ (dd, $1 \mathrm{H}, J=5.3,11.9 \mathrm{~Hz}, \mathrm{H}-6 \mathrm{a}), 3.90(\mathrm{dd}, 1 \mathrm{H}, J=1.2,11.9 \mathrm{~Hz}$, $\mathrm{H}-6 \mathrm{~b}), 5.04$ (d, 1H, $J=9.2 \mathrm{~Hz}, \mathrm{H}-1) .{ }^{13} \mathrm{C} \mathrm{NMR}(90 \mathrm{MHz}$, 
$\left.1 \mathrm{D}_{2} \mathrm{O}\right): \delta(\mathrm{ppm}) 44.1\left(\mathrm{CH}_{2}\right), 62.6(\mathrm{C}-6), 69.8,72.4,77.1,78.2$ (C-2, C-3, C-4, C-5), 79.9 (C-1), 176.5 (CONH). Analysis: Calcd for $\mathrm{C}_{8} \mathrm{H}_{16} \mathrm{~N}_{2} \mathrm{O}_{6}$ (236.22): C, 40.68; H, 6.83; N, 11.86. Found: C, 40.75; H, 6.68; N, 11.79.

$\boldsymbol{N}$-(6-Azidohexanoyl)- $\boldsymbol{\beta}$-D-glucopyranosylamine (41). Prepared from $13(0.50 \mathrm{~g}, 1.03 \mathrm{mmol})$ according to General procedure VI. The residue was purified by column chromatography $\left(\mathrm{CHCl}_{3}-\mathrm{MeOH}, 7: 3\right)$. Yield: $0.31 \mathrm{~g}(97 \%)$ colourless oil, $10 R_{\mathrm{f}}=0.66\left(\mathrm{CHCl}_{3}-\mathrm{MeOH}, 7: 3\right) ;[\alpha]_{\mathrm{D}}=+13(c=0.22$, $\mathrm{MeOH}) ;{ }^{1} \mathrm{H}$ NMR (360 MHz, MeOD): $\delta(\mathrm{ppm}) 1.42-1.49(\mathrm{~m}$, $\left.2 \mathrm{H}, \mathrm{CH}_{2}\right), 1.60-1.72\left(\mathrm{~m}, 4 \mathrm{H}, \mathrm{CH}_{2}\right), 2.25-2.32\left(\mathrm{~m}, 2 \mathrm{H}, \mathrm{CH}_{2}\right)$, 3.36-3.24 (m, 5H, H-3, H-4, H-5, $\mathrm{CH}_{2}$ ), 3.44 (pseudo t, $1 \mathrm{H}$, $J=7.9,9.2 \mathrm{~Hz}, \mathrm{H}-2), 3.69(\mathrm{dd}, 1 \mathrm{H}, J=5.3,11.9 \mathrm{~Hz}, \mathrm{H}-6 \mathrm{~b})$, $13.85(\mathrm{dd}, 1 \mathrm{H}, J=1.2,11.9 \mathrm{~Hz}, \mathrm{H}-6 \mathrm{a}), 4.92(\mathrm{~d}, 1 \mathrm{H}, J=7.9 \mathrm{~Hz}$, $\mathrm{H}-1) ;{ }^{13} \mathrm{C}$ NMR (90 MHz, MeOD): $\delta$ (ppm) 26.0, 27.4, 29.6, 36.9, $52.3\left(5 \times \mathrm{CH}_{2}\right), 62.6(\mathrm{C}-6), 71.4,73.9,79.0,79.5(\mathrm{C}-2$, C-3, C-4, C-5), 80.9 (C-1), 177.0 (NHCO); Anal. calcd. for $\mathrm{C}_{12} \mathrm{H}_{22} \mathrm{~N}_{4} \mathrm{O}_{6}$ (318.33): $\mathrm{C}$ 45.28, $\mathrm{H}$ 6.97, $\mathrm{N}$ 17.60. Found: $20 \mathrm{C} 45.36, \mathrm{H} 6.84, \mathrm{~N} 17.49$.

$\boldsymbol{N}$-(6-Aminohexanoyl)-p-D-glucopyranosylamine (42). Prepared from $41(0.18 \mathrm{~g} 0.57 \mathrm{mmol})$ according to General procedure VII. Yield: $0.09 \mathrm{~g}(57 \%)$ colourless oil, $R_{\mathrm{f}}=0.05(\mathrm{MeOH})$; $[\alpha]_{\mathrm{D}}=+11(c=0.15, \mathrm{MeOH}) ;{ }^{1} \mathrm{H} \mathrm{NMR}(360 \mathrm{MHz}, \mathrm{MeOD})$ : $\delta(\mathrm{ppm}) 1.34-1.38\left(\mathrm{~m}, 2 \mathrm{H}, \mathrm{CH}_{2}\right), 1.47-1.51\left(\mathrm{~m}, 2 \mathrm{H}, \mathrm{CH}_{2}\right)$, 1.60-1.64 (m, 2H, $\left.\mathrm{CH}_{2}\right), 2.21-2.27\left(\mathrm{~m}, 2 \mathrm{H}, \mathrm{CH}_{2}\right), 2.62-2.68$ (m, 2H, $\mathrm{CH}_{2}$ ), 3.23-3.35 (m, 3H, H-3, H-4,H-5), 3.38 (t, 1H, $J=7.9,7.9 \mathrm{~Hz}, \mathrm{H}-2), 3.62(\mathrm{dd}, 1 \mathrm{H}, J=5.3,11.9 \mathrm{~Hz}, \mathrm{H}-6 \mathrm{a})$, $3.81(\mathrm{dd}, 1 \mathrm{H}, J=1.2,11.9 \mathrm{~Hz}, \mathrm{H}-6 \mathrm{a}), 4.84(\mathrm{~d}, 1 \mathrm{H}, J=7.9 \mathrm{~Hz}$, $\mathrm{H}-1) ;{ }^{13} \mathrm{C}$ NMR (MeOD, $90 \mathrm{MHz}$ ): $\delta$ (ppm) 26.2, 27.4, 32.4, $36.9,41.9\left(5 \times \mathrm{CH}_{2}\right), 62.7(\mathrm{C}-6), 71.4,73.9,79.0,79.7$ (C-2, C-3, C-4, C-5), 81.0 (C-1), 177.2 (NHCO). Anal. calcd. for $\mathrm{C}_{12} \mathrm{H}_{24} \mathrm{~N}_{4} \mathrm{O}_{6}$ (292.33): C 49.30, $\mathrm{H}$ 8.28, N 9.58. Found: 35 C 49.36, H 8.18, N 9.45.

1,4-Bis-[1-(2,6-tetra- $O$-acetyl- $\beta$-D-glucopyranosylaminocarbonylmethyl)-1H-1,3-triazol-4-yl)|butane (44). Prepared from 12 ( $0.30 \mathrm{~g} 0.41 \mathrm{mmol})$ according to General procedure IVb. The residue was purified by column chromatography (EtOAc).

40 Yield: $0.10 \mathrm{~g}, 89 \%$, white crystalline product, mp 197-199 ${ }^{\circ} \mathrm{C}$, $[\alpha]_{\mathrm{D}}=+35(c=0.20$, DMSO $) ;{ }^{1} \mathrm{H} \mathrm{NMR}(360 \mathrm{MHz}$, DMSO-d $\left.{ }_{6}\right): \delta(\mathrm{ppm}) 1.64$ (brs, 4H, $\left.2 \times \mathrm{CH}_{2}\right), 1.93,1.95$, $1.99,2.00\left(4 \mathrm{~s}, 24 \mathrm{H}, 8 \times \mathrm{OCOCH}_{3}\right), 2.65$ (brs, $\left.4 \mathrm{H}, 2 \times \mathrm{CH}_{2}\right)$, 3.96-4.16 (m, 6H, $2 \times \mathrm{H}-5-G l c, 2 \times \mathrm{H}-6 \mathrm{a}-\mathrm{Glc}, 2 \times$

45 H-6b-Glc), 5.07 (brs, 4H, $2 \times \mathrm{CH}_{2}$ ), 4.86, 4.92, 5.34, 5.42 $(4 \mathrm{t}, 8 \mathrm{H}, J=9.2,9.2 \mathrm{~Hz}$ in each, $2 \mathrm{H}-1-\mathrm{Glc}, 2 \times \mathrm{H}-2-\mathrm{Glc}, 2 \times$ H-3-Glc, $2 \times \mathrm{H}-4-\mathrm{Glc}), 7.78(\mathrm{~s}, 2 \mathrm{H}, 2$ triazole $\mathrm{CH}), 9.20$ $(\mathrm{d}, 2 \mathrm{H}, J=9.2 \mathrm{~Hz}, 2 \times \mathrm{NH}) ;{ }^{13} \mathrm{C} \mathrm{NMR}\left(90 \mathrm{MHz}, \mathrm{DMSO}-\mathrm{d}_{6}\right)$ : $\delta(\mathrm{ppm}) 20.3,20.5,\left(8 \times \mathrm{OCOCH}_{3}\right), 24.7,28.4,51.3\left(6 \times \mathrm{CH}_{2}\right)$,

$5061.6(2 \times$ C-6-Glc), 67.7, 70.5, 72.1, 72.7 (2 C-2-Glc, $2 \times$ C-3-Glc, $2 \times$ C-4-Glc, $2 \times$ C-5-Glc), $76.8(2 \times$ C-1-Glc), 123.4 (2 triazole $\mathrm{C}-5), 146.4(2$ triazole $\mathrm{C}-4), 166.4(2 \times \mathrm{CONH})$, 169.2, 169.3, 169.5, $170.0\left(8 \times \mathrm{OCOCH}_{3}\right)$. Anal. calcd. for $\mathrm{C}_{40} \mathrm{H}_{54} \mathrm{~N}_{8} \mathrm{O}_{20}$ (966.92): C, 49.69; H, 5.63; N, 11.59; Found: C, 55 49.59; H, 5.71; N, 11.67.

1,4-Bis-[1-(2,6-tetra- $O$-acetyl- $\beta$-D-glucopyranosylaminocarbonylpentyl)-1H-1,3-triazol-4-yl)|butane (45). Prepared from 13 $(0.20 \mathrm{~g}, 0.41 \mathrm{mmol})$ according to General procedure IVb.
The residue purified by column chromatography (EtOAc$\mathrm{MeOH}, 95: 5)$. Yield: $0.21 \mathrm{~g}, 96 \%$, colourless oil, $R_{\mathrm{f}}=0.32$ $($ EtOAc $) ;[\alpha]_{\mathrm{D}}=+16\left(c=0.16, \mathrm{CHCl}_{3}\right) ;{ }^{1} \mathrm{H}$ NMR $(360$ $\left.\mathrm{MHz}, \mathrm{CDCl}_{3}\right)$ : $\delta(\mathrm{ppm}) 1.16-1.30\left(\mathrm{~m}, 4 \mathrm{H}, 2 \times \mathrm{CH}_{2}\right), 1.62-1.74$ $\left(\mathrm{m}, 4 \mathrm{H}, 2 \times \mathrm{CH}_{2}\right), 1.85-1.91\left(\mathrm{~m}, 4 \mathrm{H}, 2 \times \mathrm{CH}_{2}\right), 2.01,2.03$, $2.04,2.07\left(4 \mathrm{~s}, 24 \mathrm{H}, 8 \times \mathrm{OCOCH}_{3}\right), 2.18-2.22(\mathrm{~m}, 4 \mathrm{H}, 2 \times$ $\left.\mathrm{CH}_{2}\right), 2.52-2.56\left(\mathrm{~m}, 2 \mathrm{H}, \mathrm{CH}_{2}\right), 2.72-2.76\left(\mathrm{~m}, 4 \mathrm{H}, 2 \times \mathrm{CH}_{2}\right)$, 3.84 (ddd, $2 \mathrm{H}, J=1.1,2.6,10.6 \mathrm{~Hz}, 2 \times \mathrm{H}-5-\mathrm{Glc}$ ), 4.13-4.07 $\left(\mathrm{m}, 4 \mathrm{H}, 2 \times \mathrm{CH}_{2}\right), 4.27-4.31(\mathrm{~m}, 6 \mathrm{H}, 2 \times \mathrm{H}-6 \mathrm{a}-\mathrm{Glc}, 2 \times$ H-6b-Glc, $\mathrm{CH}_{2}$ ), 5.28, 5.24, 5.06, 4.93 (4 pseudo t, 8H, $J=$ 9.2, 10.6 Hz in each, $2 \times \mathrm{H}-1-G l c, 2 \times \mathrm{H}-2-G l c, 2 \times \mathrm{H}-3-G l c$, $2 \times \mathrm{H}-4-\mathrm{Glc}), 6.57(\mathrm{~d}, 2 \mathrm{H}, J=7.9 \mathrm{~Hz}, 2 \times \mathrm{NH}), 7.34(\mathrm{~s}, 2 \mathrm{H}$, 2 triazole $\mathrm{CH}) ;{ }^{13} \mathrm{C} \mathrm{NMR}\left(90 \mathrm{MHz}, \mathrm{CDCl}_{3}\right): \delta(\mathrm{ppm}) 20.3$, $20.4,\left(8 \times \mathrm{OCOCH}_{3}\right), 24.1,25.1,25.7,28.6,29.7,35.7,49.5$ $\left(14 \times \mathrm{CH}_{2}\right), 61.6(2 \times \mathrm{C}-6-\mathrm{Glc}), 68.0,70.4,72.7,73.3(2 \times$ C-2-Glc, $2 \times$ C-3-Glc, $2 \times$ C-4-Glc, $2 \times$ C-5-Glc), $77.8(2 \times$ C-1-Glc), 120.6 (2 triazole C-5), 147.7 (2 triazole C-4), 169.4, 169.6, 170.0, $170.4\left(8 \times \mathrm{OCOCH}_{3}\right), 172.9(2 \times \mathrm{NHCO})$. Anal. calcd. for $\mathrm{C}_{48} \mathrm{H}_{70} \mathrm{~N}_{8} \mathrm{O}_{20}$ (1079.13): C 53.43, H 6.54, N 10.38. Found: C 53.49, H 6.62, N 10.45.

1,4-Bis-[1-(2,6-tetra- $O$-acetyl- $\beta$-D-glucopyranosylaminocarbonyldecyl)-1H-1,3-triazol-4-yl)|butane (46). Prepared from 14 ( $0.20 \mathrm{~g} 0.36 \mathrm{mmol})$ according to General procedure IVb. The residue purified by column chromatography (EtOAc). Yield: $0.136 \mathrm{~g}, 62 \%$, colourless oil; $[\alpha]_{\mathrm{D}}=+7\left(c=0.62, \mathrm{CHCl}_{3}\right) ;{ }^{1} \mathrm{H}$ $\mathrm{NMR}\left(\mathrm{CDCl}_{3}, 90 \mathrm{MHz}\right): \delta(\mathrm{ppm}) 1.26$ (brs, $\left.24 \mathrm{H}, 12 \times \mathrm{CH}_{2}\right)$, 1.56-1.59(m, 4H, $\left.2 \times \mathrm{CH}_{2}\right), 1.73-1.78\left(\mathrm{~m}, 4 \mathrm{H}, 2 \times \mathrm{CH}_{2}\right)$, 1.85-1.89 (m, 4H, $\left.2 \times \mathrm{CH}_{2}\right), 2.02,2.03,2.04,2.08(4 \mathrm{~s}, 24 \mathrm{H}$, $\left.8 \times \mathrm{OCOCH}_{3}\right), 2.10-2.25\left(\mathrm{~m}, 4 \mathrm{H}, 2 \times \mathrm{CH}_{2}\right), 2.73-2.76(\mathrm{~m}, 4 \mathrm{H}$, $\left.2 \times \mathrm{CH}_{2}\right), 3.83(\mathrm{~m}, 2 \mathrm{H}, J=2.4,4.3,9.9 \mathrm{~Hz}, 2 \times \mathrm{H}-5-\mathrm{Glc}), 4.08$ $(\mathrm{dd}, 2 \mathrm{H}, J=2.3,12.3 \mathrm{~Hz}, 2 \times \mathrm{H}-6 \mathrm{~b}-\mathrm{Glc}), 4.27-4.34(\mathrm{~m}, 6 \mathrm{H}, 2$ $\times$ H-6a-Glc, $2 \times \mathrm{CH}_{2}$ ), 4.93, 5.06, 5.27, 5.31 (4 pseudo t, $8 \mathrm{H}$, $J=9.6,9.9 \mathrm{~Hz}$ in each, $2 \times \mathrm{H}-1-\mathrm{Glc}, 2 \times \mathrm{H}-2-\mathrm{Glc}, 2 \times \mathrm{H}-3-$ Glc, $2 \times \mathrm{H}-4-\mathrm{Glc}), 6.42(\mathrm{~d}, 2 \mathrm{H}, J=9.2 \mathrm{~Hz}, 2 \times \mathrm{NH}), 7.28$ (s, 2H, 2 triazole $\mathrm{CH}) ;{ }^{13} \mathrm{C} \mathrm{NMR}\left(90 \mathrm{MHz}, \mathrm{CDCl}_{3}\right): \delta(\mathrm{ppm})$ 20.4, 20.5, $20.6\left(8 \times \mathrm{OCOCH}_{3}\right), 25.0,25.3,26.3,28.7,28.8$, $28.9,29.0,29.1,29.2,29.6,30.2,50.0,\left(24 \times \mathrm{CH}_{2}\right), 61.6(2 \times$ C-6-Glc), 68.1, 70.5, 72.6, 73.4 (2 C-2-Glc, $2 \times$ C-3-Glc, $2 \times$ C-4-Glc, $2 \times$ C-5-Glc), $78.0(2 \times$ C-1-Glc $), 120.4(2$ triazole C-5), 147.8 (2 triazole C-4), 169.5, 169.8, 170.5, $170.8(8 \times$ $\left.\mathrm{OCOCH}_{3}\right), 173.4(2 \times \mathrm{CONH})$. Anal. calcd. for $\mathrm{C}_{58} \mathrm{H}_{90} \mathrm{~N}_{8} \mathrm{O}_{20}$ (1219.38): C, 57.13; H, 7.44; N, 9.19; Found: C, 57.22; H, 7.32; N, 9.30 .

1,4-Bis-[1-(2,6-tetra- $O$-acetyl- $\beta$-D-glucopyranosylaminocarbonylpentadecyl)-1 $\boldsymbol{H}$-1,3-triazol-4-yl)|butane (47). Prepared from 15 (0.30 g $0.41 \mathrm{mmol})$ according to General procedure IV. The residue purified by column chromatography (EtOAc). Yield: $0.28 \mathrm{~g}, 50 \%$, white crystalline product, $\mathrm{mp} 144-146{ }^{\circ} \mathrm{C} ;[\alpha]_{\mathrm{D}}=$ $+14\left(c=0.24, \mathrm{CHCl}_{3}\right) ;{ }^{1} \mathrm{H} \mathrm{NMR}\left(360 \mathrm{MHz}, \mathrm{CDCl}_{3}\right): \delta(\mathrm{ppm})$ $1.20-1.35\left(\mathrm{~m}, 26 \mathrm{H}, 13 \mathrm{CH}_{2}\right), 1.40-1.50\left(\mathrm{~m}, 8 \mathrm{H}, 2 \times \mathrm{CH}_{2}\right)$, $1.60-1.77\left(\mathrm{~m}, 8 \mathrm{H}, 2 \times \mathrm{CH}_{2}\right), 1.82-1.90\left(\mathrm{~m}, 8 \mathrm{H}, 2 \times \mathrm{CH}_{2}\right), 2.02$, $2.03,2.05,2.06\left(4 \mathrm{~s}, 24 \mathrm{H}, 8 \times \mathrm{OCOCH}_{3}\right), 2.32-2.27(\mathrm{~m}, 2 \mathrm{H}$, $\left.\mathrm{CH}_{2}\right), 2.60-2.52\left(\mathrm{~m}, 4 \mathrm{H}, 2 \times \mathrm{CH}_{2}\right), 2.73-2.80\left(\mathrm{~m}, 2 \mathrm{H}, \mathrm{CH}_{2}\right)$, 3.70 (ddd, $2 \mathrm{H}, J=1.1,2.6,10.6 \mathrm{~Hz}, 2 \times \mathrm{H}-5-\mathrm{Glc}), 4.11-4.20$ (m, 8H, $4 \mathrm{CH}_{2}$ ), 4.37-4.44 (m, 4H, $\left.2 \times \mathrm{H}-6 \mathrm{a}-\mathrm{Glc}, 2 \times \mathrm{H}-6 \mathrm{~b}-\mathrm{Glc}\right)$, 4.94, 5.00, 5.11, 5.19 (4 pseudo t, $8 \mathrm{H}, J=9.2,10.6 \mathrm{~Hz}$ in each, $2 \times \mathrm{H}-1-\mathrm{Glc}, 2 \times \mathrm{H}-2-\mathrm{Glc}, 2 \times \mathrm{H}-3-\mathrm{Glc}, 2 \times \mathrm{H}-4-\mathrm{Glc})$, 
$6.73(\mathrm{~d}, 2 \mathrm{H}, J=7.9 \mathrm{~Hz}, 2 \mathrm{NH}), 7.34(\mathrm{~s}, 2 \mathrm{H}, 2$ triazole $\mathrm{CH}) ;{ }^{13} \mathrm{C}$ NMR $\left(90 \mathrm{MHz}, \mathrm{CDCl}_{3}\right): \delta(\mathrm{ppm}) 20.4,20.5\left(8 \times \mathrm{OCOCH}_{3}\right)$. $22.1,22.5,23.0,23.6,24.8,25.1,25.8,26.1,26.6,27.0,27.5$, $29.8,30.7,31.7,35.7,36.7,50.1\left(32 \times \mathrm{CH}_{2}\right), 60.6(2 \times$ 5 C-6-Glc), 69.3, 71.0, 72.0, $72.8(2 \times$ C-2-Glc, $2 \times$ C-3-Glc, $2 \times$ C-4-Clc, $2 \times C-5-G l c), 77.6(2 \times$ C-1-Glc), 121.0 (2 triazole C-5), 146.6 (2 triazole C-4), 169.4, 169.6, 169.9, $170.1(8 \times$ $\left.\mathrm{OCOCH}_{3}\right), 171.8(2 \times \mathrm{HHCO})$. Anal. calcd. for $\mathrm{C}_{68} \mathrm{H}_{110} \mathrm{~N}_{8} \mathrm{O}_{20}$ (1359.68): C, 60.07; H, 8.15; N, 8.24; Found: C, 60.16; H, 8.22; $10 \mathrm{~N}, 8.33$.

1,4-Bis-[1-( $\beta$-D-glucopyranosylaminocarbonylmethyl)-1 H-1,3Q10 triazol-4-yl),2]butane (48). Prepared from $44(0.10 \mathrm{~g}, 0.10 \mathrm{mmol})$ according to General procedure VI. Yield: $0.042 \mathrm{~g}, 65 \%$, 5 white crystalline product, $\operatorname{mp} 235-236{ }^{\circ} \mathrm{C},[\alpha]_{\mathrm{D}}=42$ $(c=0.22, \mathrm{DMSO}) ;{ }^{1} \mathrm{H}$ NMR $\left(360 \mathrm{MHz}, \mathrm{D}_{2} \mathrm{O}\right): \delta(\mathrm{ppm}) 1.64$ (brs, $4 \mathrm{H}, 2 \times \mathrm{CH}_{2}$ ), 2.70 (brs, $\left.4 \mathrm{H}, 2 \times \mathrm{CH}_{2}\right), 3.39-3.57(8 \mathrm{H}, \mathrm{m}$, $2 \times$ H-2-Glc, $2 \times$ H-3-Glc, $2 \times$ H-4-Glc, $2 \times$ H-5-Glc), 3.71 $(\mathrm{dd}, 2 \mathrm{H}, J=5.311 .9 \mathrm{~Hz}, 2 \times \mathrm{H}-6 \mathrm{~b}-\mathrm{Glc}), 5.01(\mathrm{~d}, 2 \mathrm{H}, J=9.2 \mathrm{~Hz}$, $202 \times \mathrm{H}-1-\mathrm{Glc}), 3.85(\mathrm{dd}, 2 \mathrm{H}, J=<1,11.9 \mathrm{~Hz}, 2 \times \mathrm{H}-6 \mathrm{a}-$ Glc), 5.24-5.27 (s, 4H, $\left.2 \times \mathrm{CH}_{2}\right), 7.73(\mathrm{~s}, 2 \mathrm{H}$, triazole $\mathrm{CH}) ;{ }^{13} \mathrm{C}$ NMR $(90 \mathrm{MHz}$, DMSO-d 6$): \delta(\mathrm{ppm}) 24.7,28.4,51.5(6 \times$ $\left.\mathrm{CH}_{2}\right), 60.8(2 \times \mathrm{C}-6-\mathrm{Glc}), 69.9,72.6,77.3,78.7(2 \times \mathrm{C}-2-\mathrm{Glc}$, $2 \times$ C-3-Glc, $2 \times$ C-4-Glc, $2 \times$ C-5-Glc), $79.7(2 \times$ C-1-Glc $)$, 25123.5 (2 triazole C-5), 146.5 (2 triazole C-4), $166.1(2 \times$ CONH). Anal. calcd. for $\mathrm{C}_{24} \mathrm{H}_{38} \mathrm{~N}_{8} \mathrm{O}_{12}$ (630.62): C, 45.71; H, 6.07; N, 17.77; Found: C, 45.80; H, 5.97; N, 17.54.

1,4-Bis-[1-( $\beta$-D-glucopyranosylaminocarbonylpentyl)-1 $\boldsymbol{H}$-1,3triazol-4-yl),2]butane (49). Prepared from 45 (0.21 g 0.19 $30 \mathrm{mmol}$ ) according to General procedure VI. Yield: $0.09 \mathrm{~g}$, $66 \%$, white crystalline product, $\mathrm{mp}: 150-152{ }^{\circ} \mathrm{C} ;[\alpha]_{\mathrm{D}}=$ $+14(c=0.12, \mathrm{MeOH}) ;{ }^{1} \mathrm{H}$ NMR $\left(360 \mathrm{MHz}, \mathrm{D}_{2} \mathrm{O}\right): \delta(\mathrm{ppm})$ $1.20-1.25\left(\mathrm{~m}, 4 \mathrm{H}, 2 \times \mathrm{CH}_{2}\right), 1.52-1.64\left(\mathrm{~m}, 8 \mathrm{H}, 4 \times \mathrm{CH}_{2}\right)$, 1.80-1.88(m, 4H, $\left.2 \times \mathrm{CH}_{2}\right), 2.22-2.28\left(\mathrm{~m}, 4 \mathrm{H}, 2 \times \mathrm{CH}_{2}\right)$, $352.66-2.70\left(\mathrm{~m}, 4 \mathrm{H}, 2 \times \mathrm{CH}_{2}\right), 3.33-3.42(\mathrm{~m}, 6 \mathrm{H}, 2 \times \mathrm{H}-3-\mathrm{Glc}$, $\left.2 \times \mathrm{H}-4-\mathrm{Glc}, \mathrm{CH}_{2}\right), 3.50(\mathrm{ddd}, 2 \mathrm{H}, J=1.2,5.3,9.2 \mathrm{~Hz}, 2 \times$ H-5-Glc), 3.52 (t, 2H, $J=9.2,9.2 \mathrm{~Hz}, 2 \times \mathrm{H}-2-\mathrm{Glc}), 3.70$ $(\mathrm{dd}, 2 \mathrm{H}, J=5.3,11.9 \mathrm{~Hz}, 2 \times \mathrm{H}-6 \mathrm{~b}-\mathrm{Glc}), 3.85(\mathrm{dd}, 2 \mathrm{H}, J=$ 1.2, 11.9 Hz, $2 \times \mathrm{H}-6 \mathrm{a}-\mathrm{Glc}), 4.31-4.37$ (m, $\left.4 \mathrm{H}, 2 \times \mathrm{CH}_{2}\right), 4.91$

$40(\mathrm{~d}, 2 \mathrm{H}, J=9.2 \mathrm{~Hz}, 2 \times \mathrm{H}-1-\mathrm{Glc}), 7.82(\mathrm{~s}, 2 \mathrm{H}, 2$ triazole $\mathrm{CH})$; ${ }^{13} \mathrm{C}$ NMR (90 MHz, $\left.\mathrm{D}_{2} \mathrm{O}\right): \delta$ (ppm) 24.0, 24.1, 25.2, 27.8, 29.1, 35.6, $50.4\left(14 \times \mathrm{CH}_{2}\right), 60.7$ (2 xC-6-Glc) 69.4, 71.9, 76.7, 77.7 $(2 \times$ C-2-Glc, $2 \times$ C-3-Glc, $2 \times$ C-4-Glc, $2 \times$ C-5-Glc), 79.4 (2x C-1-Glc), 123.8 (2 triazole C-5), 146.2 (2 triazole C-4), $178.1(2 \times \mathrm{NHCO})$. Anal. calcd. for $\mathrm{C}_{32} \mathrm{H}_{54} \mathrm{~N}_{8} \mathrm{O}_{12}$ (742.83): $\mathrm{C}$ 51.74, H 7.33, N 15.08. Found: C 51.69, H 7.25, N 15.02.

1,4-Bis-[1-( $\beta$-D-glucopyranosylaminocarbonyldecyl)-1 $\mathrm{H}$-1,3triazol-4-yl),2]butane (50). Prepared from 46 (0.07 g, $0.06 \mathrm{mmol})$

50 according to General procedure VI. Precipitated from the reaction mixture. Yield: $0.048 \mathrm{~g}, 95 \%$, white amorphous product; $[\alpha]_{\mathrm{D}}=+16(c=0.37$, DMSO $) ;{ }^{1} \mathrm{H}$ NMR $\left(360 \mathrm{MHz}, \mathrm{DMSO}-\mathrm{d}_{6}+\mathrm{D}_{2} \mathrm{O}\right): \delta(\mathrm{ppm}) 1.20$ (brs, $24 \mathrm{H}, 12 \times$ $\left.\mathrm{CH}_{2}\right), 1.45,1.60,1.75,2.06,2.60$ (5 brs, 20H, $10 \times \mathrm{CH}_{2}$ ), $553.00-3.19$ (m, 8H, $2 \times \mathrm{H}-2-G l c, 2 \times \mathrm{H}-3-G l c, 2 \times \mathrm{H}-4-G l c, 2 \times$ H-5-Glc), 3.38 (dd, 2H, $J=4.6,11.6 \mathrm{~Hz}, 2 \times \mathrm{H}-6 \mathrm{~b}-\mathrm{Glc}), 3.61$ (dd, $2 \mathrm{H}, J<1.0,11.2 \mathrm{~Hz}, 2 \times \mathrm{H}-6 \mathrm{a}-\mathrm{Glc}), 4.23-4.27(\mathrm{~m}, 4 \mathrm{H}$, $\left.2 \times \mathrm{CH}_{2}\right), 4.68(\mathrm{~d}, 2 \mathrm{H}, J=8.9 \mathrm{~Hz}, 2 \times \mathrm{H}-1-\mathrm{Glc}), 7.80(\mathrm{~s}, 2 \mathrm{H}$, 2 triazole $\mathrm{CH}) ;{ }^{13} \mathrm{C}$ NMR $\left(90 \mathrm{MHz}, \mathrm{DMSO}-\mathrm{d}_{6}+\mathrm{D}_{2} \mathrm{O}\right)$ : $\delta(\mathrm{ppm}) 24.8,25.0,25.9,28.4,28.5,28.9,29.7,35.5,49.2$ $\left(24 \times \mathrm{CH}_{2}\right), 60.9(2 \times \mathrm{C}-6-\mathrm{Glc}), 69.9,72.3,77.4,78.4(2 \times$ C-2-Glc, $2 \times$ C-3-Glc, $2 \times$ C-4-Glc, 2x C-5-Glc), $79.4(2 \times$ C-1-Glc), 121.7 (2 triazole C-5), 146.8 (2 triazole C-4), 173.0 $(2 \times C \mathrm{ONH})$. Anal. calcd. for $\mathrm{C}_{42} \mathrm{H}_{74} \mathrm{~N}_{8} \mathrm{O}_{12}$ (883.08): C, 57.12; H, 8.45; N, 12.69; Found: C, 57.23; H, 8.56; N, 12.58 .

1,4-Bis-[1-( $\beta$-D-glucopyranosylaminocarbonylpentadecyl)1H-1,2,3-triazol-4-yl),2]butane (51). Prepared from 47 (0.2 g, $0.147 \mathrm{mmol}$ ) according to General procedure VI. Yield: $0.12 \mathrm{~g}$, $80 \%$, white crystalline product, $\mathrm{mp} 158-160{ }^{\circ} \mathrm{C} ;[\alpha]_{\mathrm{D}}=+25$ $(c=0.20, \mathrm{MeOH}) ;{ }^{1} \mathrm{H}$ NMR $\left(360 \mathrm{MHz}, \mathrm{D}_{2} \mathrm{O}\right): \delta(\mathrm{ppm})$ 1.19-1.32 (m, 30H, $\left.15 \times \mathrm{CH}_{2}\right), 1.49-1.70\left(\mathrm{~m}, 4 \mathrm{H}, 2 \times \mathrm{CH}_{2}\right)$, 1.91-1.98 (m, 4H, $\left.2 \times \mathrm{CH}_{2}\right), 2.18-2.38\left(\mathrm{~m}, 8 \mathrm{H}, 4 \times \mathrm{CH}_{2}\right)$, 2.51-2.90 (m, 20H, $\left.10 \times \mathrm{CH}_{2}\right), 3.32-3.39$ (m, 4H, $2 \times \mathrm{H}-3-\mathrm{Glc}$, 2x H-4-Glc), 3.45 (ddd, $2 \mathrm{H}, J=1.2,5.3,9.2 \mathrm{~Hz}, 2 \times \mathrm{H}-5-\mathrm{Glc}$ ), $3.49(\mathrm{t}, 2 \mathrm{H}, J=9.2,9.2 \mathrm{~Hz}, 2 \mathrm{x} \mathrm{H}-2-\mathrm{Glc}), 3.79$ (dd, $2 \mathrm{H}, J=$ $5.3,11.9 \mathrm{~Hz}, 2 \times \mathrm{H}-6 \mathrm{~b}-\mathrm{Glc}), 3.87(2 \mathrm{H}, \mathrm{dd}, J=1.2,11.9 \mathrm{~Hz}, 2 \mathrm{x}$ H-6a-Glc), 4.41-4.47 (m, 4H, $\left.2 \times \mathrm{CH}_{2}\right), 5.01(\mathrm{~d}, 2 \mathrm{H}, J=$ $9.2 \mathrm{~Hz}, 2 \times \mathrm{H}-1-\mathrm{Glc}), 7.67$ (s, $2 \mathrm{H}, 2$ triazole $\mathrm{CH}) ;{ }^{13} \mathrm{C} \mathrm{NMR}$ (90 MHz, D $\left.\mathrm{D}_{2} \mathrm{O}\right): \delta$ (ppm) 21.7, 22.9, 23.3, 24.1, 24.8, 25.3, 25.8, 27.1, 27.6, 28.1, 29.5, 31.2, 32.0, 33.1, 36.7, 37.4, $51.2(34 \times$ $\left.\mathrm{CH}_{2}\right), 61.5(2 \times \mathrm{C}-6-\mathrm{Glc}), 69.0,72.1,76.3,77.3(2 \times \mathrm{C}-2-\mathrm{Glc}$, $2 \times$ C-3-Glc, $2 \times$ C-4-Glc, $2 \times$ C-5-Glc), $78.1(2 \times$ C-1-Glc $)$, 121.5 (2 triazole C-5), 146.5 (2 triazole C-4), $179.3(2 \times$ $\mathrm{NHCO}$ ). Anal. calcd. for $\mathrm{C}_{52} \mathrm{H}_{94} \mathrm{~N}_{8} \mathrm{O}_{12}$ (1023.38): C, 61.06; H, 9.26; N, 10.95; Found: C, 61.13; H, 9.36; N, 10.88 .

\section{Enzyme assays}

(a) Against RMGPa. The inhibitory activity of the prepared compounds against rabbit muscle glycogen phosphorylase a (RMGPa) was monitored using microplate reader (BIO-RAD) based on the published method. ${ }^{35}$ In brief, GPa activity was measured in the direction of glycogen synthesis by the release of phosphate from glucose-1-phosphate. Each prepared compound was dissolved in DMSO and diluted to different concentrations for $\mathrm{IC}_{50}$ determination. The enzyme was added into $100 \mu \mathrm{L}$ of buffer containing $50 \mathrm{mM}$ Hepes $(\mathrm{pH}=7.2)$, $100 \mathrm{mM} \mathrm{KCl}, 2.5 \mathrm{mM} \mathrm{MgCl}_{2}, 0.5 \mathrm{mM}$ glucose-1-phosphate, $1 \mathrm{mg} / \mathrm{ml}$ glycogen and the test compound in 96-well microplates (Costar). After the addition of $150 \mu \mathrm{L}$ of $1 \mathrm{M} \mathrm{HCl}$ containing $10 \mathrm{mg} / \mathrm{ml}$ ammonium molybdate and $0.38 \mathrm{mg} / \mathrm{ml}$ malachite green, reactions were run at $22{ }^{\circ} \mathrm{C}$ for $25 \mathrm{~min}$, and then the phosphate absorbance was measured at $655 \mathrm{~nm}$. The $\mathrm{IC}_{50}$ values were estimated by fitting the inhibition data to a dose-dependent curve using a logistic derivative equation.

(b) Against RMGPb. Glycogen phosphorylase b (RMGPb) was prepared from rabbit skeletal muscle according to the method of Fischer and Krebs, ${ }^{41}$ using dithiothreitol instead of L-cysteine, and recrystallized at least three times before use. Kinetic experiments were performed in the direction of glycogen synthesis using $\mathrm{RMGPb}$ as described. ${ }^{36,42} \mathrm{IC}_{50}$ values were determined in the presence of $4 \mathrm{mM} \alpha$-D-glucose1-phosphate, $1 \mathrm{mM}$ AMP, $1 \%$ glycogen and varying concentrations of the inhibitor. ${ }^{43}$ Inhibitors were dissolved in dimethyl sulfoxide (DMSO) and diluted in the assay buffer (50 $\mathrm{mM}$ triethanolamine, $1 \mathrm{mM}$ EDTA and $1 \mathrm{mM}$ dithiothreitol) so that the DMSO concentration in the assay should 
1 be lower than $1 \%$. The means of standard errors for all calculated kinetic parameters averaged to less than $10 \%$.

\section{Acknowledgements}

HBS thanks financial support by National Natural Science Foundation of China (Grants 30672523 and 90713037), research grants from Chinese Ministry of Education (Grants 706030 and 20050316008) and the program for New Century

10 Excellent Talents in University (NCET-05-0495). In Hungary this research was supported by the National Office for Research and Technology as well as the Hungarian Scientific Research Fund (Grants NI-61336, NK-68578, and CK-77712). The authors also thank NORT (Hungary, CHN15 25/05) and the Program for Chinese-Hungarian Scientific and Technological Cooperation (China, No. CHN-7/2006) for supporting this bilateral R\&D project.

\section{References}

20

1 D. E. Moller, Nature, 2001, 414, 821-827.

2 P. Zimmet, K. G. M. M. Alberti and J. Shaw, Nature, 2001, 414, 782-861.

3 J. Diamond, Nature, 2003, 423, 599-602.

4 P. Staehr, O. Hother-Nielsen and H. Beck-Nielsen, Diabetes, Obes. Metab., 2002, 4, 215-223.

5 N. G. Oikonomakos and L. Somsák, Curr. Opin. Invest. Drugs, 2008, 9, 379-395.

6 L. Somsák, K. Czifrák, M. Tóth, É. Bokor, E. D. Chrysina, K. M. Alexacou, J. M. Hayes, C. Tiraidis, E. Lazoura, D. D. Leonidas, S. E. Zographos and N. G. Oikonomakos, Curr. Med. Chem., 2008, 15, 2933-2983.

307 D. J. Baker, P. L. Greenhaff and J. A. Timmons, Expert Opin. Ther. Pat., 2006, 16, 459-466.

8 L. Agius, Best Pract. Res. Clin. Endocrinol. Metab., 2007, 21, 587-605.

9 N. G. Oikonomakos, Curr. Protein Pept. Sci., 2002, 3, 561-586.

10 E. D. Chrysina, M. N. Kosmopolou, C. Tiraidis, R. Kardarakis, N. Bischler, D. D. Leonidas, Z. Hadady, L. Somsák, T. Docsa, P. Gergely and N. G. Oikonomakos, Protein Sci., 2005, 14, 873-888.

11 L. Somsák, V. Nagy, Z. Hadady, T. Docsa and P. Gergely, Curr. Pharm. Des., 2003, 9, 1177-1189.

12 L. Somsák, V. Nagy, Z. Hadady, N. Felföldi, T. Docsa and P. Gergely, in Frontiers in Medicinal Chemistry, ed. A. B. Reitz, C. P. Kordik, M. I. Choudhary and A. U. Rahman, Bentham, 2005, pp. 253-272.

13 J. Chen, J. Liu, Y. C. Gong, L. Y. Zhang, W. Y. Hua and H. B. Sun, J. China Pharm. Univ., 2006, 37, 397-402.

14 J. Chen, J. Liu, L. Y. Zhang, G. Z. Wu, W. Y. Hua, X. M. Wu and H. B. Sun, Bioorg. Med. Chem. Lett., 2006, 16, 2915-2919.

4515 K. G. Cheng, P. Zhang, J. Liu, J. Xie and H. B. Sun, J. Nat. Prod., 2008, 71, 1877-1880.

16 X. Wen, H. Sun, J. Liu, K. Cheng, P. Zhang, L. Zhang, J. Hao, L. Zhang, P. Ni, S. E. Zographos, D. D. Leonidas, K. M. Alexacou, T. Gimisis, J. M. Hayes and N. G. Oikonomakos, J. Med. Chem., 2008, 51, 3540-3554.

17 P. Dzubak, M. Hajduch, D. Vydra, A. Hustova, M. Kvasnica, D. Biedermann, L. Markova, M. Urban and J. Sarek, Nat. Prod. Rep., 2006, 23, 394-411.
18 C. D. Shomin, S. C. Meyer and I. Ghosh, Bioorg. Med. Chem., 2009, 17, 6196-6202.

19 H. Li, Y. J. Guan, A. Szczepanska, A. J. Moreno-Vargas, A. T. Carmona, I. Robina, G. K. Lewis and L. X. Wang, Bioorg. Med. Chem., 2007, 15, 4220-4228.

20 J. L. Arolas, G. M. Popowicz, J. Lorenzo, C. P. Sornmerhoff, R. Huber, F. X. Aviles and T. A. Holak, J. Mol. Biol., 2005, 350, 489-498.

21 T. Selwood, K. C. Elrod and N. M. Schechter, Biol. Chem., 2003, 384, 1605-1611.

22 X. Wu and B. S. Cooperman, Bioorg. Med. Chem. Lett., 2000, 10, $2387-2389$.

23 T. Steinmetzer, M. Renatus, S. Kunzel, A. Eichinger, W. Bode, P. Wikstrom, J. Hauptmann and J. Sturzebecher, Eur. J. Biochem., 1999, 265, 598-605.

24 J. J. Lundquist and E. J. Toone, Chem. Rev., 2002, 102, 555-578.

25 S. Cecioni, O.-A. Argintaru, T. Docsa, P. Gergely, J.-P. Praly and S. Vidal, New J. Chem., 2009, 33, 148-156.

26 V. L. Rath, M. Ammirati, D. E. Danley, J. L. Ekstrom, E. M. Gibbs, T. R. Hynes, A. M. Mathiowetz, R. K. McPherson, T. V. Olson, J. L. Treadway and D. J. Hoover, Chem. Biol., 2000, 7, 677-682.

27 S. Furukawa, Y. Tsurumi, K. Murakami, T. Nakanishi, K. Ohsumi, M. Hashimoto, M. Nishikawa, S. Takase, O. Nakayama and M. Hino, J. Antibiot., 2005, 58, 497-502.

28 C. Tiraidis, K. M. Alexacou, S. E. Zographos, D. D. Leonidas, T. Gimisis and N. G. Oikonomakos, Protein Sci., 2007, 16, $1773-1782$.

29 K. Cheng, J. Liu, X. Liu, H. Li, H. Sun and J. Xie, Carbohydr. Res., 2009, 344, 841-850.

30 M. Meldal and C. W. Tornoe, Chem. Rev., 2008, 108, 2952-3015.

31 X. Wen, P. Zhang, J. Liu, L. Zhang, X. Wu, P. Ni and H. Sun, Bioorg. Med. Chem. Lett., 2006, 16, 722-726.

32 Z. Györgydeák and J. Thiem, Adv. Carbohydr. Chem. Biochem., 2006, 60, 103-182.

33 L. Kovács, E. Ösz, V. Domokos, W. Holzer and Z. Györgydeák, Tetrahedron, 2001, 57, 4609-4621.

34 E. I. Petsalakis, E. D. Chrysina, C. Tiraidis, T. Hadjiloi, D. D. Leonidas, N. G. Oikonomakos, U. Aich, B. Varghese and D. Loganathan, Bioorg. Med. Chem., 2006, 14, 5316-5324.

35 W. H. Martin, D. J. Hoover, S. J. Armento, I. A. Stock, R. K. McPherson, D. E. Danley, R. W. Stevenson, E. J. Barrett and J. L. Treadway, Proc. Natl. Acad. Sci. U. S. A., 1998, 95, 1776-1781.

36 E. Ösz, L. Somsák, L. Szilágyi, L. Kovács, T. Docsa, B. Tóth and P. Gergely, Bioorg. Med. Chem. Lett., 1999, 9, 1385-1390.

37 E. D. Chrysina, E. Bokor, K.-M. Alexacou, M.-D. Charavgi, G. N. Oikonomakos, S. E. Zographos, D. D. Leonidas, N. G. Oikonomakos and L. Somsák, Tetrahedron: Asymmetry, 2009, 20, 733-740.

38 K. M. Alexacou, J. M. Hayes, C. Tiraidis, S. E. Zographos, D. D. Leonidas, E. D. Chrysina, G. Archontis, N. G. Oikonomakos, J. V. Paul, B. Varghese and D. Loganathan, Proteins: Struct., Funct., Bioinf., 2008, 71, 1307-1323.

39 É. Bokor, T. Docsa, P. Gergely and L. Somsák, Bioorg. Med. Chem., 2009, submitted.

40 U. Aich and D. Loganathan, J. Carbohydr. Chem., 2005, 24, $1-12$.

41 E. H. Fischer and E. G. Krebs, Methods Enzymol., 1962, 5, 369-372.

42 L. Somsák, L. Kovács, M. Tóth, E. Ösz, L. Szilágyi, Z. Györgydeák, Z. Dinya, T. Docsa, B. Tóth and P. Gergely, J. Med. Chem., 2001, 44, 2843-2848.

43 M. Benltifa, S. Vidal, B. Fenet, M. Msaddek, P. G. Goekjian, J.-P. Praly, A. Brunyánszki, T. Docsa and P. Gergely, Eur. J. Org. Chem., 2006, 4242-4256. 